\title{
Understanding unintended pregnancy in Bangladesh: Country profile report
}

Fauzia Akhter Huda

Sabiha Chowdhuri

Yolande Robertson

Noushin Islam

Bidhan Krishna Sarker

See next page for additional authors

Follow this and additional works at: https://knowledgecommons.popcouncil.org/departments_sbsr-rh

Part of the Demography, Population, and Ecology Commons, Family, Life Course, and Society Commons, Gender and Sexuality Commons, International Public Health Commons, Maternal and Child Health Commons, and the Women's Health Commons How does access to this work benefit you? Let us know!

\section{Recommended Citation}

Akhter Huda, Fauzia, Sabiha Chowdhuri, Yolande Robertson, Noushin Islam, Bidhan Krishna Sarker, Ashrafi Jahan Azmi, and Laura Reichenbach. 2013. "Understanding unintended pregnancy in Bangladesh: Country profile report." Dhaka: icddr,b. 


\section{Authors}

Fauzia Akhter Huda, Sabiha Chowdhuri, Yolande Robertson, Noushin Islam, Bidhan Krishna Sarker, Ashrafi Jahan Azmi, and Laura Reichenbach 


\section{STEP 鸟UP}

STRENGTHENING EVIDENCE FOR PROGRAMMING ON UNINTENDED PREGNANCY
BANGLADESH

RESEARCH REPORT

DECEMBER 2013

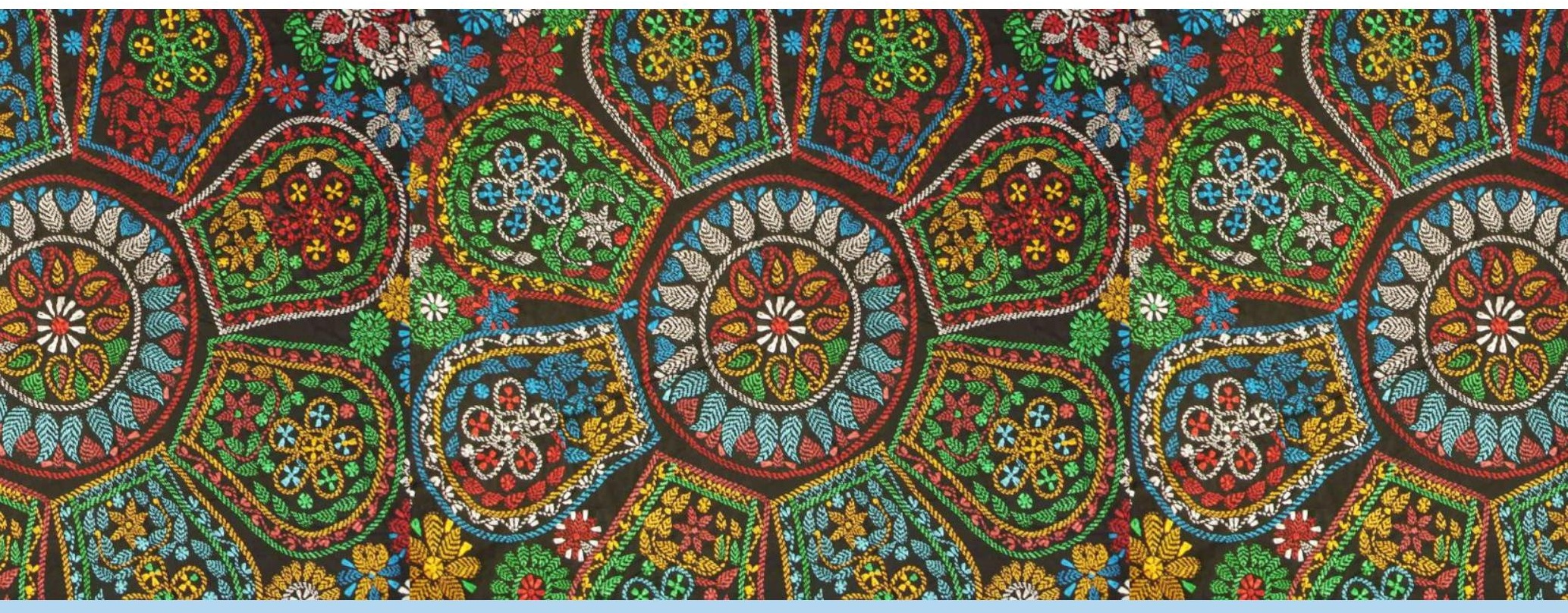

\section{Understanding Unintended Pregnancy in Bangladesh: Country Profile Report}

FAUZIA AKHTER HUDA, SABIHA CHOWDHURI, YOLANDE ROBERTSON, NOUSHIN ISLAM, BIDHAN KRISHNA SARKER, ASHRAFI JAHAN AZMI AND LAURA REICHENBACH 


\section{Understanding Unintended Pregnancy in Bangladesh: Country Profile Report}

FAUZIA AKHTER HUDA, SABIHA CHOWDHURI, YOLANDE ROBERTSON, NOUSHIN ISLAM, BIDHAN KRISHNA SARKER, ASHRAFI JAHAN AZMI AND LAURA REICHENBACH

Centre for Reproductive Health, icddr,b, Dhaka, Bangladesh 
The STEP UP (Strengthening Evidence for Programming on Unintended Pregnancy) Research Programme Consortium generates policy-relevant research to promote an evidence-based approach for improving access to family planning and safe abortion. STEP UP focuses its activities in five countries: Bangladesh, Ghana, India, Kenya and Senegal. STEP UP is coordinated by the Population Council in partnership with the African Population and Health Research Center; icddr,b; the London School of Hygiene and Tropical Medicine; Marie Stopes International and Partners in Population and Development. STEP UP is funded by UKaid from the UK Government. www.stepup.popcouncil.org

\section{(9) icddr,b}

Dedicated to saving lives, icddr,b is an international public health research organisation located in Bangladesh. Through the generation of knowledge and translation of research into treatment, training, and policy advocacy, icddr,b addresses some of the most critical health concerns facing the world today. www.icddrb.org

\section{(2) Population Council}

The Population Council confronts critical health and development issues-from stopping the spread of HIV to improving reproductive health and ensuring that young people lead full and productive lives. Through biomedical, social science and public health research in 50 countries, we work with our partners to deliver solutions that lead to more effective policies, programs and technologies that improve lives around the world. Established in 1952 and headquartered in New York, the Council is a nongovernmental, nonprofit organization governed by an international board of trustees. www.popcouncil.org

Suggested citation: Huda, FA; Chowdhuri, S; Robertson, Y; Islam, N; Sarker, BK; Azmi, AJ and Reichenbach, L. 2013. "Understanding Unintended Pregnancy in Bangladesh: Country Profile Report," STEP UP Research Report. Dhaka: icddr,b.

(c) 2013 icddr,b.

Please address any inquiries about STEP UP to the RPC co-directors:

Dr. Harriet Birungi, hbirungi@popcouncil.org

Dr. Ian Askew, laskew@popcouncil.org

Funded by

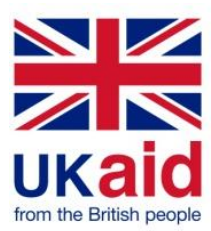




\section{TABLE OF CONTENTS}

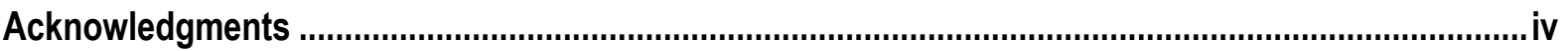

List of Abbreviations

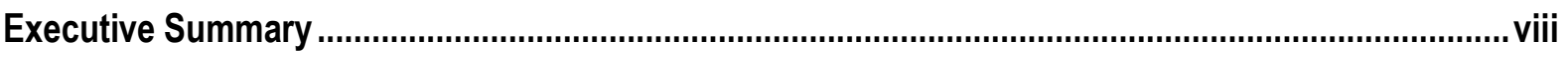

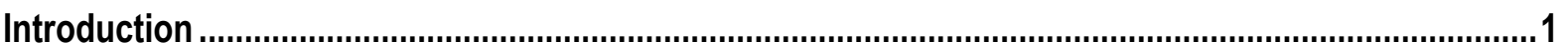

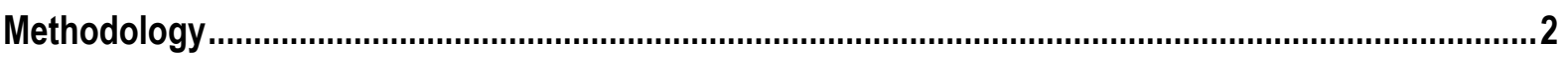

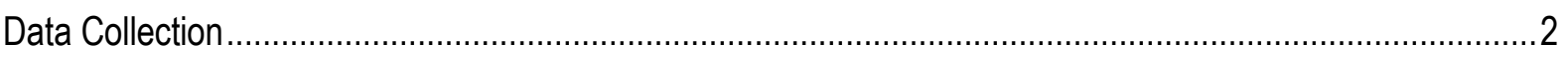

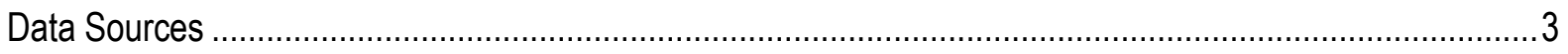

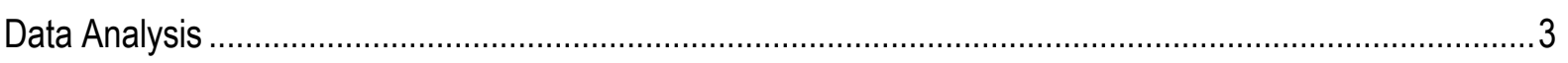

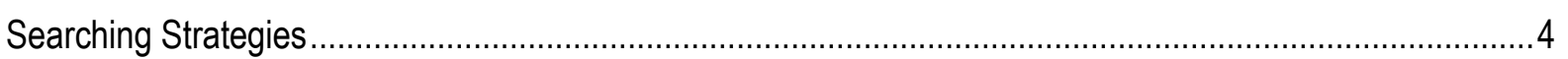

Time Frame

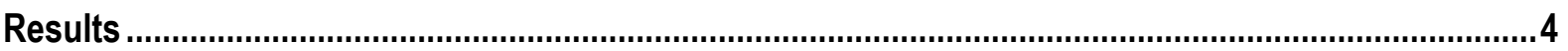

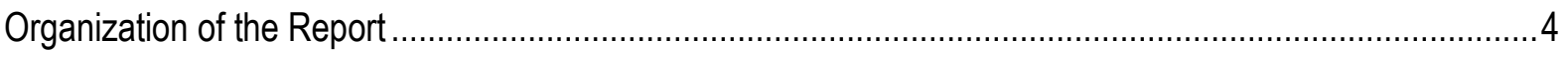

Part 1: Sexual and Reproductive Health Rights in Bangladesh: the Legal, Policy and Socio-

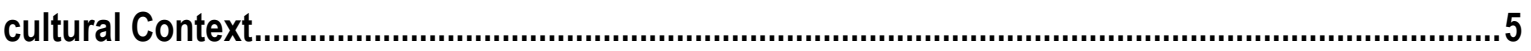

A. Reproductive Health, Family Planning and MR and Abortion Laws and Policy ....................................

B. International Human Rights Commitments and the Legal Context ......................................................... 7

C. Policy, Political and Institutional Influences on Family Planning and Menstrual Regulation ......................8

D. Non-discrimination and Recognition of Vulnerable Groups .................................................................

E. Socio-cultural Norms and Trends Concerning Family Formation and Childbearing over Time................11

Part 2: Family Planning and Reproductive Health Indicators: Trend and Equity Analyses ................13

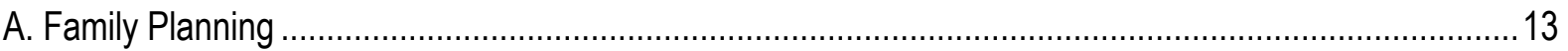

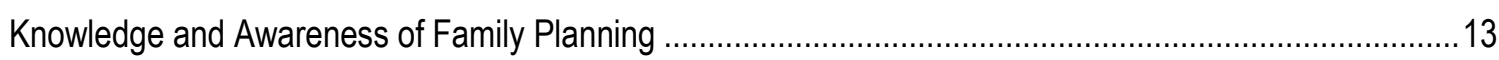

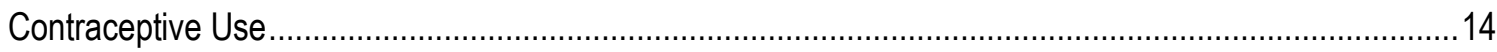

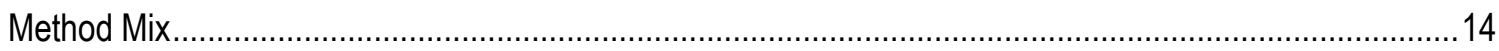

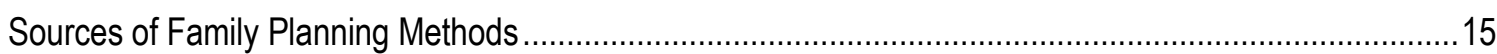

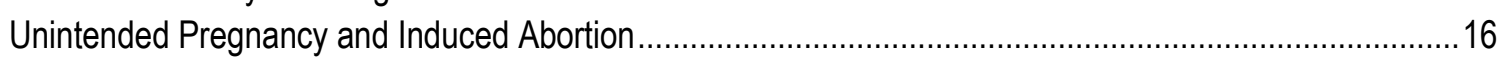

Figure 2: Trends of Unwanted Pregnancy in Bangladesh during 1993 - 2011 (BDHS 2011).....................16

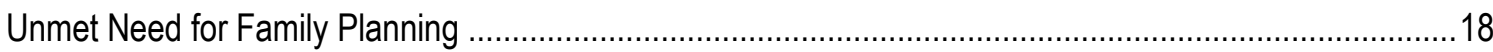

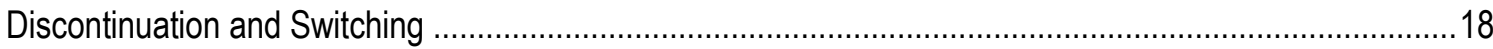

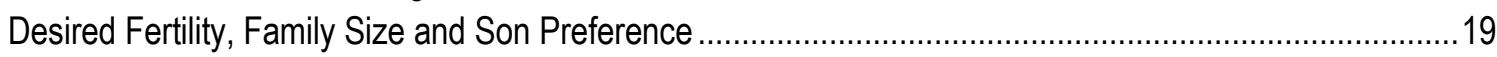

Figure 3: Trends In All Methods Discontinuation Rates from 1993/94 to 2011 (Vlassoff m. et. al. 2012).....19

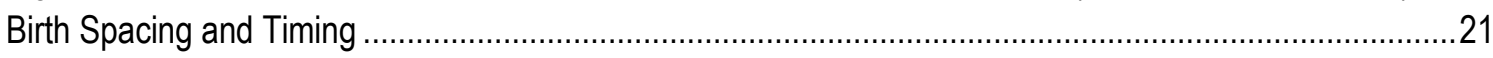

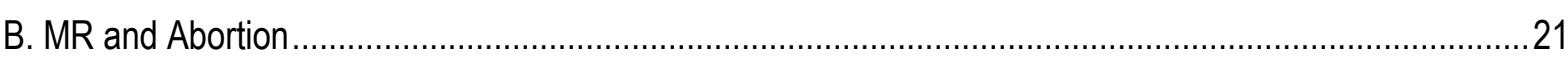

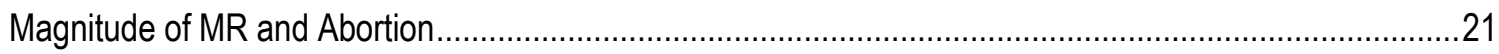

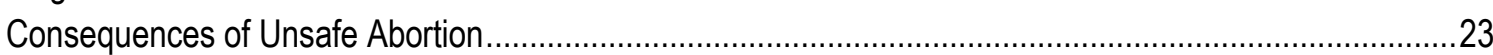


Part 3: Access to and quality of family planning and post-abortion/abortion services

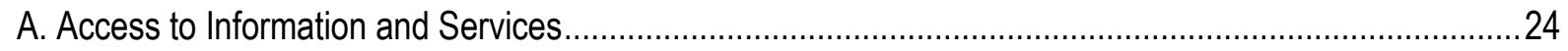

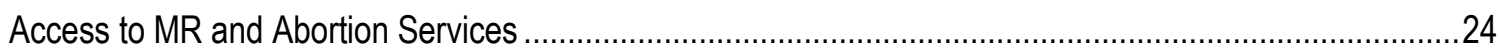

Cost of MR Services and Treatment for Abortion Complications ............................................................24

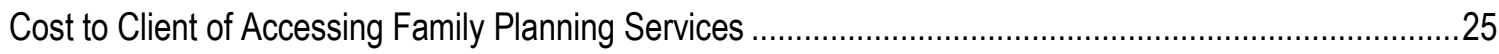

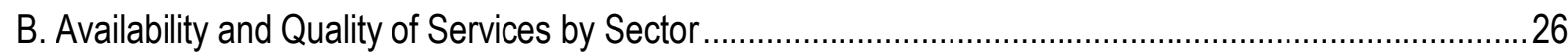

Availability of Family Planning, MR and Post-abortion Care (PAC) Services.............................................26

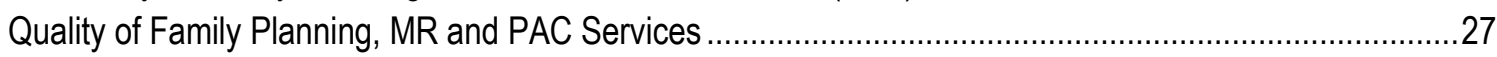

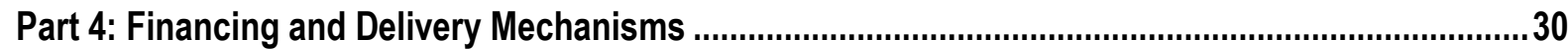

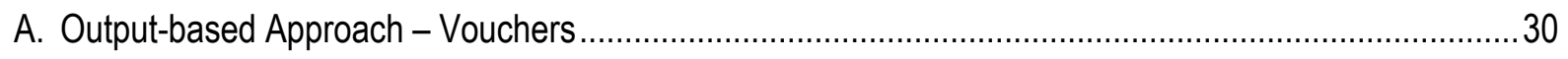

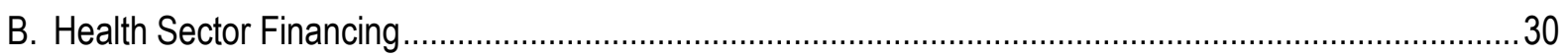

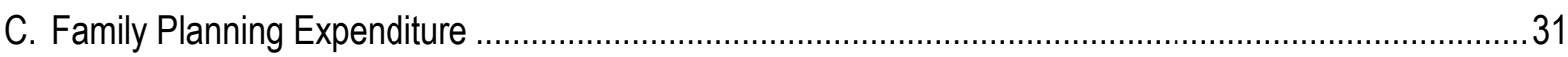

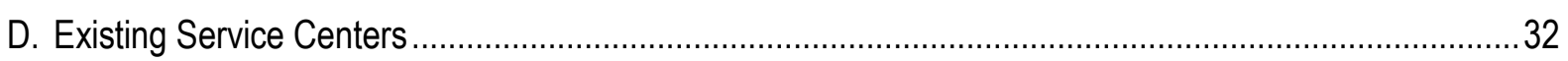

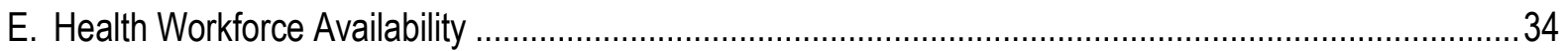

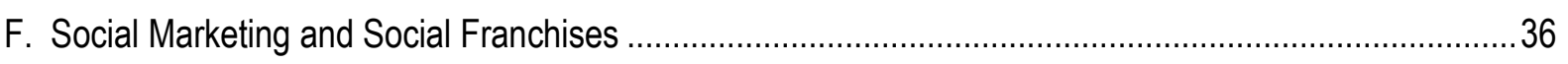

G. Faith-based Organizations (FBO) and Non-governmental Organizations (NGO) ...................................38

H. ICT, E-health/M-health and Media for IEC and SBCC on FP and Abortion/PAC ...................................40

I. Commodity Procurement and Supply Logistics by Sector .............................................................. 41

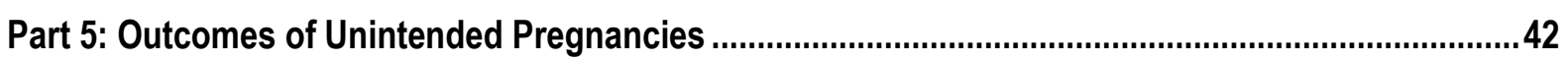

Maternal Mortality and Morbidities Attributed to Unintended Pregnancies ................................................42

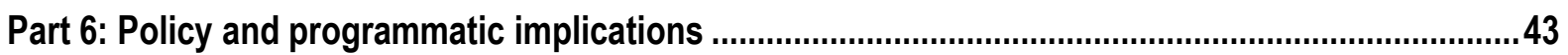

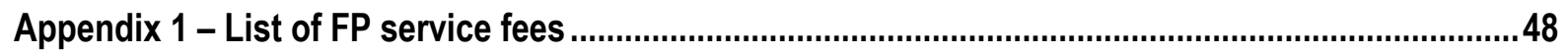

Appendix 2 - GIS Maps of HealthCare Facilities Offering MNCH-FP Services in Bangladesh ............51

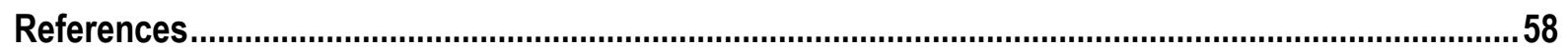




\section{LIST OF TABLES AND FIGURES}

\section{Tables}

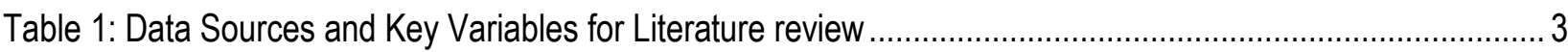

Table 2: searching methods used for report focus topics ......................................................................... 4

Table 3: Trends in Current Use of Contraceptive Methods …....................................................................... 15

Table 4: Percent Distribution of Currently Married Women Aged 15-49 by Desire for Children According to

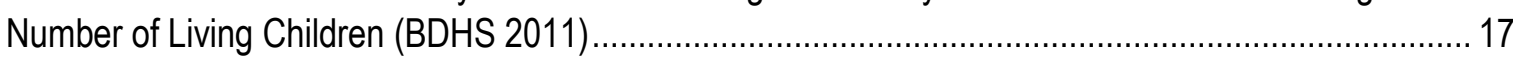

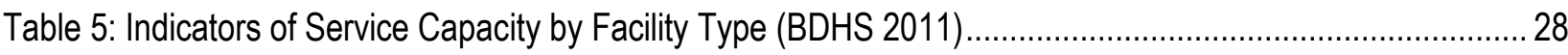

Table 6: Budget Allocated to Government HPNSDP Operational Plans (2011 -2016)...................................... 31

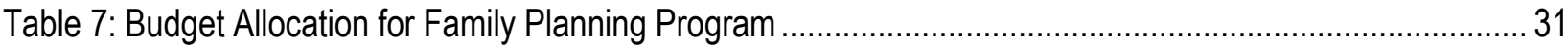

Table 8: FP, MR and Abortion-related SRH Services ................................................................................. 39

Figures

Figure 1: Organizational Chart for the National FP and RH Communication Strategy .................................... 13

Figure 2: Trends of Unwanted Pregnancy in Bangladesh during 1993 - 2011 (BDHS 2011)........................... 16

Figure 3: Trends In All Methods Discontinuation Rates from 1993/94 to 2011 (Vlassoff m. et. al. 2012)............ 19

Figure 4: Fertility Preferences among Currently Married Women Aged 15-49 .................................................. 20

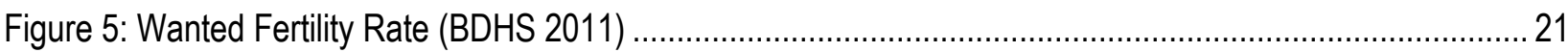

Figure 6: Rate of Ever-use of MR among Ever-married and Currently Married Women (BDHS 2011) .............. 22 


\section{Acknowledgments}

We acknowledge support from the STEP UP (Strengthening Evidence for Programming on Unintended Pregnancy)

Research Programme Consortium. STEP UP was funded by UKaid from the Department for International

Development (DFID), grant number SR1111D-6. icddr,b acknowledges with gratitude the commitment of UKaid to its research efforts.

The authors would like to express their gratitude to all of the participants at the National Task Force meeting held on September 20, 2012 and stakeholders' consultation held from June 22-23, 2013 for their valuable input and recommendations, particularly senior government officials from the Ministry of Health and Family Welfare (MoHFW) and the Directorate General of Family Planning (DGFP).

The authors would also like to thank Partners in Population and Development (PPD) for their role in engaging government officials in the full process of the study and their extensive and continued support in disseminating the report and uptake of the findings at the national level.

icddr,b is thankful to the Governments of Australia, Bangladesh, Canada, Sweden and the UK for providing core/unrestricted support. 


\section{List of Abbreviations}

AMTSL - Active Management of Third Stage of Labour

ANC - Antenatal Care

AOR - Adjusted Odds Ratio

ARI - Acute Respiratory IIIness

ASRH - Adolescent Sexual and Reproductive Health

BAPSA - Bangladesh Association for Prevention of Septic Abortion

BCC - Behaviour Change Communication

BDHS - Bangladesh Demographic and Health Survey

BDT - Bangladeshi Taka

BMMS - Bangladesh Maternal Mortality and Health Care Survey

BRAC -Bangladesh Rural Advancement Committee

BSMMU - Bangabandhu Sheikh Mujib Medical University

BSP - Blue Star Network of Providers

BWHC - Bangladesh Women's Health Coalition

CC - Community Clinic

CCSD - Clinical Contraception Service Delivery

CEDAW - Committee on the Elimination of Discrimination against Women

$\mathrm{Cl}$ - Confidence Interval

CPR - Contraceptive Prevalence Rate

CRC - Committee on the Rights of the Child

CSBA - Community Skilled Birth Attendant

CSP - Community Service Provider

DALYs - Disability-adjusted Life Years

D\&C - Dilation and Curettage

DGFP - Directorate General of Family Planning

DGHS - Directorate General of Health Services

DMCH - Dhaka Medical College and Hospital

DOTS - Direct Observed Treatment Short Course

DP - Development Partner

DSF - Demand-side Financing

EmOC - Emergency Obstetric Care

EPI - Expanded Program on Immunization

EVA - Electric Vacuum Aspiration

FBO - Faith-based Organizations

FMO - Franchise Manager Organization

FP - Family Planning

FPAB - Family Planning Association of Bangladesh

FPFSD - Family Planning Field Services Delivery

FWA - Family Welfare Assistant

FWC - Family Welfare Center

FWV - Family Welfare Visitor

FWVTI - Family Welfare Visitors Training Institute 
GDP - Gross Domestic Product

GD - Graduate Doctors

GoB - Government of Bangladesh

HFA - Health Facility Assessment

HFS - Health Facility Survey

HIVIAIDS - Human Immunodeficiency Virus/Acquired Immune Deficiency Syndrome

HNPSP - Health, Nutrition and Population Sector Programme

HPN - Health, Population \& Nutrition

HPNSDP - Health, Population and Nutrition Sector Development Programme

HPSP - Health and Population Sector Programme

ICPD - International Conference on Population and Development

ICT - Information Communication Technology

ICU - Intensive Care Unit

IEC - Information, Education and Communication

IPPF - International Planned Parenthood Federation

ISO - International Organization for Standardization

IUD - Intrauterine Device

IYCF - Infant and Young Child Feeding

LAPM - Long Acting and Permanent Method

LMIS - Logistics Management Information System

LMP - Last Menstrual Period

MCHTI - Maternal and Child Health Training Institute

MCWC - Mother and Child Welfare Center

$\mathrm{M} \& \mathrm{E}$ - Monitoring and Evaluation

MFSTC - Mohammadpur Fertility Services and Training Centre

MIS - Management Information System

MIS-FP - Management information System of Family Planning

MMR - Maternal Mortality Ratio

MCH-FP- Maternal Child Health (and Family Planning)

MoHFW - Ministry of Health and Family Welfare

MR - Menstrual Regulation

MSI - Marie Stopes International

MVA - Manual Vacuum Aspiration

NGMP - Non-graduate Medical Practitioners

NGO - Non-governmental Organization

NID - National Immunization Day

NSDP - Nongovernmental Organization Service Delivery Project

NSV - Non-Scalpel Vasectomy

OGSB - Obstetrical and Gynecological Society of Bangladesh

OOP - Out of Pocket Expenditure

OP - Operational Plan

OR - Odds Ratio

PAC - Post-Abortion Care 
PME-FP - Planning, Monitoring and Evaluation of FP

PNC - Post-natal Care

PPH - Postpartum Hemorrhage

PPP - Public Private Partnership

P4P - Pay for Performance

PSSMP - Procurement, Storage and Supply Management Program

PSMS - Procurement and Supply Management System

$\mathrm{RD}$ - Rural Dispensaries

RHP - Reproductive Health Promoter

RHSTEP - Reproductive Health Services, Training and Education Program

RSDP - Rural Service Delivery Partnership

RTC - Regional Training Center

RTI - Reproductive Tract Infection

SACMO - Sub-assistant Community Medical Officer

SDP - Service Delivery Point

SES - Socio-economic Status

SMC - Social Marketing Company

SRH - Sexual and Reproductive Health

SSF - Supply-side Financing

SSFP - Smiling Sun Franchise Program

STI - Sexually-transmitted Infection

SWAP - Sector-wide Approach Program

TBA - Traditional Birth Attendant

TFR - Total Fertility Rate

THC - Thana Health Complex

TOT - Training of Trainers

UHC - Upazila Health Complex

UHFWC - Union Health and Family Welfare Centre

UIMS - Upazila Inventory Management System

UNDP - United Nations Development Programme

UNFPA - United Nations Population Fund

USAID - United States Agency for International Development

VIA - Visual Inspection of Cervix through Acetic Acid

WIMS - Warehouse Inventory Management System

WHO - World Health Organization 


\section{Executive Summary}

Background: Bangladesh boasts an impressive sevenfold increase in its contraceptive prevalence rate (CPR) in less than forty years. Yet, the rate of unintended pregnancy declined only gradually during the period of 1993-2007, and there is still a significant unmet need for family planning (FP). A key concern in FP programs in Bangladesh is the high rates of discontinuation and switching to less-safe or less-effective contraceptive methods. Risks of abortionrelated morbidity and mortality increase as a result of unintended pregnancies, particularly in countries like Bangladesh where abortion is against the law.

Access to contraception is an essential component of reproductive health services. Bangladesh's pledge in the London Summit on Family Planning includes increasing contraceptive access and use for poor people in urban and rural areas, improving choice and availability of Long Acting and Permanent Methods (LAPMs), involving men, and improving post-partum and post-abortion services.

Objectives: The objective of this report is to identify the determinants of unintended pregnancy and unmet need for family planning in Bangladesh and therefore provide a strong body of evidence that will contribute to issue identification, evidence generation, and communication for use of evidence in policy and programming. The evidence generated can be used to find ways to reduce the rate of unintended pregnancy and hence reduce the risk of abortion related morbidity and mortality; ultimately this will aid Bangladeshi couples in reaching their fertility goals.

Methods: Local research-based organisations working on family planning, unintended pregnancy and related issues in Bangladesh were identified and relevant documents such as posters, flipcharts, books and leaflets were collected. PubMed/MEDLINE, HINARI, JSTOR and Google Scholar were searched for literature relevant to preselected outcomes. Search results were restricted to literature published after 2000 , although some exceptions were granted to papers from 1996-1999 on a case-by-case basis. Reference lists from retrieved literature were reviewed for identification of additional sources of relevant data based on our search criteria.

\section{Results}

Sexual and Reproductive Health Rights in Bangladesh: the Legal, Policy and Socio-cultural Context: The current abortion law in Bangladesh is highly restrictive, permitting abortion only if the mother's life is in danger. However, in an effort to reduce the number of unsafe abortions, the government of Bangladesh introduced "Menstrual Regulation" (MR) into its national family planning program in 1979.

A succession of four five-year plans, each building on core strategic policies outlined in the 1976 population policy, focused on a progressive strengthening of the healthcare infrastructure in Bangladesh in order to provide comprehensive FP services.

Discrimination against women has been identified as one of the prime reproductive health issues in Bangladesh and exists in education, employment, marriage, and dowry, and often results in violence.

In the current government health strategy, geographically-isolated populations do not get any special policy consideration. Thus, the central health policy is inadequately designed to address the special geographical conditions and needs of these areas.

Family Planning and Reproductive Health Indicators: Trend and Equity Analyses: Knowledge of family planning methods is widespread and consistent throughout Bangladesh. Contraceptive use has increased significantly from a mere $8 \%$ in 1975 to $61 \%$ in 2011. Married women in their thirties show the highest use of contraceptives. The oral contraceptive pill is most widely used $(27 \%)$ followed by injectables at $11 \%$; condoms at $6 \%$; and female sterilization at $5 \%$. Use of IUDs, implants and male sterilization is found only in 1\%. The method mix in Bangladesh has changed 
over the past two decades, with a consistent decline in long-acting and permanent methods (LAPM) seen from the early 1990s.

The public sector is the major source of contraception, supplying over $50 \%$ of methods. The private sector provides $38 \%$ of methods, with pharmacies providing $33 \%$ of these supplies, mainly pills and condoms. There has been a gradual decline in unintended pregnancy from 33\% to $29 \%$ from 1993 to 2011.

The unmet need for family planning nationwide lies at $13.5 \%$, which includes $5 \%$ for spacing and $8 \%$ for limiting births, and is higher among young women. About $36 \%$ method users discontinue use within 1 year nationwide. This rate is higher among users of short acting methods. Only $14 \%$ of discontinuers switched to another method.

Ever-use of MR currently lies at $9 \%$. Despite availability of FP services, $2.8 \%$ of all pregnancies result in MR and $1.5 \%$ in induced abortion. Deaths due to abortion have decreased from $5 \%$ in 2001 to $1 \%$ in 2010 , though there is significant underreporting of abortion, and actual rates are likely to be higher. Adolescents are at higher risk of unsafe abortion, particularly unmarried ones who were shown to be 35 times at greater risk than their married counterparts.

Access to and quality of family planning and post-abortion/abortion service: In Bangladesh, about 1 facility per 20,000 population offers FP services. Fifty three percent of the facilities had staff trained in general FP services, insertion of IUD and Norplant, and providing MR and sterilization.

Only fifty seven percent of public and private facilities that are expected to provide MR actually do so. MR services in the public sector should be free, yet actualization of this law is highly inconsistent. NGOs and Private clinic charges vary by type of procedure, with subsidized or free services for poor women. Public facilities showed poorer quality of care than private or NGO facilities, but with slightly better conditions for providing post-abortion care (PAC).

Financing and Delivery Mechanisms: A new health financing strategy was developed by MoHFW to channel public resources more effectively. In 2012, revised fees for clinical contraception services were introduced by the government for service providers and clients.

The Social Marketing Company (SMC) is the largest contributor for FP methods, followed by the Blue Star Network and the Smiling Sun Franchise, which provide a wider variety of FP/RH services.

\section{Discussion and Policy Implications}

Bangladesh has shown progress and promise in several areas of family planning and contraceptive use. Its reduction of the TFR to almost replacement level, in some areas already at or below replacement level, and its MR program's influence on the reduction of abortion related mortality is noteworthy. However, challenges such as heavy reliance on short-term methods, high rates of discontinuation and switching of FP methods, and limited use of LAPMs are issues that need urgent attention. Women who have reached their desired family size by their late twenties need to be targeted to ensure they are using appropriate FP methods for limiting births. Additionally, high rates of MR and abortion imply that there is a demand for high quality, effective and accessible family planning methods.

The HPNSDP's (2011-2016) goal of increasing the CPR from $61 \%$ to $74 \%$ by 2016 , though ambitious, may be achievable if the program focuses on geographic areas which have not yet reached replacement level TFR and have a lower overall CPR. Collaboration between the government and the private sector and NGOs need to: address the needs of young people, especially young couples; reduce regional disparities, work with leaders and communities to delay early marriage and childbirth; and increase male involvement. 


\section{Introduction}

Unintended pregnancies constitute 80 million of the 210 million pregnancies that occur globally each year [1]. Risks of abortion-related morbidity and mortality increase as a result of unintended pregnancies, particularly in countries where abortion is against the law. Unsafe abortion, often an outcome of an unintended pregnancy, results in the deaths of 80,000 women every year, $95 \%$ of which take place in developing countries [1]. Unintended pregnancies have a wide range of negative effects including on mental health, antenatal care, breastfeeding and infant mortality [1]. Recent estimates show that up to 100,000 maternal deaths and 4.6 million disability-adjusted life years (DALYs) could be prevented worldwide if unintended pregnancies could be avoided [2]. Furthermore, the rate of unintended pregnancy can be seen as an indicator of, not only the condition of women's reproductive health, but also the degree of autonomy women have in deciding if, when and how many children they should have [3].

Data from 1993-2007 show that there has been a gradual decline in trends of unintended pregnancy in Bangladesh from $33 \%$ to $29 \%$; among the $29 \%, 15 \%$ were mistimed (wanted later) while $14 \%$ were unwanted [1]. In $2011,61 \%$ of married women were current users of a contraceptive method [4], either modern or traditional, which is a small increase from the data collected in the Bangladesh Demographic and Health Survey (BDHS) 2007. Despite this rise in contraceptive prevalence rate (CPR), the unmet need for family planning is estimated to be $14 \%$ among women of reproductive age in the country [4]. There is speculation that the conventional definition of unmet need underestimates the actual need for family planning. Analysis of 2004 data suggests that over one-third of currently married women in Bangladesh have an unmet need for family planning when broader independent variables-such as method failure and users who are prone to health risks during pregnancy-are included in the definition of unmet need [5]. To understand the issue of unmet need for family planning on a deeper level, its significance, dimensions, use as an indicator and value as a means of designing program interventions must be further explored.

A key concern in family planning programs in Bangladesh is the high rates of discontinuation and switching of contraceptives to less-safe or less-effective methods, resulting in unintended pregnancies. A broad understanding of the relationship between switching and discontinuation of family planning methods and unmet need for family planning is essential in identifying factors that are correlates of contraceptive switching behaviour among Bangladeshi women. Other factors-such as method mix, intended family size and son preference-may also affect the contraceptive behaviour of married couples and need to be examined more closely.

Access to contraception is an essential component of reproductive health services, which helps to lower the levels of unmet need for family planning and, in turn, the numbers of unintended pregnancy. In order to make contraceptives, information and services available and affordable to an additional 120 million girls and women in the world's poorest countries by 2020, the London Summit on Family Planning was held in July 2012 by the UK Government and the Bill \& Melinda Gates Foundation-in partnership with UNFPA and others. The Government of Bangladesh's pledge in this summit includes increasing contraceptive access and use for poor people in urban and rural areas, improving choice and availability of Long Acting and Permanent Methods (LAPMs), including men and post-partum and post-abortion services [6].

Through the investigation of the determinants of contraceptive behaviour and unmet need of family planning in Bangladesh, this paper provides a strong body of evidence that will contribute to identification, generation, communication and use of evidence for policy and programming and can inform the achievement of the London Summit on Family Planning Goals of Bangladesh. 


\section{Methodology}

This report consists of a rigorous review and synthesis of published and unpublished documents and literature related to family planning, menstrual regulation (MR) and abortion in Bangladesh. We have produced a country-specific synthesis of the existing evidence that describes the policies, programs, status, impacts and implications of family planning in Bangladesh. Current reports that describe some or all of these issues were reviewed for completeness in order to avoid duplication.

\section{Data Collection}

\section{Phase 1:}

The first phase of data collection involved identifying and visiting relevant research-based and government organizations that have been working on family planning, unintended pregnancy and related issues. Through group discussion and snowball sampling techniques we identified 18 Dhaka-based government, non-government, local and international organizations that are currently or have previously been working on relevant family planning and unintended pregnancy-related issues in Bangladesh. Program-based organizations in these specific areas were excluded from the study. Data collection was conducted through physical visits to each of the 18 organizations. Many published and unpublished documents including reports, posters, leaflets, flipcharts, books, calendars and booklets were collected. The proposed data collection approach and list of organizations was shared with the National Task Force on South to South Collaboration for its inputs and suggestions at a meeting organized by STEP UP partner PPD.

\section{Phase 2:}

After completing the first phase of data collection process, certain areas were identified where further review was required. Search engine Google was used to conduct initial online searches for recent articles dating back to 1999 . We also utilized database websites, such as Google scholar and PubMed/Medline. Other online journals specific to family planning and related issues were also accessed. Searches included key words derived from the key variables outlined below, as well as "Bangladesh", to ensure that all articles identified were contextually relevant. The proposed country profile outline provided by STEP UP and the Population Council informed the selection of key variable terms. 


\section{Data Sources}

Table 1: Data Sources and Key Variables for Literature review

\begin{tabular}{|c|c|c|c|}
\hline Section & Section Title & Data Sources & Key Variables \\
\hline $\begin{array}{l}\text { Section } \\
\text { one }\end{array}$ & $\begin{array}{l}\text { Sexual and reproductive } \\
\text { health rights in } \\
\text { Bangladesh: The legal, } \\
\text { policy and socio-cultural } \\
\text { context }\end{array}$ & $\begin{array}{l}\text { - Desk reviews of published/unpublished } \\
\text { literature } \\
\text { - Government policy documents }\end{array}$ & \multirow{3}{*}{$\begin{array}{l}\text { - Unintended pregnancy } \\
\text { - Menstrual regulation } \\
\text { - Abortion policies and } \\
\text { practices } \\
\text { - Contraceptive use } \\
\text { - Method mix } \\
\text { - Demand, practices and } \\
\text { unmet need for FP } \\
\text { - Discontinuation and } \\
\text { switching } \\
\text { - Access to FP } \\
\text { information and } \\
\text { services } \\
\text { - Availability and quality } \\
\text { of services } \\
\text { - Cost of FP services }\end{array}$} \\
\hline $\begin{array}{l}\text { Section } \\
\text { two }\end{array}$ & $\begin{array}{l}\text { Family planning and } \\
\text { reproductive health } \\
\text { indicators: trend and } \\
\text { equity analyses }\end{array}$ & $\begin{array}{l}\text { - Bangladesh Demographic and Health } \\
\text { Surveys 2007, } 2011 \\
\text { - Bangladesh Urban Health Survey } 2006 \\
\text { - USAID reports urban/rural } \\
\text { - Matlab Demographic Surveillance System }\end{array}$ & \\
\hline $\begin{array}{l}\text { Section } \\
\text { three }\end{array}$ & $\begin{array}{l}\text { Access to and quality of } \\
\text { family planning and post- } \\
\text { abortion/abortion services }\end{array}$ & $\begin{array}{l}\text { - Desk reviews of published/unpublished } \\
\text { literature } \\
\text { - Bangladesh Maternal Mortality and Health } \\
\text { Care Survey } 2010 \\
\text { - Bangladesh Demographic and Health } \\
\text { Surveys 2007, } 2011\end{array}$ & \\
\hline $\begin{array}{l}\text { Section } \\
\text { four }\end{array}$ & $\begin{array}{l}\text { Financing and delivery } \\
\text { mechanisms }\end{array}$ & $\begin{array}{l}\text { - Desk reviews of published/unpublished } \\
\text { literature } \\
\text { - Data will be collected from government and } \\
\text { non-government organisations }\end{array}$ & \multirow{3}{*}{$\begin{array}{l}\text { - Fertility Preferences } \\
\text { and Intentions } \\
\text { - Adolescents } \\
\text { - Post-abortion care } \\
\text { - Social norms and } \\
\text { barriers to use FP } \\
\text { services } \\
\text { - Financing and markets }\end{array}$} \\
\hline $\begin{array}{l}\text { Section } \\
\text { five }\end{array}$ & $\begin{array}{l}\text { Outcomes of unintended } \\
\text { pregnancies }\end{array}$ & $\begin{array}{l}\text { - Bangladesh Maternal Mortality and Health } \\
\text { Care Survey } 2010 \\
\text { - Matlab maternal morbidity study } \\
\text { - Bangladesh Bureau of Statistics }\end{array}$ & \\
\hline $\begin{array}{l}\text { Section } \\
\text { six }\end{array}$ & $\begin{array}{l}\text { Policy and programmatic } \\
\text { implications }\end{array}$ & $\begin{array}{l}\text { - icddr,b study } \\
\text { - Directorate of Family Planning MIS }\end{array}$ & \\
\hline
\end{tabular}

\section{Data Analysis}

After a rigorous and extensive data collection process, 263 articles were retrieved and the resulting articles were subjected to further screening based on their title and abstract. Following this process, 97 articles were finally selected for further and detailed review. These articles were read and reviewed and key information was extracted and arranged in a pre-designed matrix. 


\section{Searching Strategies}

Table 2: searching methods used for report focus topics

\begin{tabular}{|l|l|l|l|}
\hline Topic & $\begin{array}{l}\text { Search engine } \\
\text { used }\end{array}$ & Key word applied & Final outcome \\
\hline $\begin{array}{l}\text { Access to abortion information } \\
\text { and services }\end{array}$ & $\begin{array}{l}\text { Pub-Med central, } \\
\text { Google }\end{array}$ & $\begin{array}{l}\text { Access, abortion services, } \\
\text { Bangladesh }\end{array}$ & 193 articles retrieved \\
\hline $\begin{array}{l}\text { Cost of client accessing abortion } \\
\text { services }\end{array}$ & $\begin{array}{l}\text { Pub-Med central, } \\
\text { Google }\end{array}$ & $\begin{array}{l}\text { Cost, abortion services, } \\
\text { Bangladesh }\end{array}$ & 137 articles retrieved \\
\hline $\begin{array}{l}\text { Availability of abortion services by } \\
\text { sector }\end{array}$ & $\begin{array}{l}\text { Pub-Med central, } \\
\text { Google }\end{array}$ & $\begin{array}{l}\text { Abortion service, } \\
\text { Bangladesh }\end{array}$ & 263 articles retrieved \\
\hline Quality of abortion services & $\begin{array}{l}\text { Pub-Med central, } \\
\text { Google }\end{array}$ & $\begin{array}{l}\text { Quality, abortion services, } \\
\text { Bangladesh }\end{array}$ & 153 articles retrieved \\
\hline Cost of abortion services & $\begin{array}{l}\text { Pub-Med central, } \\
\text { Google }\end{array}$ & $\begin{array}{l}\text { Access and abortion } \\
\text { service, Bangladesh }\end{array}$ & 137 articles retrieved \\
\hline $\begin{array}{l}\text { Barrier and reasons for use and } \\
\text { non-use of abortion services }\end{array}$ & $\begin{array}{l}\text { Pub-Med central, } \\
\text { Google }\end{array}$ & $\begin{array}{l}\text { Barrier abortion service, } \\
\text { Bangladesh }\end{array}$ & 53 articles retrieved \\
\hline $\begin{array}{l}\text { Outcome of unintended } \\
\text { pregnancies (apart from abortion) }\end{array}$ & $\begin{array}{l}\text { Pub-Med central, } \\
\text { Google }\end{array}$ & $\begin{array}{l}\text { Outcome, unintended } \\
\text { pregnancy, Bangladesh }\end{array}$ & 91 articles retrieved \\
\hline
\end{tabular}

\section{Time Frame}

The time frame criterion for inclusion of review materials was from the year 2000 to present. While the selection of the year 2000 was somewhat arbitrary, we felt it allowed enough time to show trends while still being manageable in terms of the review process. However, during the documentation process, we remained flexible with the time frame to include some very landmark research and publications related to family planning, unintended pregnancy and associated issues that were published between1996 and1999. Some of these articles were included based on their relevance and importance.

\section{Results}

\section{Organization of the Report}

The report is organized into six parts that address a wide range and number of aspects that inform and influence the understandings of unintended pregnancy in Bangladesh. These sections were selected in conjunction with other STEP UP country partners and allow for the potential for cross-country examination and analysis. Part one covers the legal, policy and socio-cultural context in Bangladesh. Part two presents trends and current indicators of family planning and reproductive health-including equity analysis. Part three examines access to and quality of family planning, MR and post-abortion services. Part four reviews the literature on financing and delivery mechanisms and part five describes the outcomes of unintended pregnancies. The final part six describes the policy and programmatic implications of the country profile. A two-day stakeholder workshop with policymakers was held in June 2013, during which the draft country profile was disseminated. Recommendations from this workshop have been incorporated in the final section of this report. 


\section{Part 1: Sexual and Reproductive Health Rights in Bangladesh: the Legal, Policy and Socio-cultural Context}

\section{A. Reproductive Health, Family Planning and MR and Abortion Laws and Policy}

The policy and legal foundations for population and family planning are contained in the core population policy outlined in 1976, which emphasized population and family planning as a major factor in the overall development of the nation. As a result, the organizational structure of the population and family planning programs were strengthened and so were the monitoring system and decentralization of administrative and financial powers [7]. Activities carried out included offering a choice of various contraceptive methods; reinforcing mother and child care initiatives; including youth and women groups, religious leaders, community leaders and voluntary organizations; introducing educational programs on FP issues; and offering research and training activities. Increasing the legal age of marriage and reinforcing the vital registration system were also given priority [7].

The current abortion law in Bangladesh is based on highly restrictive British Colonial law, written in 1860, that permits abortion only if the mother's life is in danger (Penal Code of India of 1860, section 312-316) [8]. The law inherited from the British Raj has long since been relaxed in Britain itself, as well as throughout many other developed nations worldwide. In the history of Bangladesh, the abortion law has been waived only once; for women who were victims of rape during the Liberation War and the resulting separation of East and West Pakistan in 1971. The Bangladesh National Population Policy attempted to legalise first-trimester abortion in 1976 but did not follow through with legislative action and, thus, the 1860 law still stands [9].

Despite the ongoing presence of the restrictive abortion law, in an effort to reduce the number of unsafe abortions being performed throughout the country, the government of Bangladesh introduced "Menstrual Regulation" (MR) into its national family planning program in 1979 [10]. MR is defined as an "interim method of establishing non-pregnancy" and can legally be performed up to 10 weeks following a missed period $[5,10,11]$. Technically, MR does not come under the provision of penal code section 312 , as it cannot be defined as abortion when pregnancy is unable to be proven at such an early stage, making criminal prosecution near impossible. It is also, therefore, only performed in the absence of a pregnancy test. This has allowed for the successful integration of MR into the national family planning program as a service that is available at all healthcare tiers, from district and higher-level tertiary hospitals down to union health centers [10]. However, many women do not know about the availability of MR service, about the MR service providers or the time limits for MR. The $2011 \mathrm{BDHS}$ reported that $30 \%$ of women had never heard of MR (an increase from $20 \%$ in the $2007 \mathrm{BDHS}$, which suggests awareness about MR may be declining). Furthermore, there is great disparity in access to MR between rural and urban settings, with rural areas being more disadvantaged [11].

The Government of Bangladesh does not consider MR as conflicting with abortion legislation as it is viewed as a method of contraception, rather than an abortifacient. A 1980 government memorandum states that MR can be performed within eight weeks of the beginning of the last menstrual period (LMP) by family welfare visitors (FWV) ${ }^{1}$ and by medical doctors within 10 weeks of a missed menstrual period [8]. Currently, over 4,000 government facilities and 200 NGO clinics provide MR services and this widespread access is due, in part, to the successful training of specific cadres of healthcare workers as part of the newly formed government of independence's population policy in the 1970s.

In 1976, the prognosis for Bangladesh's fertility rates and uptake of family planning services was not optimistic, with demographers predicting the country would be unable to make the transition from high to low fertility like many of its Asian neighbours [12]. However, Bangladesh has managed to increase contraceptive prevalence rate (CPR) from $3 \%$ following independence in 1971, to the current figure of $61 \%$ [13] and has significantly decreased the total fertility rate

\footnotetext{
${ }^{1}$ Health service providers having at least 10 years of formal schooling and 18 months of training in family planning and maternal and child healthcare and additional training, specifically in MR.
} 
(TFR) from 6.3 in 1971 to 2.3 in the most recent BDHS data [4,14]. In the late 1970s, a cadre of female family welfare assistants (FWAs) was trained to deliver information and contraceptives to women at their homes, bypassing restrictive social barriers that existed due to strong patriarchal social norms [13]. Other factors such as mass media, establishing family planning clinics in rural areas and promoting IEC activities were additional reasons for the successful fertility decline [15].

A succession of four five-year plans, each building on core strategic policies outlined in the 1976 population policy, focused on a progressive strengthening of the healthcare infrastructure in Bangladesh in order to provide comprehensive family planning services [9]. The first five-year plan (1973-1978) regenerated a family planning program that had all but ceased during the liberation War [12]. The initial focus was on female sterilisation [13], with the aim to reach replacement-level fertility by 1985 , although uptake levels were lower than those seen before 1970 . During this time, family planning with maternal and child health activities were combined and placed under the Ministry of Health and Population Control, which later became the Ministry of Health and Family Welfare (MoHFW) [12].

Following completion of the rollout of the five-year plans, the government introduced sector-wide approach programs (SWAP), the first of which was the Health and Population Sector Programme (HPSP) in 1998, which later became the Health, Nutrition and Population Sector Programme (HNPSP) in 2003. The specific aims of the recently completed HNPSP five-year cycle were: i) to reduce TFR from 3.3 to 2 by the year 2011 ; ii) to increase CPR from $55.8 \%$ to $72 \%$ by the year 2011; iii) to reduce maternal mortality rate (MMR) from 3 to 2.75 by the year 2011 [16].

Data from the $2011 \mathrm{BDHS}$ indicates that there has been significant progress toward these goals. During this same time period, UNFPA, in conjunction with the MoHFW, upgraded emergency obstetric care facilities in all 64 maternal and child welfare centres (MCWCs), resulting in a marked increase in utilization of emergency obstetric care (EmOC) services [8]. For example, in Rajshahi Division, uptake of new services-such as caesarean sections and patients treated for obstetric complications-increased by 273 and 31 respectively from 1995-96 to 1997-98. Also, existing services such as antenatal visits and deliveries increased by 147 and 192 respectively during the same time period [17]. From 2000 to 2004, further equipment upgrades and training of medical officers in all the district hospitals, as well as in 120 of 400 sub-district hospitals, was another significant step in systems strengthening. However, government investment in maternal health still remains relatively low in Bangladesh [8].

The most recent Health, Population and Nutrition Sector Development Programme (HPNSDP) was initiated in July 2011 and will run until June 2016, drawing on the sector-wide approach program (SWAP) first introduced in 1998. The overall goal of the program is to "ensure quality and equitable health care for all citizens in Bangladesh by improving access to and utilisation of health, population and nutrition services" [16]. It also aims to stimulate demand and improve access to and utilization of health, population and nutrition services in order to reduce morbidity and mortality, reduce the population growth rate and improve nutritional status, especially for women and children. Specific objectives and strategies relating to family planning include the expansion and increased quality of and access to maternal and child health services, as well as revitalized family planning interventions to reach replacement fertility levels [16]. The HPNSDP has set the following goals for 2016: i) to reach replacement-level fertility, i.e. TFR = 2.1; ii) to increase CPR from $61 \%$ to $74 \%$; iii) to decrease the MMR from 194 to < 143 deaths per 100,000 live births; iv) to reduce unmet need from $17.1 \%$ to $9 \%$; v) to reduce discontinuation rates of $\mathrm{FP}$ methods from $56.5 \%$ to $20 \%$; and vi) to ensure share of LAPM from $7.3 \%$ to $20 \%$ in CPR [16].

Some specific interventions relevant to addressing unintended pregnancy during the five-year period include: i) promoting delayed marriage and childbearing and use of post-partum FP, post abortion FP and FP for targeted segments of the population; ii) strengthening FP awareness-building efforts through mass communication and IEC activities and considering local specificities; iii) using different service delivery approaches for different geographical regions and segments of the population; iv) maintaining focus on commodity security and ensuring uninterrupted availability of quality FP services closer to the people (at the community level); v) compensating for lost wages 
(reimbursement for opportunity costs) for long-acting and permanent-method contraceptive performance; vi) effective coordination of services between Directorate General of Health Services (DGHS) and Directorate General of Family Planning (DGFP) to utilize appropriate opportunities to strengthen FP services, especially post-partum and postabortion FP and demand generation. The major impact on fertility is expected to come from increasing the age of marriage which, in turn, will increase the age of first birth [16].

\section{B. International Human Rights Commitments and the Legal Context}

Of the eight major international human rights treaties, Bangladesh has ratified five, including the International Covenant on Economic, Social and Cultural Rights; the Convention on the Elimination of All Forms of Discrimination against Women and its optional protocol; the Convention on the Rights of the Child and its optional protocol; the International Convention on the Protection of the Rights of All Migrant Workers and Members of their Families; and the Convention on the Rights of Persons with Disabilities and its optional protocol. These treaties are legally binding documents under international law that are overseen by UN monitoring bodies. They call on governments to eliminate all forms of discrimination and some specifically address discrimination against women. Mechanisms for the adoption of convention articles into national laws are outlined in the treaties and periodic reports are tendered to the monitoring committees by states for review and recommendations.

The Government of Bangladesh has submitted country reports, most recently to the Committee on the Elimination of Discrimination against Women (CEDAW) in March 2010 [18]; and the Committee on the Rights of the Child (CRC) in June 2009 [19]. There has yet to be a report submitted to the Committee on Social, Economic and Cultural Rights or the Committee on Civil and Political Rights since the respective treaties have been signed by Bangladesh. In response to the reporting, the UN committees have provided recommendations for ways in which the conventions can be implemented by the state.

In relation to sexual and reproductive health, the concluding remarks from the CRC in 2009 state that Bangladesh should "develop a separate comprehensive policy on the critical issues affecting the rights of adolescents, including... reproductive health services," as well as, "pay special attention to the psycho-social needs of adolescents, especially girls and provide appropriate, child-friendly and confidential counselling services in schools and clinics" [20]. In 2011, CEDAW expressed concern at the lack of disaggregated data on women's health in Bangladesh that was provided in the country report, as well as, "the inadequate attention to women's reproductive healthcare services" [21]. The recommendations urge the government to strengthen efforts to provide family planning and contraceptive services to all women, particularly those in rural areas and also to increase access to reproductive health facilities and services.

Furthermore, emphasis is placed on the need for education and awareness-raising programs on the importance of the use of contraceptives, risk of unsafe abortion and women's reproductive rights.

The Government of Bangladesh has also made commitments to other major international declarations and goals that relate specifically to reproductive health, such as the ICPD Programme of Action, the Beijing Platform for Action, the Millennium Development Declaration and the United Nations General Assembly Special Session on HIVIAIDS and the Special Session on Children. These commitments all identify that there can be no improvement in reproductive health without the recognition and protection of reproductive rights.

The Constitution of the People's Republic of Bangladesh outlines human rights, such as the protection of the right to life and personal liberty (Article 32). It also states that there shall be no discrimination "against any citizen on grounds only of religion, race caste, sex or place of birth," and that, "women shall have equal rights with men in all spheres of the State and of public life" (Article 28) [22]. Despite these very clear statements, there is still systemic discrimination based on gender in Bangladesh, as well as incidents of the enforcement of Islamic Shariah law in some communities. The constitution does not specifically address fertility or reproductive rights, such as the number and timing of children; nor does it say anything about when life begins. 


\section{Policy, Political and Institutional Influences on Family Planning and Menstrual Regulation}

There has been a strong focus on the importance of effective family planning policies since the separation of Bangladesh from Pakistan in 1971. The new government in Bangladesh was faced with endemic poverty, high population growth and density and chronic unemployment. The solution to many of the challenges facing national development was seen in the control of population growth. This central idea was influenced by the international political community, particularly following the Third World Population Conference held in Bucharest in 1974, which provided technical guidance for policies and programs and helped to cement population as a priority issue $[23,24]$.

The Planning Commission, established in 1972, identified population and food production as the top priorities for economic development, allocating resources specifically to population activities and reassigning funding from other sectors when resources fell short [24]. From 1983 to 1998, expenditure on health and population activities consistently increased as a proportion of gross domestic product (GDP) and total budget expenditures, rising from $0.8 \%$ of GDP in $1983 / 84$ to $1.3 \%$ in $1997 / 98$ [25]. Per capita spending almost doubled in this same time period, although the level reported in 1997 remained very low at US $\$ 3.33$ (in constant 1987 prices). When compared to regional neighbours India, Sri Lanka and Pakistan, which reported per capita health expenditure in 1990 at US\$21, US\$18 and US\$12 respectively, Bangladesh still performed poorly with just US\$7.3 spent per capita [25].

In real terms, total health expenditure has more than doubled over this time period from US $\$ 1,140$ million in 1997 to US $\$ 2,331$ million in 2007 , which is an average growth rate of $8 \%$ per year [26]. Health expenditure per capita has also increased from US $\$ 9.09$ in 2000 to US\$23.29 in 2010 [World Bank Indicators]. Recent National Health Accounts report for 1997-2007 shows that Bangladesh has the lowest per capita spending on health of any country in the South Asian region and Sri Lanka reporting the highest at US\$57 [26].

A strong influence on the policy and program decisions of the government is the financial and technical support provided by international organisations [24, 27]. Bangladesh had a high dependence on foreign aid following liberation and the organizations that were primarily involved in providing assistance also had population and family planning programs high on their agenda [24]. Family planning came under the development budget, which was largely funded by external sources, the largest of these being USAID. In the years since independence, USAID has provided more than US $\$ 5$ billion in development assistance, ensuring that family planning has remained a government priority [24].

\section{Non-discrimination and Recognition of Vulnerable Groups}

\section{Married Adolescents and Gender Discrimination}

Although autonomy over health choices for women has developed significantly over the past decades, there are still structural inequalities and social and cultural settings that prevent them from accessing the services they need [28]. This is particularly significant for married girls who, on average, have a lower level of education compared to their married male counterparts, have a lower social status in their husband's family and suffer higher rates of maternal mortality and domestic violence $[29,30]$.

Early marriage is a social and cultural norm in Bangladesh; $74 \%$ of women aged $20-49$ years married before the age of 18 and $86 \%$ married by the age of 20 . In this age group, the median age of first marriage is 15.8 years for women, compared to 24.2 years for men [14]. Although a large proportion of marriages still occur before the legal age of 18 , there has been an increase in the median age of first marriage seen over time, particularly in the proportion of women marrying in their early teens: The proportion of women marrying by age 15 has declined by two-thirds over time, from 65 among women in the $45-49$ age group to $21 \%$ among women aged $15-19$ [14]. Level of education is positively associated with the median age at marriage. Women with no education marry two years earlier than those with secondary or higher education [14]. Also, women from the lowest wealth quintile tend to marry two years earlier than those from the highest wealth quintile. 
A study conducted in Matlab indicates that poverty impacts early marriage and that many women considered this time of marital transition to be especially traumatic [31]. As young married women usually live with their in-laws, they felt that having children soon after marriage substantiated their position within their new households and communities. Early marriage almost always leads to early pregnancy [32] and therefore increases the need for effective family planning and reproductive health services to this young and often socially vulnerable age group.

Discrimination against women has been identified as one of the prime reproductive health issues in Bangladesh. This discrimination exists in education, employment, marriage, dowry and often manifests itself in violence against women. Women who have experienced violence tend to have higher rates of reproductive health problems such as gynaecological problems, HIV and sexually transmitted infections (STIS), miscarriages, abortions, unwanted pregnancy and low birth weight [33]. Violence against women is defined as and encompasses, but is not limited to, physical, sexual and psychological violence occurring within the family and community. This includes battering; sexual abuse of female children; dowry-related violence; marital rape; traditional, non-spousal, harmful violence to women; violence related to exploitation; sexual harassment and intimidation at work, in educational institutions and elsewhere; trafficking of women; forced prostitution; and violence perpetrated or condoned by the state.

The physical consequences of violence against women include homicide, serious injuries and disease vulnerability. Violence may also be responsible for a sizeable but unrecognized share of maternal mortality, especially among young, unwed, pregnant women. The most recent national Bangladesh Maternal Mortality Health Care Survey (BMMS 2010) found that the cause of death due to suicide and injuries among women of reproductive age (15-49 years) was $9 \%$ and $6 \%$ respectively. Deaths due to maternal causes were just $14 \%$ in comparison. The psychological consequences of gender-based violence include suicide and mental health problems. Older women were more likely to report to have had an unintended pregnancy than adolescents (60.1\% vs. $22.5 \%)$ [1]. Data also show that sex outside of marriage is negligible among women and that the median age at first marriage is same as the median age at first sex [14].

\section{Hard to Reach Groups}

Bangladesh has a high population density ratio and, unlike some of its neighbouring countries, is predominately homogenous in terms of language, ethnic identity and geography. Despite this, there are some extremely isolated and remote geographical areas where a sizable population is living. This is especially true in the Chittagong Hill Tracts, isolated small islands (e.g Char lands and the Haor basin) where family planning and related services are generally poor, public health facilities are limited in number and, in some places, services are entirely non-functioning compared to mainstream villages and urban areas.

\section{Bandarban (Indigenous Population in Chittagong Hill Tracts)}

Bandarban is unique from other parts of Bangladesh in that geographically it is very hilly and culturally it is home to various indigenous groups. A recent icddr,b study on MR services in this area showed that, often, most people do not know about the availability of MR services either in government or non-government facilities. Indigenous women faced difficulties in accessing proper FP and MR services due to the limited number of public and NGO health facilities that offer FP and MR information and services. Most of these facilities are poorly equipped in terms of human resources and quality of care so that women often have to go to district-level facilities to avail services. Due to lack of transport facilities they must usually walk and often it is too late for the MR procedure when they reach a safe service delivery point. Women who come for MR service beyond the gestational legal cut-off point (>10 weeks of gestation) are usually rejected by the service providers [34]. Therefore, many women prefer to seek MR services from traditional healers and TBAs as they are readily available and more accessible to them at any time and are comparatively less expensive.

Lack of knowledge and misperceptions related to FP, MR and abortion is a major challenge for service provision in the Bandarban region. The majority of the population does not have proper knowledge about the legal time limits of 
MR and $59 \%$ of them had no knowledge of FP methods. The CPR in Bandarban area is 25\% [35]; much lower than the national average of $61 \%$ [4]. Most of the people here prefer traditional methods for family planning, although the use of bio-medical methods, in particular the pill, is increasing [34]. Use of LAPMs, such as implants, IUDs and sterilization are extremely low, in part because stigma and fear are directly associated with these methods. In addition, due to the transport costs, lost wages, food, accommodation, under-the-table payments to MR providers, along with the official service fees, the total cost of FP and MR services was found to be substantially high, even in public facilities where all services are supposed to be free of cost [34]. Moreover, place of residence, religion, age, school attendance, distance to local service centers and access to mass media were found to be significant determinants of FP knowledge to women in this area.

\section{Char-dwellers}

It is believed that between 5 and 6 million people in Bangladesh live in char lands (deep, isolated or detached from mainland). The chars are extremely unstable and people of these areas are among the poorest and most vulnerable in Bangladesh. Due to their temporary nature and separation from the mainland, infrastructure is limited and almost no health services are available to serve char-dwellers [36]. As in Bandarban, char-dwellers also must travel long distances in order to receive health services from qualified providers. The government health facilities are based at the union level (mainland), however, some vaccination camps or satellite clinics are held in char lands very intermittently by some NGO workers and rarely by government workers [37]. No FP, MR or MNCH services are offered for the char-dwellers by any government facilities.

\section{Haor Population}

A haor is defined as a body of water formed by a shallow depression that stays filled all year but swells in the monsoon season. The haor area in Bangladesh is located within the low-lying Central Basin or Sylhet Depression (Netrokona, Habiganj, Brahmanbaria, Kishorgonj, Sunamgonj, Maulovibazar and Sylhet), a large bowl-shaped depression that occupies the middle of the northeast region of Bangladesh. The area of the Central Basin is about $6,000 \mathrm{~km}^{2}$, with the maximum north-south and east-west widths being approximately $113 \mathrm{~km}$ [38]. Generally, the status of health services in haor areas is lower than that of other regions. An overwhelming majority of the population in haor areas depends on traditional healers, as in the char lands and hill tracts. Government hospitals for the haor population are inadequate, of poor quality and are in poor condition with shortage of modern facilities, human resources, medicine etc.

\section{Issues Faced in Haor/Char Areas}

One of the biggest issues for the hard-to-reach populations is that, in general, government healthcare facilities at the union and upazila levels (mainland) do not function in these areas. The shortage of doctors, nurses, trained midwives and family planning workers, in conjunction with the lack of well-equipped laboratories, medical equipment and medicines, means that providing even basic $\mathrm{MNCH}$, FP and MR related services are huge challenges in these areas [39]. For example, each upazila health complex (UHC) should have nine doctors, 10 nurses, five cleaners and other medical support personnel, whereas in reality sometimes only one doctor, a few nurses and one cleaner are found in the hospitals in haor/char areas [39].

Common health issues among the haor and char people are high maternal and child mortality, malnutrition, pelvic infection, nutritional deficiencies-especially among the children and pregnant women, chronic respiratory infections and low weight. Women, especially the poorer ones in these areas, do not get pre-natal and post-natal services from the health center. Poor communication and transport facilities, especially in the dry season, make it difficult to carry patients to district hospitals for proper management. There is a lack of supply of medicines in the hospitals and, although most of the medicines are to be provided free of cost in the public facilities, in many cases poor patients are forced to pay from their own pockets. Distance to the hospitals usually increases the transport cost of health service seekers from remote areas. The seasonal variations in geographic access also create specific challenges for service delivery planning and logistics [39]. 
In the current government health strategy, geographically isolated populations do not get any special policy consideration or priority. Thus, the central health policy is inadequately designed to address the special geographical conditions of these areas.

\section{Urban Slums}

In Bangladesh, nearly $25 \%$ of the population lives in urban areas and $33 \%$ of the urban population lives in urban slums [40]. The urban population is increasing rapidly, mainly due to the influx of the rural poor who are migrating to cities for economic opportunities. Slums are mostly established on government land without any official authorization. As informal settlements, or slums, are considered 'illegal', populations that live in these areas often have no formal addresses and are commonly denied basic rights and entitlements, including the right to access water, sanitation, education and healthcare [41]. Urban slum dwellers are exposed to poor structural and environmental conditions such as overcrowding, poor quality drinking water and sanitation and lack of waste removal. Ignorance and difficult life conditions in the slums are likely to contribute to limited healthcare use and hygiene awareness, lack of knowledge about the origin of sickness and proper measures for cure, improper food habits and breast-feeding practice and low acceptance of vaccination $[42,43]$. A review of health services for people who live in informal settlements in Dhaka city found that only $7.3 \%$ have access to a public health clinic [41].

Mothers and children living under such conditions are at especially high risk for mortality and morbidity. In Bangladesh the health situation in urban slums is often worse than in rural and non-slum urban areas [44]. For example, the mortality rate in Bangladesh for children under the age of five is 65 per 1,000 live births while in urban slums it is approximately 81 per 1,000 live births [14]. Similarly, neonatal and infant mortality are higher in urban slums than in rural areas; for both groups, mortality in urban slums is double that in non-slum areas [14]. The neonatal mortality rate is 44 per 1,000 live births for urban slums and only 20 per 1,000 live births in non-slum areas; the infant mortality rate is 63 per 1,000 live births in urban slums compared to about 30 per 1,000 live births in urban non-slum areas [14, 45].

According to the 2006 Urban Health Survey report, TFR was 2.5 for urban slum areas compared to 1.9 for non-slum areas [45]. Early child bearing is also higher in urban slums compared to non-slum areas. Findings show that $64 \%$ of women had become a mother before the age of 20 in the slums, compared to $44 \%$ in non-slum areas. The proportion of pregnancy among married teenagers in the slums is estimated at $21 \%$, which is twice as high as non-slum areas which are 10\%. The report shows that those who live in the slums have very limited sources for FP methods and $50 \%$ of women primarily used the private medical sector to obtain FP methods, with $90 \%$ supplied by private pharmacies. As the private sector and pharmacies and medicine sellers are currently not regulated in Bangladesh, there are important questions about the quality of services provided in the private medical sector. Fifty-eight percent of currently married women in the slum and District Municipality areas were currently using a form of contraceptives, compared to $63 \%$ in the non-slum areas. There is a scarcity of public and private facilities providing FP services in slum areas [14].

\section{E. Socio-cultural Norms and Trends Concerning Family Formation and Childbearing over Time}

\section{Role of Men in Family Planning}

There is a gap between the role of men as the traditional decision-makers in family planning issues and their knowledge regarding sexual and reproductive health. Family planning and reproductive health programs have traditionally focused on the women of the household, even if they do not have the final say in contraceptive choice or family size [46]. Men in Bangladesh traditionally exert a strong influence over their wives, often determining the timing and conditions of sexual intercourse, family size and access to healthcare services. A lack of desired communication between spouses was cited as a barrier to contraceptive use by couples involved in a 2003 study [47]. Inter-spousal communication was seen to be least frequent between very young (10-14 years) and older women. 
A qualitative study conducted by Shahjahan and Kabir in 2007 explored the nature of male perception, attitudes and knowledge of reproductive health issues [46]. Male dominance, religious superstitions, shyness and lack of awareness were identified as reasons for not accessing family planning methods. Men generally perceived that condoms might be damaged at the time of use; there are fewer options for male methods; as males are involved in economic activities they expect their wives to use family planning methods; condom use during intercourse limits satisfaction; and condom use and disposal is troublesome. Permanent male sterilisation was also seen as a risky operation that may decrease male strength and is only suitable for men who have reached their desired family size. This is often a point of contention among married couples as women often desire a smaller family size than men.

\section{Early Marriage and Dowry}

Early marriage is still widely practiced in Bangladesh and it is second only to Niger in the annual number of child marriages. In a qualitative study conducted by Khan et al. in 2002, respect for elders in families was seen as an important reason for the continuation of early marriage. It is believed, particularly by older women, that at a young age, girls 'are like tender bamboos' and can be molded according to the wishes of her husband and in-laws. If the girls are married at a later age, it is more difficult to change their behaviour [48]. Independent thinking and any suspicion of assertion by young women are major causes of domestic violence in Bangladesh. Despite its illegality, the payment of a dowry to the groom is still a widely accepted practice in Bangladesh [28]. Demands for dowry payment are made before and after marriage and are a major cause of violence against women, suicide and even homicide.

\section{Education on Sexual and Reproductive Health}

Various studies have revealed that young women have little to no information on family planning prior to their marriage $[30,47,48]$. Girls are often informed about sexual intercourse just a few days before marriage and generally this responsibility is given to sister-in-laws, married friends or some elder female relatives in the family. Only 18 out of 54 informants in the 2002 Khan study felt relatively well informed about sexual life in marriage and those reported being well-informed had received a middle or higher level of education [48]. Many informants reported that, while they received no information on sexual life before marriage, their mother, grandmother, sister-in-laws or other female family members had advised them to use pills regularly starting from the day of the marriage. While some were told this was to protect them against early pregnancy, many were not provided with any detailed information.

Initiation of discussions of sexual life, family planning or reproductive goals is nearly always the responsibility of men; women rarely take the initiative [46]. Most women felt that talking about sex, even with their husband, was 'shameful'. Some women felt that, if they initiated discussion on this topic, their husbands might consider them shameless and even suspect them of having had pre/extra-marital relationships. Results show that almost half of the women mentioned that they did not like to express sexual desire to their husbands; in Bengali culture, first the husband has to show his desire and then the wife submits herself to his wishes. Findings from this study also suggested that women had no influence over their husbands' choice to use a condom or not [46]. 


\section{Part 2: Family Planning and Reproductive Health Indicators: Trend and Equity}

Analyses

\section{A. Family Planning}

\section{Knowledge and Awareness of Family Planning}

Knowledge of family planning methods is widespread and consistent throughout Bangladesh, with almost all evermarried and currently married women being able to identify at least one modern method of contraception [14]. Seven out of 10 women were able to identify at least one traditional method. On average, women surveyed were able to identify 7.4 different methods of contraception [14]. However, knowledge of traditional methods such as periodic abstinence and withdrawal has decreased and is lower than knowledge of modern methods. Also, an increasing number of currently married women are aware of implants as a method than in the past $(56 \%$ in $1999-2000$ to $82 \%$ in 2007) [14].

Another important indicator for awareness and changing demand for family planning is the extent to which non-users of contraception plan to use family planning in the future [14]. Sixty-five percent of surveyed non-users in the 2011 BDHS stated that they planned to use a method of contraception in the future.

\section{National Communication Strategy for FP and RH and BCC Efforts of FPAB}

The National Communication Strategy for Family Planning and Reproductive Health (2008) is a road map developed by the MoHFW for program implementers and service providers to help develop their action plans for FP- and RHrelated education, information, counselling and services [49] [Figure 1].

Figure 1: Organizational Chart for the National FP and RH Communication Strategy

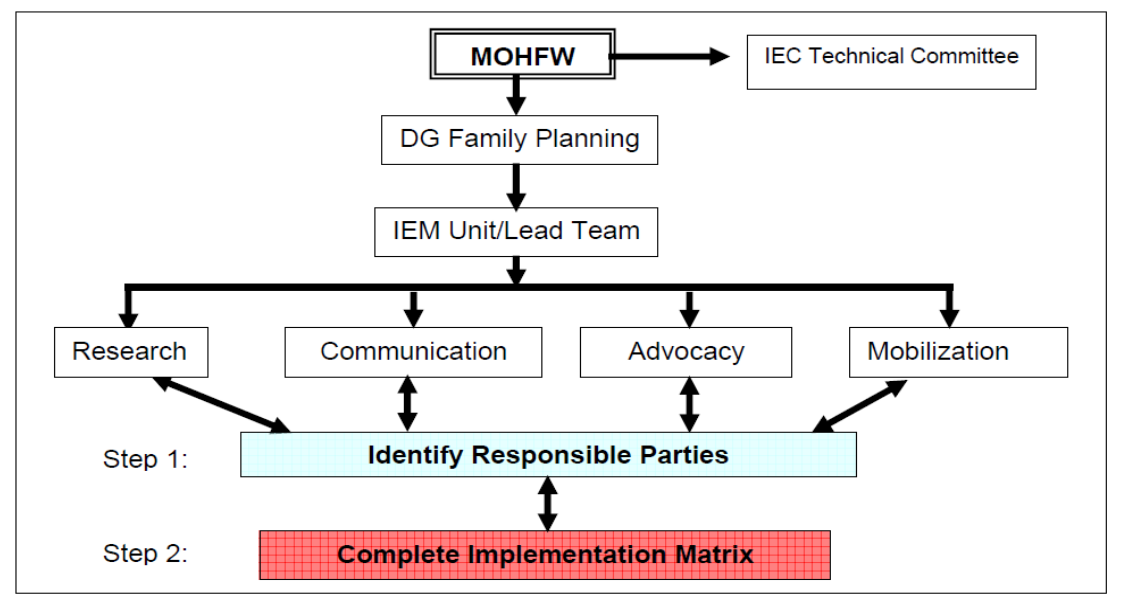

Materials have been developed, including curricula/guides for field workers, booklets about contraceptive methods, video to improve skills required for safe IUD insertion and removal, "special days" discussion and rallies throughout the nation. Among many challenges, there were limited resources for pretesting, producing and disseminating quality, culturally appropriate and geographically relevant media materials [49]. Their approach is to target specific audiences, such as newlyweds and low parity couples, married couples with desired family size, husbands/males, poor underserved communities (hard to reach), adolescents, unmarried youth service providers, program managers and supervisors, religious and community leaders, political leaders/policymakers and mass media personnel. They found entertainment education to be a successful method of Behavior Change Communication (BCC) and mass media to be an effective means of increasing interpersonal communication about FP methods. They also suggested a central 
Media Materials Resource Center should be created for FP and RH so that individuals and organizations have access to relevant materials and to avoid the potential duplication of new materials [49].

The Family Planning Association of Bangladesh's (FPAB) strategy for improving access to FP methods is to increase access to quality sexual reproductive health and rights (SRHR) information and service by reducing social, cultural, religious and infrastructural barriers that impede access of men and women to essential services [50]. As BCC efforts, FPAB produced a number of materials including film, video, booklet, poster and other print materials on relevant issues. Radio drama serial and TV talk show programs were also produced and broadcast. Special focus was given on adolescent reproductive health issues. FPAB offers an award in journalism each year to one journalist for publishing newspaper reports on population, health, women empowerment or relevant issues (FPAB website) [50]. Additionally, they produce booklets for madrasas on Islamic views on family planning and also have khutbas for Friday prayers on various SRHR topics (English translations of which can be found on their website) [50].

\section{Contraceptive Use}

Contraceptive use has increased significantly since the introduction of the first outline of the national population policy in 1976 , from a mere $8 \%$ in 1975 to $61 \%$ in 2011 . Use of contraceptives varies by women's background characteristics: the group that consistently shows the highest use is married women in their 30s [4, 14], with approximately $70 \%$ of them currently using some method of family planning, whether modern or traditional. The proportion of women using traditional methods of contraception, however, has varied little, with only a slight increase from $8 \%$ to $9 \%$ over the four years between the $2007 \mathrm{BDHS}$ and the $2011 \mathrm{BDHS}$. There are proportionally more in the 25-34-year age groups than in the 30-39-year age groups in the 2011 survey.

The difference in contraceptive use between urban and rural residents continues to narrow. In 2007 , only $54 \%$ of women in rural areas reported using contraception, while use among urban women was reported to be $62 \%$. The BDHS 2011 data indicates a notable increase to $60 \%$ among women in rural areas compared to women in urban areas who experienced a small increase to $64 \%$. The urban-rural differential is mainly due to the greater use of condoms in urban areas (10.3\%) versus $3.9 \%$ in rural areas [14]. Contraceptive use ranges from $69 \%$ in Rangpur and $67 \%$ in Rajshahi and Khulna to $45 \%$ in Sylhet [4]. Unlike other developing countries, there has consistently been only a small difference in contraceptive use between education levels and wealth quintile groups.

\section{Method Mix}

The oral contraceptive pill is by far the most common method of contraception, with $27 \%$ of women reporting current use in 2011 ; followed by injectables at $11 \%$; condoms at $6 \%$; and female sterilization at $5 \%$. Approximately $1 \%$ of women mentioned the use of male sterilization, IUDs and implants [4]. [Table 1]

Use of female sterilization has stagnated since 2004 and there is evidence that there may be a slight increase in the use of male sterilization between 2007 and 2011 (from 0.7 to 1.2\%) [4]. However, the greatest increases in modern contraceptive use are seen in the pill and injectables. Twenty-seven percent of women currently use the pill, compared to just $14 \%$ in 1991. Although the proportion of women using the pill has doubled since 1991, it has always been the most used method (among about one-half of all users). Similarly, injectable use has also increased from 3\% in 1991 to $11 \%$ in 2011, with the highest uptake among women in the lower wealth quintiles [4]. While contraceptive pills are favored by women of all education levels, women with no education are more likely to use female sterilization than women of other educational levels and women in the lowest wealth quintile are the most likely to report using male sterilization. Use of condoms increases with education level and wealth quintile, while use of injectables declines as wealth increases [4]. 
Table 3: Trends in Current Use of Contraceptive Methods

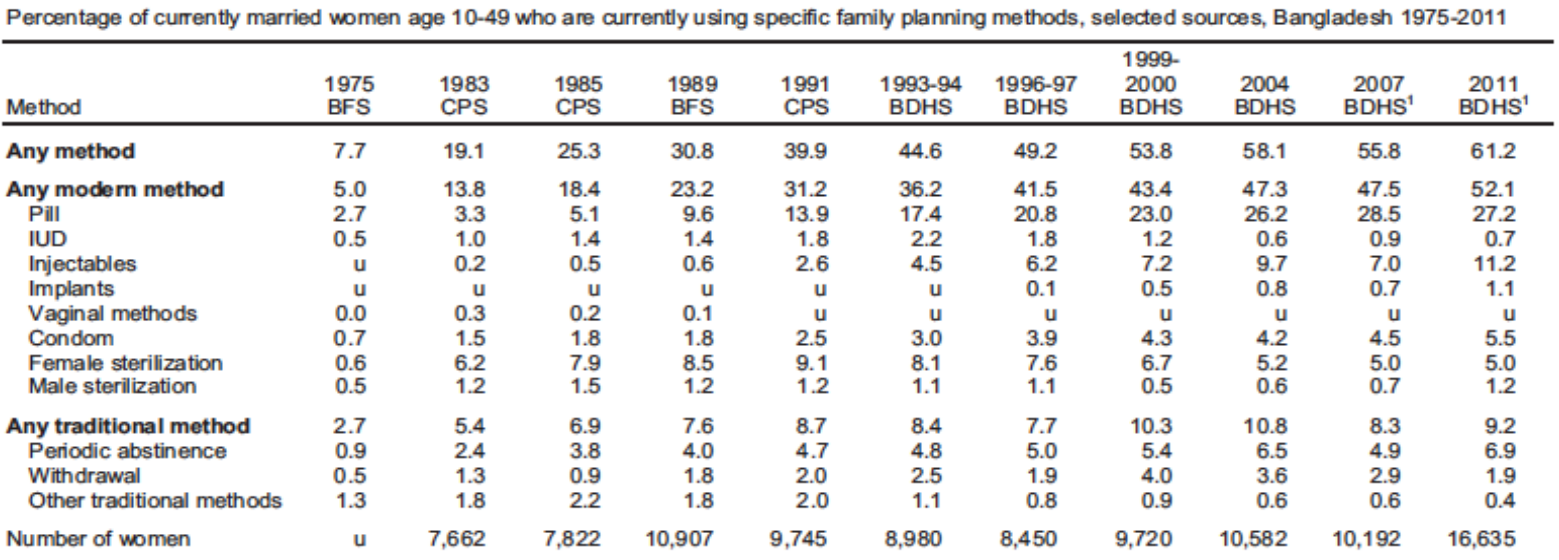

$\mathrm{u}=$ Unknown (not available)

Data from 2007 and 2011 are restricted to currently married women age 15-49

Sources: 1975 Bangladesh Fertility Survey (BFS) (Islam and Islam, 1993:43); 1983 Contraceptive Prevalence Survey (CPS) (Mitra and Kamal, $1985: 159) ; 1985$ CPS (Mitra 1987:147); 1989 BFS (Huq and Cleland, 1990:64); 1991 CPS (Mitra et al., 1993:53); 1993-1994 Bangladesh Demographic and Health Survey (BDHS) (Mitra et al., 1994:45); 1996-1997 BDHS (Mitra et al., 1997:50); 1999-2000 BDHS (NIPORT et al., 2001:53); 2004 BDHS (NIPORT et at., 2005:67), and 2007 BDHS (NIPORT et al., 2008: 52)

The method mix in Bangladesh has changed over the past two decades, with a consistent decline in long-acting and permanent methods (LAPM) witnessed from the early 1990s. There was stabilisation in 2007 and there are indications that there has been a slight increase in the 2011 data [4]. In 1991 LAPM accounted for almost 30\% of contraceptive use, whereas it now stands at just $13 \%$. This is a cause for concern as the majority of women in Bangladesh reach their desired fertility and family size in their 20 s leaving them a significant number of reproductive years during which they require effective contraception to ensure protection from unintended pregnancies.

Moreover, the fertility rate for women aged 30-39 has dropped significantly between the 2007 and 2011 BDHS (in between the 2007 and 2011 BDHS surveys, the fertility rate of the 30-34 years age group has dropped from 70 to 56 per 1,000 women and among the 35-39 year age group it has dropped from 34 to 21) [14]. This age group may require further investigation to ascertain their level of risk of unintended pregnancy.

Until now, the success of the country's FP program has been largely dependent upon the use of non-clinical temporary methods, such as the oral pills and condoms. In order to reach the target of reducing fertility level to replacement level, the Health Population Nutrition Sector Development Program (HPNSDP) aims to increase the CPR from $62 \%$ to $72 \%$ and to lower the TFR from 2.5 to 2.0 by 2016 by implementing the following strategies: (i) increase the percentage of use of LAPM in the method mix; (ii) decrease the proportion of unmet need for family planning from $17.1 \%$ to $9 \%$; (iii) make certain there is a continuous flow of logistics supply; (iv) target low-performing and hard-toreach areas with specialized interventions and programs; and $(v)$ increase in the awareness development program on a large scale. Additionally, in order to increase the use of LAPM methods, the Government of Bangladesh plans on outsourcing NGOs to serve hard-to-reach areas and low-performing areas [16].

\section{Sources of Family Planning Methods}

The major source of contraception continues to be the public sector in the country, which supplies over $50 \%$ of the methods [4]. Government field workers serve as the predominant source in this sector, providing $23 \%$ of the methods. Meanwhile, Upazila Health Complexes (UHC) and Family Welfare Centres (FWC) each provide $8 \%$ of the supply of methods [51]. Long-term methods, such as sterilization, IUDs, implants and injectables, are largely acquired in the public sector, with the UHC providing mostly sterilization s and implants. Even so, private sources, such as private hospitals and clinics, are used by one-fifth of the women who obtain sterilization procedures, while a mere $4 \%$ obtain this service from a NGO clinic [51]. As the government field workers are now permitted to supply injectables, they have become a more common source for this method. They are also the primary supplier of pills. Pharmacies provide 
$33 \%$ of modern contraceptive methods and are the largest suppliers in the private sector, providing mainly temporary methods such as the pill and condom. In total, the private medical source contributes to $38 \%$ of family planning methods [4].

\section{Unintended Pregnancy and Induced Abortion}

An unintended pregnancy is a pregnancy that is either mistimed (occurred earlier than the desired time) or unwanted (occurred when no more children were desired) at the time of conception [1]. In Bangladesh, examining the data from the last five BDH surveys from 1993 to 2007 shows that there has been a gradual decline in trends of unwanted pregnancy from $33 \%$ to $29 \% ; 15 \%$ were mistimed (wanted later), while $14 \%$ were unwanted [1]. [Figure 2]. However, BDHS 2007 indicates that, if unwanted births could be prevented, the TFR would drop below the replacement level of fertility (2.1 children per woman) [14]. As one of the goals of the nation's population policy is reaching replacement level of fertility, reducing unintended pregnancy would help achieve this goal.

BDHS 2011 data shows that, overall, $65 \%$ of currently married women in Bangladesh would like to limit the number of children they have. Fifty-nine percent say they do not want any more children (up slightly from $57 \%$ in 2007) and an additional $6 \%$ have been sterilized [Table 2] [4].

The proportion of women who either want no more children or have been sterilized increases sharply with the number of living children, from $16 \%$ among women with one child to $82 \%$ among women with two children and to $93 \%$ among women with four or five children. The proportion of women who want to limit childbearing over the past four years has risen slightly (63\% in 2007 to $65 \%$ in 2011), while the wish to have another child has declined slightly from $34 \%$ in 2007 to $31 \%$ in 2011 [4]. [Table 2].

Figure 2: Trends of Unwanted Pregnancy in Bangladesh during 1993 - 2011 (BDHS 2011)

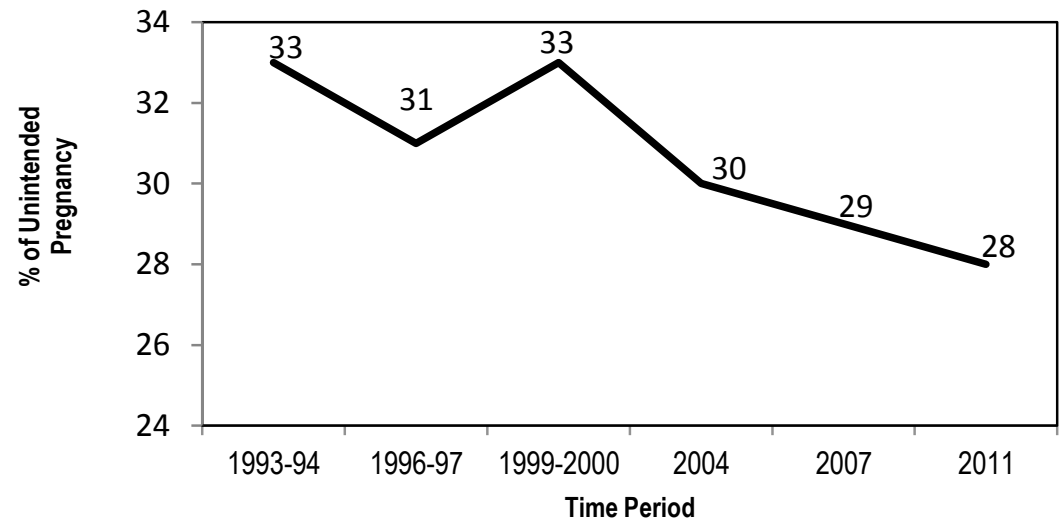

In a study on the prevalence and socioeconomic correlates of unintended pregnancy among rural Bangladeshi women, it was found that, overall, $30 \%$ of the women reported that their most recent pregnancy had been unintended [1].

Unintended pregnancy varied significantly by age, education, religion, discussion of FP with husband, wealth index and contraceptive users versus non-users. The oldest women were more likely to report having had an unintended pregnancy than the adolescents ( $60.1 \%$ vs. $22.5 \%)$ [1]. Risk of unintended pregnancies increased among older women as they were more uncertain to use modern methods of contraceptives than younger women [1]. Unintended pregnancy among women with secondary or higher education was $25.4 \%$, while it was $35.8 \%$ among those who had no formal education [1]. Women who were married before they turned $18 \mathrm{had}$ a higher rate of unplanned pregnancy $(30.5 \%)$ than those who married at age 18 or older $(27.3 \%)$. Incidence of unintended pregnancy was about $10 \%$ 
higher among Muslim women than non-Muslim (30.9\% vs. $20.3 \%)$. Meanwhile, women who discussed FP with their husbands had a lower prevalence of unplanned pregnancy (28.4\%) than those who never discussed it (31.1\%) [1].

Wealth index appeared to be inversely associated with unintended pregnancy. Contraceptive users reported unintended pregnancy more often than non-users. Also, adolescents reported 31\% current pregnancies as being mistimed [1]. An increased risk of unintended pregnancy among women with more than two living children was found [51], which is also suggested in a report by Rahman et al. [2]. BDHS 2007 and 2011 data provides important insights into the relationship between women's autonomy in household decision-making and pregnancy intention status in Bangladesh. Although the relationship is complex, some patterns can be discerned as results indicate that autonomy reduces unintended pregnancy of women in Bangladesh [51].

Table 4: Percent Distribution of Currently Married Women Aged 15-49 by Desire for Children According to Number of Living Children (BDHS 2011)

\begin{tabular}{|c|c|c|c|c|c|c|c|c|}
\hline \multirow[b]{2}{*}{ Desire for children } & \multicolumn{7}{|c|}{ Number of living children ${ }^{1}$} & \multirow[b]{2}{*}{ Total } \\
\hline & 0 & 1 & 2 & 3 & 4 & 5 & $6+$ & \\
\hline $\begin{array}{l}\text { Have another soon }{ }^{2} \\
\text { Have another later }{ }^{3} \\
\text { Have another, undecided when } \\
\text { Undecided } \\
\text { Want no more } \\
\text { Sterilized } \\
\text { Declared infecund } \\
\text { Missing }\end{array}$ & $\begin{array}{r}65.8 \\
27.4 \\
1.6 \\
1.5 \\
0.9 \\
0.5 \\
2.3 \\
0.0\end{array}$ & $\begin{array}{r}17.4 \\
62.3 \\
1.5 \\
2.1 \\
14.5 \\
1.0 \\
1.1 \\
0.1\end{array}$ & $\begin{array}{r}4.9 \\
10.2 \\
0.3 \\
1.5 \\
76.2 \\
5.3 \\
1.3 \\
0.3\end{array}$ & $\begin{array}{r}1.6 \\
2.7 \\
0.0 \\
1.2 \\
80.7 \\
11.1 \\
2.4 \\
0.2\end{array}$ & $\begin{array}{r}1.1 \\
1.1 \\
0.1 \\
0.3 \\
81.4 \\
11.4 \\
4.1 \\
0.4\end{array}$ & $\begin{array}{r}0.5 \\
0.2 \\
0.1 \\
0.5 \\
80.7 \\
12.1 \\
5.8 \\
0.0\end{array}$ & $\begin{array}{r}0.3 \\
0.0 \\
0.7 \\
0.4 \\
86.3 \\
6.1 \\
5.9 \\
0.2\end{array}$ & $\begin{array}{r}10.9 \\
19.8 \\
0.6 \\
1.4 \\
58.7 \\
6.2 \\
2.3 \\
0.2\end{array}$ \\
\hline $\begin{array}{l}\text { Total } \\
\text { Number of women }\end{array}$ & $\begin{array}{l}100.0 \\
1,268\end{array}$ & $\begin{array}{l}100.0 \\
3,740\end{array}$ & $\begin{array}{l}100.0 \\
4,886\end{array}$ & $\begin{array}{l}100.0 \\
3,365\end{array}$ & $\begin{array}{l}100.0 \\
1,836\end{array}$ & $\begin{array}{r}100.0 \\
853\end{array}$ & $\begin{array}{r}100.0 \\
689\end{array}$ & $\begin{array}{r}100.0 \\
16,635\end{array}$ \\
\hline
\end{tabular}

${ }_{2}^{1}$ The number of living children includes current pregnancy

${ }^{2}$ Wants next birth within 2 years

${ }^{3}$ Wants to delay next birth for 2 or more years

${ }^{4}$ Includes both female and male sterilization

A follow-up study report by Gipson and Hindin in 2008 revealed that $80 \%$ of pregnancies resulted in live births, while $11 \%$ of all pregnancies were terminated [5]. The remaining $7 \%$ were spontaneous miscarriages and $3 \%$ were stillbirths. A higher number of pregnancies $(29 \%)$ were terminated by couples in which neither of the partners reported wanting more children than by couples in which either of the partners wanted more children (2\%). Further analysis indicates that after controlling for other socio-demographic variables, women who reported that they did not want to have any more children were more than five times as likely to have a subsequent pregnancy termination (AOR: 5.25 ; $95 \%$ Cl: $2.89,9.55)$, as compared to women who said that they wanted another child [52]. The inclusion of husbands' preferences somewhat attenuated the effect of wives' preferences; however, the analysis indicates that both wives' (AOR=4.25; 95\% Cl= 2.26, 7.99) and husbands' (AOR= 3.35; 95\% $\mathrm{Cl}=1.72,6.54$ ) preferences independently and significantly predicted subsequent pregnancy termination after controlling for socio-demographic characteristics. This result indicates that it is not only important to consider the woman's fertility preference but also the husband's when considering communicating family planning messages [52].

More than half the couples from the study participating in the in-depth interviews revealed that they had tried to terminate at least one pregnancy. Many participants reported initial attempts to use informal or traditional methods to terminate a pregnancy, including: allopathic or homeopathic medicine, plant roots, bottles of yellow liquid from the kobiraj (traditional healer) and the use of oral contraceptives. Some women reported that they first attempted one of these methods, but when it failed, they opted for another method [52]. 
In comparison to wanted children, unwanted children show lower neonatal mortality but higher mortality thereafter [53]. Those children who were "up to God" experience the highest mortality, however the authors have drawn no significant conclusions from the differentials, as these took no account of numerous associated measured and unmeasured explanatory variables (e.g. birth order of the child). The study estimates indicate that unwanted births experience an elevated risk of mortality during infancy that is large and statistically significant. In early childhood, in contrast, unwanted births show a net additional risk that is small in magnitude and is not significant [53].

\section{Unmet Need for Family Planning}

The current level of unmet need for family planning in Bangladesh is approximately $14 \%$ (2011), with $5.4 \%$ for spacing and $8.1 \%$ for limiting births [4]. Women with unmet need are defined as those who are fecund, currently married and say that they do not want to have any more children, or that they want to wait at least another two years before having another child but are not currently using any contraception [4]. It is estimated that the existing total demand for family planning is $75 \%$, with $84 \%$ of this demand being met [4]. Unmet need is currently at a similar proportion to that seen in $2004(11 \%)$ and has decreased since $2007(17 \%)[4,14]$. The consistent trend is that unmet need decreases with increasing age. In women aged $15-19$, the unmet need is $14 \%$, dropping to $8 \%$ among women aged $45-49$ [4].

Unmet need has dropped across all geographic divisions since the previous BDHS, with the highest unmet need now seen in Chittagong and the lowest in Khulna and Rangpur divisions. Sylhet and Barisal divisions have both made marked decreases in unmet need, with both divisions decreasing by 10 percentage points each [4].

The determinants of unmet need among married women in a selected rural area were explored and it was found that fear of side effects was cited as a major reason for not using contraceptives among $46 \%$ of respondents. Religious reasons, husband's or family disapproval, lack of knowledge about methods, lack of information from family planning worker and economic reasons were mentioned as other causes of not using family planning methods [51]. Several other studies reiterated these reasons $[54,55]$. The program implementation plan of the HPNSDP stated more technical reasons for the high level of unmet need, including stock out of FP methods, inadequate manpower at the field level, low standard of monitoring and supervision and insufficient interventions in areas that were hard to reach and had low performance [16].

In order to address the above-mentioned issues, the government recruited the necessary manpower and ensured that the contraceptives forecasting and procurement were time bound. Additionally, to assure that monitoring and supervision at all levels were effective, they carried out special activities. They are anticipating that implementing these initiatives, as well as various interventions that are being undertaken within the operational plans (OP) of the DGFP under the current HPNSDP will ensure that the goal of reducing unmet need from $17 \%$ to $9 \%$ will be achievable [16].

\section{Discontinuation and Switching}

Approximately one in three users of contraceptive methods in Bangladesh stop using that method within 12 months [4]. As expected, these rates are much higher in more short-acting methods, such as pills, injectables and condoms, which are the most widely used methods in the country, compared to longer-acting methods, such as implants and the IUD [4]. Since 2007, there has been an encouraging overall decline in discontinuation rates in the country, from $57 \%$ to $36 \%[4,14]$. A cohort analysis using two sources of Matlab data showed contraceptive switching patterns of different birth cohorts of women. The median duration for pill use was found to be about the same across all birth cohorts. While younger cohorts may be discontinuing the pill in order to have a birth, older women are usually limiters [56].

The most common reasons for discontinuation were the desire to become pregnant (7\%), other fertility reasons (including infrequent sex/husband's absence/ separation, menopause/difficulty becoming pregnant - $6 \%$ ) and side 
effects or health concerns (11\%) [4]. Only $14 \%$ of discontinuation episodes were followed by switching to another method [4].

A study showed that, on an average, women had used 2.5 modern methods of contraception over their reproductive lives, while the mean number of switches (inclusive of switching from modern to traditional methods or stopping between methods) is 13.5 [56]. It was also found that the frequency of switching increases with women's level of education and also with their socio-economic status, although the correlation was weak. The contraceptive switching was shown to increase with parity — during the period between second and third births, women on average had switched 3.3 times; only $5.6 \%$ users were satisfied with only one method. From marriage to first birth and from first to subsequent births, the most preferred switching method was from pill to injection; IUD users also preferred to switch to pill or injection. Usually women tended to switch from IUD to injection after their third birth. Moreover, younger women were found to switch more between methods than older women [56].

The largest decline in discontinuation among methods is seen in the discontinuation of traditional methods, withdrawal and the rhythm method, although discontinuation has decreased for all methods [4]. Overall, rates of discontinuation have been relatively consistent over the past decade, plateauing at just fewer than 50\% from 1993 until a spike to $57 \%$ in the 2007 BDHS, with the current rate of $36 \%$ being the lowest seen this decade [4]. [Figure 3]

\section{Desired Fertility, Family Size and Son Preference}

The most recent BDHS data indicates that $65 \%$ of currently married women in Bangladesh want to limit childbearing; $59 \%$ wanted no more children and an additional $6 \%$ have undergone sterilization [Figure 4]. The proportion of women who either want no more children or have been sterilized increases rapidly with parity, from $16 \%$ among women with one child to $82 \%$ among women with two children and to $93 \%$ among women with four or five children [2].

Figure 3: Trends In All Methods Discontinuation Rates from 1993/94 to 2011 (Vlassoff m. et. al. 2012)

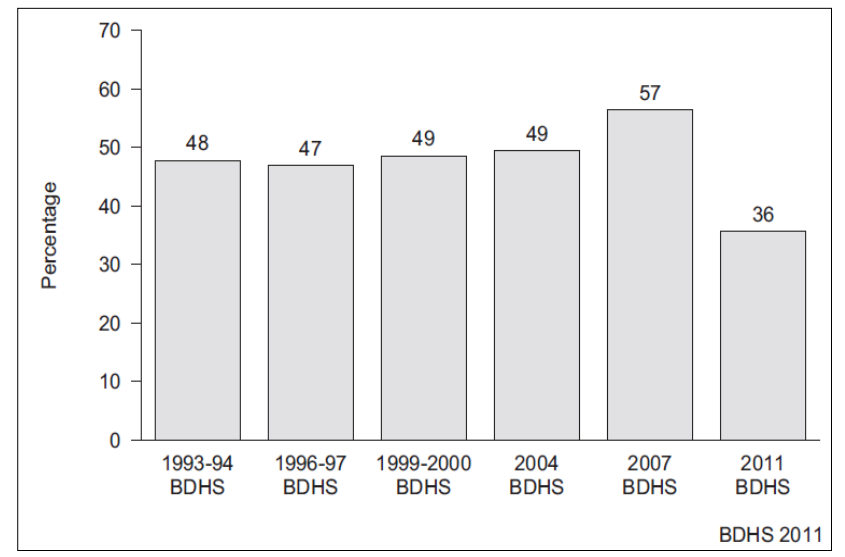

There has been a small increase in the proportion of women who want to limit childbearing over the past four years (63\% in 2007 to $65 \%$ in 2011), while the desire to have another child has decreased from $34 \%$ in 2007 to $31 \%$ in 2011 [2]. Fertility in Bangladesh has declined sharply starting in the seventies and then plateaued at around 3.3 births per woman for most of the 1990s. During the current decade, it has begun to decline again, reaching a TFR of 2.3 in 2011 $[4,14]$. There is also regional variation in TFR, with some divisions in Bangladesh already at replacement or below replacement level fertility (e.g. TFR in Khulna was 1.9 and in Rajshahi was 2.1).

There has been an overall $16 \%$ decline in the total wanted fertility rate for Bangladesh from 1.9 estimated in 2007 to the current rate of 1.6. The TFR is estimated as 2.3 children, the same decline (15\%) in the same time period. If unwanted births could be avoided, women would have 0.7 children less than their actual number of children and the 
TFR would be 30\% lower. From 1999-2000 to 2011, the gap between wanted and actual fertility rates has reduced from 1.1 to 0.7 respectively [4] [Figure 5].

The gap between wanted and observed fertility rates varies by characteristics of women. Among rural women the gap is higher than among urban women (0.9 vs. 0.5). Women in Sylhet (1.3) and Chittagong (1.1) also show a wider gap than their counterparts in Khulna and Rajshahi (both 0.5). As education and wealth increases, the gap between wanted and actual fertility rates decreases. Women with a secondary or higher level of education have a narrower gap (0.4) than those with no education (1.1). Also, women in the lowest wealth quintile showed a wider gap (1.3) than women in the highest wealth quintile (0.4) [4].

Saha et al argue that the gap between the level of wanted fertility and the TFR is possibly due to a preference for male children, a desire for security against infant and child mortality, a shortage of quality family planning services and ineffective use of family planning methods. The study recommends addressing these issues in order to reduce this gap [57].

The 2011 BDHS data showed that, as parity increases, women's desire to limit having more children decreases. Moreover, women who want to limit having children has increased $2 \%$ between the two BDH surveys $(63 \%$ to $65 \%$ ) [4].

Figure 4: Fertility Preferences among Currently Married Women Aged 15-49

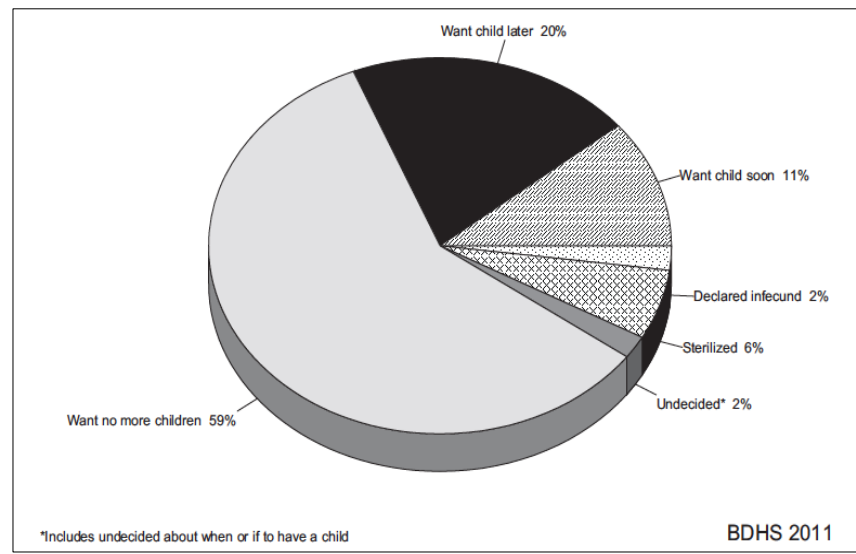

Son preference may make men less likely to desire fewer children compared to men having no preference [58]. Additionally, as women are traditionally more dependent on their husbands and children, especially sons, for social and economic security, their preference for male children is a means of ensuring social and financial support, especially in their old age. Social practices, such as early marriage, large age difference between spouses, early childbearing and reduced educational and employment opportunities for women reinforce women's dependency on sons, although evidence shows these practices are gradually changing [59]. Additionally, sons also bring dowry, although illegal, to the family through marriage [60]. Another study suggests that fertility would decrease by $6 \%$ if the preference for male children could be eliminated [58].

Men who are educated, even at the primary level, tend to prefer smaller family size. Younger men also hold modern views of having fewer healthier children, while older men desire traditional large families [58]. Occupation of men also affect their fertility preference, as men who work in modern sectors can depend on pension, gratuities and savings as their old age support and self-dependent men are more likely to incur higher costs in rearing their children [58]. Thus, they may prefer fewer children rather than place emphasis on having a male child, although the association between occupation and fertility preference was not significant in this study. Low literate people have also been observed to mistakenly believe that large family sizes were required by religion [58]. 


\section{Birth Spacing and Timing}

Short inter-pregnancy intervals are associated with higher rates of infant and child mortalities, maternal death, thirdtrimester bleeding, premature rupture of membranes, puerperal endometritis and anaemia. A study in Matlab showed that more than $20 \%$ of inter-pregnancy intervals were less than 15 months and nearly $10 \%$ were less than six months, which identifies a large number of women and their infants who are at substantial risk of associated morbidities and mortality [61]. Shorter inter-pregnancy intervals ( $<6$ months) are associated with significantly increased odds of induced abortion, miscarriage and stillbirth. Similarly, inter-pregnancy intervals of 6-14 months are strongly associated with an increased likelihood of induced abortion. The increased odds of induced abortion associated with a short interpregnancy interval after a live birth undoubtedly reflect the fact that women did not intend to become pregnant so soon after a previous pregnancy [61].

Figure 5: Wanted Fertility Rate (BDHS 2011)

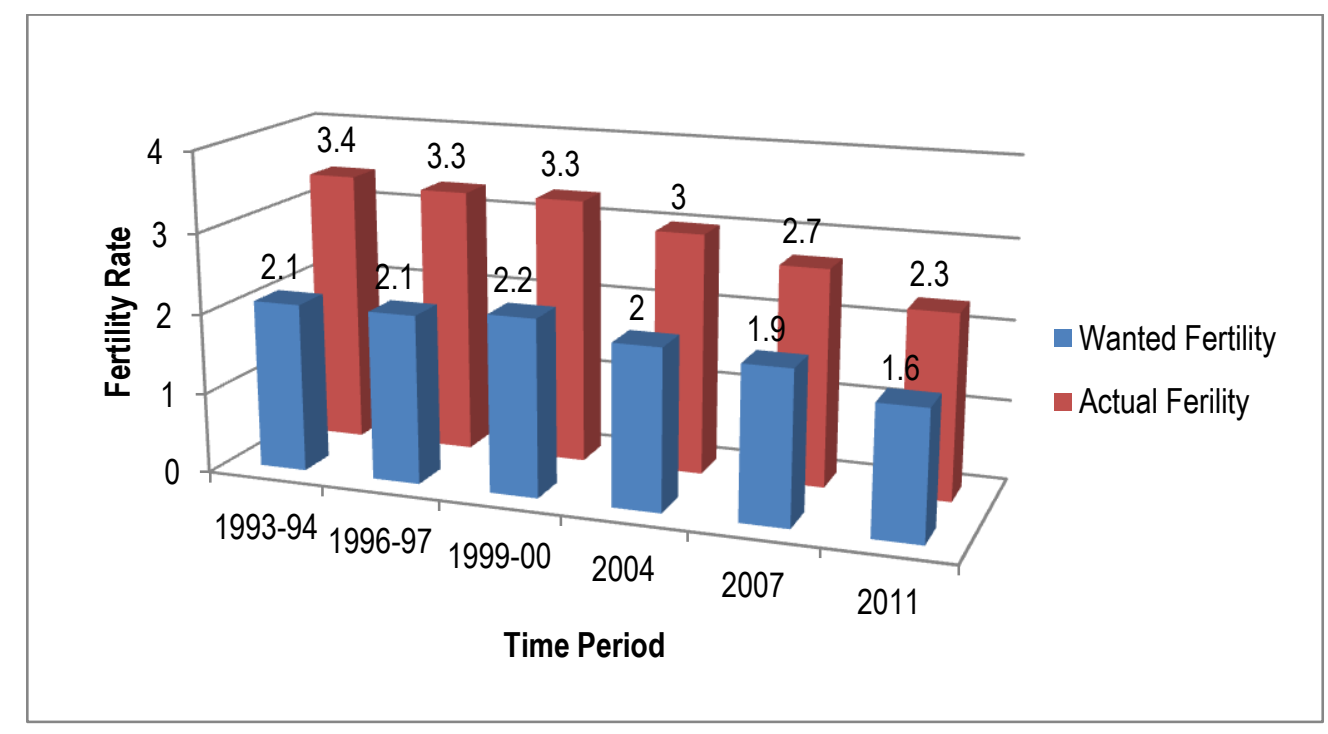

In an analysis of DHS data over a period of 20 years, as intervals of less than 36 months are associated with higher levels of infant and child mortality and some maternal morbidity, improving the spacing of pregnancies is essential in reducing these adverse health outcomes. Rates of infant and child mortality would be 5.8-9.4\% lower if all pregnancy intervals were three-to-five years in duration [62].

\section{B. MR and Abortion}

\section{Magnitude of MR and Abortion}

The exact magnitude of MR and abortion in Bangladesh is unknown, as much social stigma is still attached to both procedures, despite MR being a legal procedure. Women may not be entirely forthcoming with information about their own experiences, and statistics from illegal abortion practices are difficult to obtain. Despite the challenges of collecting data on these practices, Bangladesh has several reliable and national data that provide a clearer picture of MR and abortion use. For example, the BDHS asks women about knowledge and ever-use of MR, and Singh et al have previously (1995) and very recently (2012) estimated national level rates of MR and induced abortion in Bangladesh. The recent BMMS 2010 also estimates abortion-related mortality [44].

According to the $2007 \mathrm{BDHS}$, the rates of ever-use of MR among ever-married and currently married women gradually increased from 1996-97 to 2004 and remained steady at 6\% until 2007 [14]. BDHS 2011 data shows that ever-use of MR has now increased to the current rate of 9\% [4]. [Figure 6]. Interestingly, knowledge of MR declined from $81 \%$ among currently married women to $70 \%$ between 2007 and 2011 BDHS. 
In the 2004, 2007 and 2011 BDHS, rates of ever-use continue to be highest among women in their thirties; the rate of ever use of MR among currently married women and ever-married women in the 30-34 age group is 12.4 while among 35-39 age group it is 14.1 [4]. The BDHS figures differ from WHO estimates that $2.8 \%$ of all pregnancies result in MR and $1.5 \%$ in induced abortion, despite the wide availability of family planning services [63].

A study conducted by Oliveras et al in 2008 compiled data from icddr,b surveillance sites nationally and found large variations in reported statistics on MR and abortion numbers. The overall proportion of women who reported having had an MR or abortion varied from $5.2 \%$ in the $2007 \mathrm{BDHS}$ to $36.9 \%$ among brothel-based sex workers [64]. Among ANC clients at one of the NGO clinics, $11.4 \%$ reported ever-use of MR or abortion and, among clients of an urban health clinic in Chittagong, $17.6 \%$ reported use of MR or abortion. Fewer street-based sex workers (14.5\%) reported use than did women seen at the urban health clinic in Chittagong [64].

The recent study by the Guttmacher Institute, which relied on health facility surveys (HFS), has estimated that 653,100 MR procedures were performed in Bangladesh in 2010 [65]. Almost two-thirds of these were performed in the public sector and almost half were performed in UH\&FWCs. Nationally, the private sector accounted for nine percent of MR procedures, although this was higher in Dhaka and Khulna divisions (15-21\%). NGO providers accounted for a little over one-quarter of procedures. The proportion of MR services offered varied widely by division, ranging from $37 \%$ in Khulna to $76 \%$ in Barisal [65].

The Guttmacher study estimated the number of induced abortions to be 646,600 in 2010 , with an average annual rate of 18 abortions per 1,000 women aged 15-44. There were notable variations across divisions with a higher than average rate in Rajshahi and Khulna (22 and 25, respectively) and an exceptionally low rate in Barisal [8]. The low rate in Barisal could be possibly because all women who received care for post-abortion complications were not accounted for in the HFS, or perhaps women in this division were less inclined to use abortion services [66]. The ratio of abortions to live births was 18 per 100 nationally, meaning that approximately one woman has an induced abortion for every five who give birth. The combined ratio of MRs and induced abortions is 37 per 100, indicating that almost two pregnancies are ended for every five that result in a live birth. This ratio is higher than the estimate for the SouthCentral Asian Region abortion ratio in 2008 (26 per 100) [66].

Figure 6: Rate of Ever-use of MR among Ever-married and Currently Married Women (BDHS 2011)

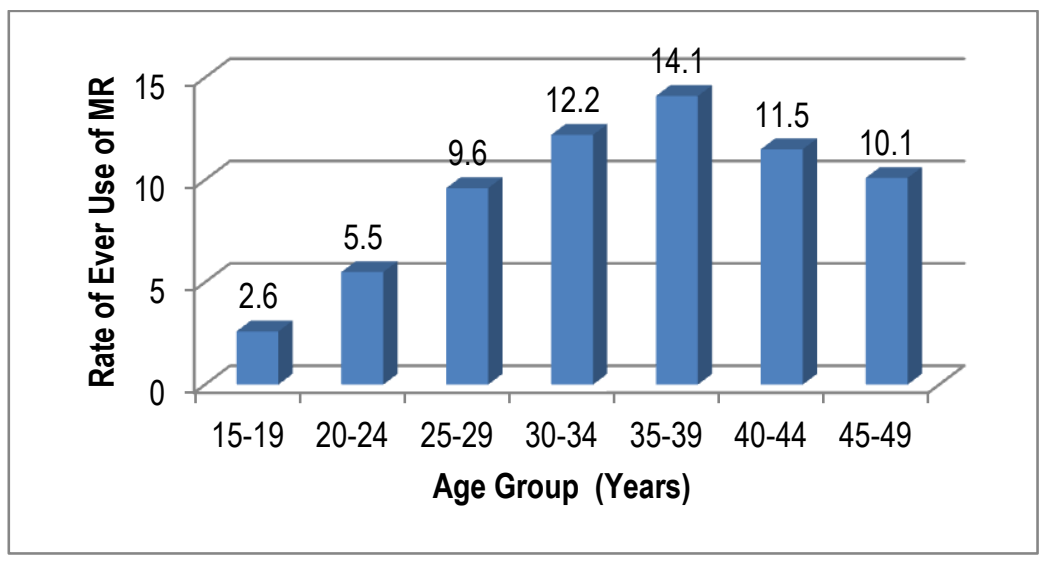

The 2010 BMMS estimated that abortion-related deaths have decreased from 5\% of the total MMR in 2001 to just $1 \%$ [44]. However, there is significant under-reporting of abortion figures, and it is possible that this rate is much higher. It is important to note that there was not a single case of death due to infection found in the BMMS. This may be due to wide availability of antibiotics. The 2011 BDHS found that $71 \%$ of children under age 5 with symptoms of acute 
respiratory illness (ARI) had received antibiotics. Furthermore, the incidence of life-threatening illegal abortions and abortion-related mortality and morbidity may have been reduced by the increase in availability of MR services, both publicly and privately, but traditional abortion services are still practiced nonetheless [67].

Also, the incidence of abortion among contraceptive users was often shown to be higher than among non-users perhaps as a result of improper use of FP methods or method failure (68).

\section{Consequences of Unsafe Abortion}

A range of physical complications resulting from unsafe abortion has been documented in Bangladesh. One study reports that $29 \%$ of women had more than three weeks of bleeding post-abortion and $70 \%$ had a persistent fever [69]. Another study of women admitted with septic abortion found pelvic infection, hemorrhage, uterine perforation and generalized peritonitis. Among women who use MR, complications have also been documented, although they were usually milder, i.e. headache, bleeding and lower abdominal pain [64]. Indeed, there is indication that, when pregnancies are terminated using MR, women are less likely to die than when they use other methods [64].

Limited studies from the 1970s to 1990s indicate that the health consequences of unsafe abortion were severe and widespread before MR services became widely available [70]. This is suggested in a study from the 1980s in which the mean length of hospitalization for post-abortion care (PAC) was six nights. Also, in 1993, among 452 women hospitalized for complications of induced abortion, 5.4 nights of hospitalization was the length of stay for those who did not need surgery, while it was 5.2 nights for those utilizing Dilation and Curettage (D\&C) and 11.2 nights for those obtaining surgery [70].

In terms of the women who are most at risk of unsafe abortion, data are limited. However, a number of studies suggest that adolescents may be at a greater risk of using unsafe abortion services [52,71,72], although this is difficult to verify, as it is a stigmatized issue within communities. One study in Matlab showed that the risk of abortion for unmarried adolescents was 35 times greater than among those who were married, as pregnancies outside of marriage are socially unacceptable [68]. The odds ratio (OR) among 19-year-olds was $26 \%$ lower than 18-year-old adolescents, indicating that abortions were more common among young adolescents [68]. Moreover, sex workers, both street-based and brothel-based, were identified as a high-risk group, as they reported greater use of MR/abortion than the general population [64]. Among them, $60 \%$ of unmarried sex workers reported having had an MR/abortion. 


\section{Part 3: Access to and quality of family planning and post-abortion/abortion services}

\section{A. Access to Information and Services}

\section{Access to MR and Abortion Services}

Improper abortion technique and poor abortion management practices are highly prevalent in Bangladesh. These may lead to life-threatening conditions and severe health consequences for women. Adequate attention should be given to patients with MR, abortion complications and its appropriate management for improving women's reproductive health [69].

In order to utilize MR services, women must be able to access MR providers with ease [70]. Although the MR program has been run by the government since the 1970s, many women still have not heard of this service; in $2011,30 \%$ of married Bangladeshi women reported not being aware of MR [70]. Distance to facility, unofficial fees, lack of privacy, unfavorable provider attitude, inadequate infection prevention and nonobservance of protocols stand as barriers in accessing MR services [65]. Rural women also have relatively poor access to MR services. Furthermore, older cohorts of FWVs who are trained to provide MR are retiring, and there have not been enough new workers trained to replace them-which is a cause for concern for the national MR program, as they are the major providers of MR in the country [65].

Distances from government health facilities, as well as high transportation costs, cause some women to choose private MR providers closer to their homes. Often, MR providers have a negative attitude and are judgmental and ask for spousal or parental consent, which act as further deterrents in accessing MR services. In addition, women often do not know in advance how much the cost of MR will be and feel anxious about using clinics as a result [65].

An estimated $26 \%$ of women who were seeking MR services were rejected by providers in 2010 , according to respondents of the HFS in the recent Guttmacher study. Rejections were lower in public hospitals (11\%) and twice as high in all other facilities (24\%-30\%). Rural women were also rejected more often than their urban counterparts (31\% and $22 \%$ respectively) [70]. Reasons for rejection included a majority of providers (97\%) stating that women were past the LMP limits (8-10 weeks). They also stated medical reasons (49\%) as a cause, although they did not elaborate on what these reasons were. Some other reasons mentioned do not fall under government authorization, which primarily cites exceeding LMP limits as the reason for refusal of service. For example, $20 \%$ of the providers stated the clients' having no children as a reason, $12 \%$ claimed the client was too young, $7 \%$ refused service on the basis of non-consent of husband, while $8 \%$ did not want to provide service as the client was unmarried [70].

A National Health Facilities Assessment was carried out in Bangladesh in 2008, assessing the service availability in 7,680 MNCHFP facilities across all subsectors. MR or D\&C, or both, were offered at $37 \%$ of all government, $19 \%$ of all NGO and $76 \%$ of all private facilities nationally [73].

\section{Cost of MR Services and Treatment for Abortion Complications}

Few women obtain MR free of charge, despite the fact that public sector MR services are supposed to be provided at no cost. One study found that $11 \%$ of women paid nothing, $19 \%$ paid less than 100 Bangladeshi Taka (BDT), while $18 \%$ and $19 \%$ paid $500-1000$ BDT and more than 1000 BDT, respectively. Suggested explanations for this variation include the marital status of the woman, with unmarried women paying more; the type of provider and the type of procedure; duration of gestation and use of anaesthesia [64].

Three NGOs, Bangladesh Association for Prevention of Septic Abortion (BAPSA), Bangladesh Women's Health Coalition (BWHC) and Reproductive Health Services, Training and Education Program (RHSTEP) are supported by 
Swedish Sida as part of its SRHR services [74]. BAPSA charges 150-200 BDT for MR without any painkiller or sedative injections (normal), 310-500 BDT for MR with painkiller and sedative injection and 1500 BDT for MR with anesthesia. MR (normal) are usually availed by clients of lower socioeconomic status and thus if they are unable to pay, they are partially or fully exempted. Also, BAPSA aims to offer $25 \%$ of the poor free services each year. Two types of services are available in BWHC: SES1 (lower socio-economic status), which does not provide premedication, and SES2 (upper socio-economic status), which does provide it. The prices vary from 100 to 1000 BDT in different clinics. If the client is unable to pay, they are partially or fully exempt from the fees. Community volunteers in three zones identify poor clients (Category $\mathrm{C}$ ) and send them to the clinics to receive MR services free of cost. RHSTEP offers MR (normal) at 100-250 BDT, MR (less pain) 250 -300 BDT, MR (special) at 280-500 BDT [74]. However, those of lower socio-economic status receive MR services free of cost (Personal Communication-RHSTEP staff).

The costs of treatment for abortion complications have also been documented [64]. Women with monthly household income of less than 3000 BDT paid between 200 and 5000 BDT for treatment. Women requiring treatment for abortion complications are often forced to borrow money for treatment because of the high costs of care. These high costs are related not only to the treatment itself, but to the use of multiple providers; many women first try to abort using traditional providers, but when the procedure is not successful or results in complications, they seek services elsewhere [64].

The average cost of induced illegal abortion is less than MR when the out-of-pocket payment is considered. Private MR provider fees are comparatively high, on average four to five times higher than abortion services, according to an independent report from the International Planned Parenthood Federation [75]. There is also a difference between urban and rural prices, with an abortion procedure costing double in an urban area. An earlier study found that the average cost was 618 BDT and ranged between 50-6,000 BDT [76]. The average cost was higher for those who had the procedure at home or at the provider's locations compared to those who chose to go to a health facility. It has also been shown that the cost of an MR procedure averts unsafe abortion and associated maternal morbidity and mortality and on a case basis, saves scarce health system resources [77].

\section{Cost to Client of Accessing Family Planning Services}

The current Health Population \& Nutrition Sector Development Programme (HPNSDP) recognises that, in order to reach replacement level fertility by 2016 , there needs to be strong ongoing support for family planning services and programs [16]. The question of the sustainability of these programs has been raised numerous times over the past decade amid the landscape of changing donor policies, especially in the early $2000 \mathrm{~s}$, affecting funding for increasingly expensive FP initiatives [78].

Historically, there have been various forms of user fees charged for family planning services in Bangladesh. In the 1960s, voluntary agencies charged clients for condoms, and the Family Planning Association of Bangladesh (FPAB) previously charged for the different forms of contraceptives it offered [78]. The aim of this system was to attach a sense of value to contraceptives in order to reduce wastage and increase use-effectiveness. In the 1970s, the government of Bangladesh altered its family planning policy and shifted to a model that withdrew many of the previous fees. The core strategy was a massive community distribution of contraceptives based on the theory that supply would create demand. Home visits were carried out every two months, supplying women of reproductive age (15-49 years) with contraceptives, free of charge. Since the rollout of this supply-led strategy, Bangladesh has made significant improvements in family planning, with the TFR dropping from 6.3 in the mid-1970s to 2.3 in 2011; the population growth rate decreasing from $2.95 \%$ in 1979 to $1.2 \%$ in 2011 ; and the contraceptive prevalence rate increasing from just $8 \%$ in 1976 to $61 \%$ by the most recent estimates $[4,79]$.

The problem that the family planning program faced is its successful continuation and expansion within a limited funding framework. It became increasingly difficult to sustain a program that was both labor-intensive and expensive, 
particularly as there was no target or end date set for the strategy and it was seen as running indefinitely $[78,80]$. There was also the issue that supply-driven demand will, at some point, reach saturation and there needed to be other mechanisms in place to generate continued demand. The introduction of user fees theoretically satisfies this need and aims to create a "consumer awareness" that places value on commodities.

When the government introduced pricing for contraceptives in 1990, a dozen condoms cost $1 \mathrm{BDT}$, however the price had to be cut almost immediately to $0.5 \mathrm{BDT}$ due to the significant drop in utilisation [78]. NGOs do not follow a uniform pricing structure and generally charge more for services and commodities. For both sectors it was seen that the initial introduction of user fees resulted in an unwillingness-to-pay among clients. However, this was a temporary decline and data collected from the Pathfinder NGO group indicated that utilization increased within a year and unwillingness-to-pay dropped significantly [78]. The introduction of the user-fee strategy was based on the assumption that people are more willing to pay for services they deem to be of greater quality. Although government facilities provide many services free of charge, there were often unofficial fees associated with visiting these centres [78].

Many NGO-run facilities have explored the implementation of user fees as a cost-recovery mechanism following reports that suggested this might be an efficient way of achieving sustainability. In 1997, a consortium of NGOs introduced nominal user fees for contraceptive commodities and family planning services with the aim to improve their quality and accessibility [81]. They found that consumer awareness was indeed generated by the new cost-recovery strategy and that people chose to use the NGO services as they were seen as good value for money. The prices set by the NGOs were also seen as affordable by the majority of clients, with only $17-20 \%$ stating that they were too high [81].

In the public sector, the prevalence of unofficial fees adversely affected clients' attitude toward payment both to individuals and for specific services [81, 82]. The poorest individuals are also most severely affected, with a cost of a visit accounting for almost $17 \%$ of their monthly income, as compared to $3 \%$ in the richest quintile [82].

For estimated costs to clients for FP services, see Appendix 1.

\section{B. Availability and Quality of Services by Sector}

\section{Availability of Family Planning, MR and Post-abortion Care (PAC) Services}

Following a National Health Facilities Assessment for maternal, neonatal, child health and family planning (MNCHFP) facilities conducted in 2008 [73], it was estimated that there are 0.55 facilities per 10,000 population in Bangladesh that offer FP services. The assessment covered public, NGO and for-profit private facilities nationally and produced a series of GIS maps that show their geographical spread [Appendix 2]. There is a notable difference in the distribution of MNCHFP facilities across divisions and more markedly, across districts. For example, there is a high density of public, NGO and private facilities in Dhaka district, with 745 identified by the assessment. In contrast, Bandarban district has just 37 , mainly primary-level, MNCHFP facilities. Private and NGO facilities are generally clustered around major city centers, with the government facilities achieving greater coverage in the rural areas [73].

MR services can be potentially provided by numerous facilities in the public and private sector, however, only $57 \%$ of them actually do so [70]. There is wide variation in service provision by division, with $37 \%$ of potential providers in Khulna providing MR and $76 \%$ in Barisal. Proportions of services provided also differ by type of facility, with around $83-100 \%$ of MCWCs and UHCs providing these services, which is considerably higher than the national average of $48 \%$. Meanwhile, only $36 \%$ of private clinics, though smaller, provided MR services. UH\&FWCs are potentially a great source of MR service provision as they are large in number, widely distributed across the country, particularly in rural areas where $75 \%$ of the total population of Bangladesh resides. However, only two-thirds of UH\&FWCs provided MR 
services in 2010 . Among the $36 \%$ of UH\&FWCs that did not provide MR, only one in four had an alternative service provider in the vicinity. Religious or cultural reasons were mentioned by respondents at UH\&FWCs for not providing MR ( $43 \%)$ and $37 \%$ stating beliefs related to their personal health and $24 \%$ citing dislike of carrying out the procedure as reasons for not providing MR [70].

The health facility survey (HFS) carried out by Guttmacher Institute gathered information on facilities (except UH\&FWCs) with the potential to provide MR. Even though two-thirds of these facilities had adequate equipment and trained staff, only $48 \%$ of them provided MR. Private clinics showed the largest discrepancy; while $60 \%$ were potential providers only one-third of them actually provided the service. Among hospitals, $62 \%$ were potential providers, but a mere $37 \%$ actually provided MR. Virtually all MCWCs and UHCs that had necessary equipment and trained staffs (87\%) were actually providing MR (86\%) [70].

A recent study estimates that 231,000 women were treated in facilities for complications of induced abortion in 2010 [65]. However, they also estimate that 341,000 women who suffer from complications, approximately $60 \%$, did not receive any treatment. The private sector is responsible for treating approximately $43 \%$ of all post-abortion complication cases, with public-sector hospitals and other public sector facilities treating a combined $54 \%$. The study also reported that, overall, $84 \%$ of facilities had some sort of PAC services available; with $94 \%$ of public facilities and $96 \%$ of private facilities offering PAC services [65].

Most health providers across the country that have the capacity to provide PAC services actually do provide this service (84\%) [70]. There is a range of facilities providing PAC across divisions: $78 \%$ - $80 \%$ in Dhaka; $87 \%-92 \%$ in Rajshahi, Barisal and Chittagong; and 100\% in Sylhet. Meanwhile, more public facilities (94-96\%) tend to offer PAC than private facilities $(80 \%)$. Even though public facilities provide more PAC services, over half of the women obtained PAC services from private facilities [70]. This is possibly because they have difficulty accessing services from the public sector, or they perceive the service quality in public facilities to be of low standard. Although UH\&FWCs do not have adequate instruments and staff to provide services for complications related to abortion, 39\% provide some initial treatment before referring the women to PAC providers. Virtually all UH\&FWCs $(95 \%)$ referred women requiring PAC to other facilities, mostly to UHCs. A larger proportion of UH\&FWCs who provided MR also treated women needing PAC (49\%) than those who did not provide MR (26\%) [70].

Singh et al. (2012) report that $83 \%$ of MCWCs/UHCs offer contraceptive methods to PAC clients, however in all public and private facilities (excluding NGOs and UH\&FWCs), only $34 \%$ offered the same service [65].

\section{Quality of Family Planning, MR and PAC Services}

According to the 2008 Health Facilities Assessment, only $53 \%$ of the MNCHFP facilities visited had staffs that were trained in FP practices [73]. This criterion involved having at least one staff member who had general training in FP, the ability to perform the insertion of IUDs and Norplant and MR and sterilization procedures [73].

The type of health service facility used often determines the quality of MR service provided. In government facilities, lack of privacy, confidentiality and cleanliness are commonplace [10]. The majority do not have separate recovery rooms. The rural FWCs, which are operated by female paramedics, often have a large number of patients and do not have enough resources to serve them. As a result, women often have to resort to seeing untrained providers to meet their needs for discretion. MCWCs, which are located in urban and semi-urban areas, are comparatively better equipped to provide emergency obstetric services, as they are funded by different mechanisms [10].

Providers' attitudes often diminish the quality of MR services, as they are often judgemental and ask for parental or husbands' consent. Religious reasons are often stated as grounds for not providing MR services, while others only provide them at private locations and not in the public facilities. Also, hostile behaviour by providers is often experienced by unmarried women seeking MR [10]. 
Women with pregnancies over 12-14 weeks LMP are often treated with very crude termination methods by private providers [10]. Both the providers and women still call it MR, regardless of what procedure is used. Some managers suggested using electric vacuum aspiration (EVA-which some NGOs have) to terminate pregnancies beyond 10 weeks at the sub-district (upazila) level. Otherwise these women are turned away and often resort to unsafe abortions [10].

An important quality issue has to do with the equipment used for MR. A standard single-valve syringe used for MR should not be used more than 50 times as per government policy. In reality, in some NGO clinics these are often used more than 100 times or sometimes as 'long as they last" [10]. Other procedural issues that compromise quality in government facilities is the fact that examination of aspirated tissue to ensure complete evacuation was not done; infection control remains a common problem in most facilities; and most procedure rooms were very dirty except for those in NGO clinics and MCWCs. Specific gloves were not allocated for MR services and were often washed, dried and reused without proper processing. Hand-washing was widely practiced by providers, and Savlon is commonly used for disinfecting purposes, although no standard dilution procedure is followed. Instruments were disinfected by $0.5 \%$ chlorine solution in most MCWCs and NGO clinics, but not all government facilities did so. Autoclaving was used by MCWCs and NGO clinics to disinfect metallic instruments and gloves. Standard waste disposal methods were absent in most facilities. Antibiotics were regularly prescribed for women who received MR services and training manuals recommended its routine use, although current government policy does not recommend it [10]. Follow-up visits after seven days of MR provision was advised by providers to women in both public and private facilities. The MR procedure was repeated at this follow up visit if the provider felt it to have been incomplete [10].

The quality of PAC service provision varied by the physical attributes that health facilities in Bangladesh had in 2010 [Table 3] [70]. Operating theatres were available in $94 \%$ of facilities, maternity wards were present in $59 \%$ of facilities and a gynaecology ward was available in $30 \%$ of facilities. Virtually all public facilities had pharmacies on site, while $77 \%$ of private clinics did. On the whole, public facilities had better physical attributes, but still had many shortages. Intensive care units (ICU) were only present in $29 \%$ of large public hospitals that had an average of 300 beds. Among both private and public facilities, only $32 \%$ had blood transfusion facilities. Hence, public hospitals did not have enough resources to treat the most severe abortion complication patients. Also, most of the facilities did not have sufficient equipment to treat hemorrhage. Virtually all facilities provided PAC patients with counseling (99\%). Family planning was most commonly discussed in counseling sessions ( $91 \%)$, followed by pain management $(71 \%)$, emergency contraception (74\%), infection prevention (65\%), follow-up visits (63\%) and RTIs \& STIs (45\%) [70].

Table 5: Indicators of Service Capacity by Facility Type (BDHS 2011)

\begin{tabular}{|c|c|c|c|c|c|}
\hline \multirow[t]{2}{*}{ Indicator } & \multicolumn{5}{|c|}{$\%$ of facilities* with indicator } \\
\hline & All facilities & All public facilities & $\begin{array}{c}\text { Public } \\
\text { hospitalst }\end{array}$ & $\begin{array}{l}\text { Other public } \\
\text { facilities } \neq\end{array}$ & Private clinics \\
\hline Operating theatre & 94 & 94 & 96 & 93 & 95 \\
\hline Separate MR room & 22 & 41 & 27 & 45 & 14 \\
\hline Maternity ward & 59 & 68 & 87 & 64 & 55 \\
\hline Gynecology ward & 30 & 33 & 87 & 20 & 29 \\
\hline Septic ward & 5 & 7 & 26 & 3 & 4 \\
\hline Drug store & 82 & 94 & 98 & 94 & 77 \\
\hline Laboratory & 73 & 81 & 99 & 77 & 70 \\
\hline Blood transfusion system & 32 & 32 & 92 & 19 & 32 \\
\hline Intensive care unit & 6 & 5 & 29 & 0 & 6 \\
\hline
\end{tabular}




\section{Cost of Providing FP and MR/Abortion/PAC Services by Sector}

The benefits of investing in family planning initiatives is outlined in a 2011 report that shows family planning to be relatively inexpensive with a high return on investment. On average, a dollar spent on family planning saves roughly two dollars in antenatal, maternal and newborn healthcare-related costs [83]. Savings in other development sectors are even greater: every dollar invested in family planning results in saving between two to six dollars in interventions targeting other development goals. Yet, international support in family planning declined from \$723 million in 1995 to $\$ 338$ million in 2007 [83]. Past fertility declines, the AIDS epidemic, opposition from conservative institutions and fear of controversy are some of the reasons behind this decline. Moreover, family planning deals with the highly sensitive matter of sexual behavior, and governments are reluctant to intervene in the private decision-making of families [83]. The recent reinvigoration of global attention to family planning, as demonstrated in the July 2012 London Summit on Family Planning, is an encouraging shift toward mobilizing resources for family planning programs.

While investments in family planning have long been argued to be an extremely cost-effective public health investment [83], there are limited recent specific cost estimates in the context of Bangladesh. Ensor et al. (2003) derived a series of estimates for various health services at the UHCs and FWCs. Per-patient costs, on average, were approximately just over 50 BDT per capita per year, with family planning services estimated at just 28 BDT (adjusted to 34 BDT) per patient. Family planning services were included as a single item and encompassed both those provided in facilities and those delivered directly to the community either door-to-door or through community clinics [84].

MR services are much less expensive to provide than PAC services on a per-case basis [77]. Similarly, treatment of moderate post-abortion complications is less expensive than treatment of severe complications. At the tertiary level, the cost of MR was US\$11, compared to US\$9 at the upazila level (second tier of primary level) and USD $\$ 7$ at a union level (first tier of primary level) facility. Severe abortion complication care costs an average of US\$86 per case at the tertiary level, with moderate care costing approximately half of this at US $\$ 41$. At the MCWCs and UHCs the cost of moderate complication care was $\$ 21$ and $\$ 10$ per case, respectively [77]. 


\section{Part 4: Financing and Delivery Mechanisms}

\section{A. Output-based Approach - Vouchers}

In 2004, the MoHFW, with technical support from World Health Organization (WHO), developed a maternal health voucher scheme to increase maternal health service utilization and work toward the achievement of MDG5 and hence reduce maternal mortality in Bangladesh. The Directorate General of Health Services (DGHS) of the MoHFW, under the Health, Nutrition and Population Sector Program (HNPSP), initially embarked on piloting the demand-side financing (DSF) scheme in 21 upazilas, with expansion to 33 upazilas by 2007. The pilot particularly targets women from poor communities through the use of demand-side subsidies. This approach has not yet been introduced for FP or MR services, although there is a lot of discussion about the inclusion of FP services into the existing DSF scheme.

The Population Council, in collaboration with DGHS and the MoHFW, has developed the P4P Model for Increased Utilization of Maternal, Newborn and Child Health Services in Bangladesh. The P4P project tested the model for performance-based incentives, i.e. paying a financial incentive to facilities that reached certain performance targets [85]. Paying incentives to the facility, rather than to the individual, is a unique component of this model. At the UHCs where these interventions were implemented, service volume increased substantially and a progressive increase was seen in the number of institutional deliveries. Despite human resource shortages, there was an increase in the quality and quantity of $\mathrm{MNCH}$ services in response to the performance targets. The Population Council report [85] concluded that the P4P model is an effective mechanism that is required in Bangladesh to increase the level of institutional deliveries and to improve the overall quality of $\mathrm{MNCH}$.

\section{B. Health Sector Financing}

Declining development partners' (DP) contribution to the health sector and increasing out-of pocket (OOP) expenditure have influenced the government to consider alternative financing options in order to make health financing more effective and efficient for the poor [16]. The review and reform process of health financing by the MoHFW would include developing a strategy that would help adopt and choose from a wide range of options, so that public resources may be more effectively channeled. Demand-side issues, such as coverage, access and awareness, will be considered-as well as factors, such as costing, risk and contributions which affect financial suitability. It will also take into account management and organizational capacity needs, political feasibility and the legal and policy framework. The new health financing strategy will help to improve estimates for total resource requirements, options for mobilizing additional resources, including the private sector, reducing OOP spending, addressing equity and social protection and improving resource allocation and use efficiency. Simultaneously, a new model of health insurance, which was developed by the MoHFW, will also be piloted soon in a number of unions. Interventions that will be prioritized are: a) review of different health financing instruments, such as DSF, supply-side financing (SSF), and mixed systems, in order to identify their capacity to lower OOP expenditure and identify the constraints of health financing so as to find their solutions; (b) development of strategies to ensure access to quality health services for the poor, including finding methods for identifying the poor; (c) activation of relevant task groups that discuss issues of health financing framework and review of the strengths and weaknesses of the current national health financing system; (d) review and evaluation of innovative health financing approaches, such as role of pre-payment mechanisms including community health financing, user fees with rention at facility or sent to treasury, private-sector financing, public private partnership (PPP) and various types of donor financing; and (d) the scaling up of ongoing DSF program based on economic evaluation and review and piloting of new ones [16].

Currently, the Government of Bangladesh contributes $61 \%$ of the revenue budget and $15 \%$ of the development budget to the health sector. The revenue budget goes for current revenues and expenditures (i.e., maintenance of normal priority and essential services), while the development budget goes for development activities. The revenue budget is prepared by the Finance Division and the development budget is prepared by the Planning Commission. $24 \%$ of the budget comes from DPs [16]. The 2011 strategy aims to spend $7 \%$ on family planning field services 
delivery and $6 \%$ on clinical contraception services delivery [16]. Table 4 illustrates budget allocation as stated in the latest HPNSDP document.

Currently, the combined public and private sources of health financing are insufficient to achieve full coverage of health services. On an average, about $3.2 \%$ of GDP is spent on the health, population and nutrition (HPN) sector in Bangladesh, of which about $1 \%$ of GDP is represented by the public sector. This share is quite low in terms of ensuring sustainable development of the sector. Although there is scope for improving utilization of available funds and achieving greater equity, the HPN sector demands higher allocations. The share of HPN allocation in the national budget therefore needs to increase year by year. This also calls for incremental funding from the Development Partners (DPs), who have been providing support to the development of the HPN sector in Bangladesh [16].

Table 6: Budget Allocated to Government HPNSDP Operational Plans (2011 -2016)

\begin{tabular}{|l|l|l|}
\hline Operational plan 2011-2016 & Budget in crore (BDT) & Share of total budget \\
\hline $\begin{array}{l}\text { Family Planning Field Services Delivery } \\
\text { (FPFSD) }\end{array}$ & 1614 & $7 \%$ \\
\hline $\begin{array}{l}\text { Planning, Monitoring and Evaluation of FP } \\
\text { (PME-FP) }\end{array}$ & 10 & $0.05 \%$ \\
\hline $\begin{array}{l}\text { Management Information System of Family } \\
\text { Planning (MIS-FP) }\end{array}$ & 50 & $0.26 \%$ \\
\hline Clinical Contraception Service Delivery (CCSD) & 1404 & $6 \%$ \\
\hline
\end{tabular}

\section{Family Planning Expenditure}

There are three types of family planning methods offered through the DGFP_-permanent methods, such as vasectomy and tubectomy; long-term methods, such as implants and IUDs; and temporary methods, such as the contraceptive pill and condoms.

As of 2012, the government has introduced revised fees for clinical contraception services under the Family Planning Division that includes permanent, long-acting and recanalization procedures, both for the service providers and clients. According to the new strategic plan, MoHFW has decided to expand the coverage of FP field services delivery and clinical contraception service delivery to urban areas and to achieve the targets for TFR and CPR under HPNSDP. Over the last five years, the DGFP spent a total of 552 million BDT on family planning in urban areas [86].

Table 7: Budget Allocation for Family Planning Program

\begin{tabular}{|l|r|r|}
\hline Sector & $\begin{array}{l}\text { Estimated Expenditure in } \\
\text { BDT (crore) 2003-2011 }\end{array}$ & $\begin{array}{l}\text { Estimated Budget in } \\
\text { BDT (crore) 2011-2016 }\end{array}$ \\
\hline $\begin{array}{l}\text { Family Planning Field Services Delivery } \\
\text { (FPFSD) }\end{array}$ & 700 & 340 \\
\hline Sector-wide Management-Family Planning & 6 & 19 \\
\hline $\begin{array}{l}\text { Information, Education and Communication- } \\
\text { FP }\end{array}$ & 93 & 237 \\
\hline Clinical Contraception Service Delivery & 584 & 2,199 \\
\hline Human Resource Management-FP & 20 & 5 \\
\hline Improved Financial Management-FP & 3 & 7 \\
\hline
\end{tabular}

Adapted from HPNSDP 2011-2016 [13] 
The Directorate General of Family Planning (DGFP) introduced the MCH-based family planning program in 1975. To reduce maternal and child mortality and morbidity, the program is designed to provide maternal, child, reproductive and adolescent healthcare and family planning services from the same service center.

\section{Existing Service Centers}

\section{At the National Level}

The Maternal and Child Health Training Institute (MCHTI), located at Azimpur, Dhaka, is considered to be the tertiary education source for family planning services training in Bangladesh. The Mohammadpur Fertility Services and Training Centre (MFSTC) at Mohammadpur, Dhaka (two model clinics attached with two medical college and hospitals; 12 Family Welfare Visitors Training Institutes (FWVTI) and five NGO clinics) are functional at the national level [87].

\section{At the District Level}

There are six model clinics attached to the medical college and hospitals; $64 \mathrm{MCH}-\mathrm{FP}$ clinics at district hospitals; 62 Mother and Child Welfare Centres (MCWC) and 20 Regional Training Centres (RTC) at district level [87].

\section{At the Sub-district or Upazila Level}

There are $407 \mathrm{MCH}-\mathrm{FP}$ units at Upazila Health Complexes (UHC); 12 Mother and Child Welfare Centres (MCWC) and 68 NGO clinics at the sub-district level [87].

\section{At the Union Level}

There are 3,500 Union Health \& Family Welfare Centres (UH\&FWC) and 1,275 Rural Dispensaries (RD) and 23 Mother and Child Welfare Centres (MCWC) at the union level [87].

\section{At the Community Level}

Thirty thousand $(30,000)$ satellite clinics are organized per month at the community level, and 10,723 community clinics exist at this level. In addition, 23,500 unit domiciliary services and 23 MCWCs exist at this level [87].

\section{MC-RAH Services, Including Comprehensive Emergency Obstetric Care (EOC) Services through MCWCs}

Seventy functional MCWCs (District-60, Upazila-8 and Union-2) have been providing (i) EOC services 24/7 days, (ii) other safe motherhood services (ANC, safe delivery, PNC, MR and PAC), primary screening for cervical cancer through Visual Inspection of Cervix through Acetic Acid (VIA) and breast cancer screening, etc., (iii) family planning services, (iv) newborn care, child healthcare and (v) syndromic management and counseling of RTI/STD and reproductive healthcare services for women and men, including adolescents [87].

\section{New Generation of RH Services}

In addition to existing EOC-RH services, there is a new generation of services, such as adolescent-friendly health services, management of VAW, male services in MCWCs, primary screening for cervical cancer in 62 MCWCs through VIA and developing 62 MCWCs as training centers for CSBA [87]. 


\section{Upazilla MCH-FP Unit}

At present, there are $427 \mathrm{MCH}-\mathrm{FP}$ Units at upazilla level for providing MC-RAH services. Apart from the existing service delivery, PAC and VIA and breast screening through CBE of woman are new RH program activities [87].

\section{Upgrading of UH\&FWCs}

At present, there are 3,827 constructed UH\&FWCs at the union level providing services to 25,000 to 30,000 people. Out of these, already 1,441 UH\&FWCs have been functionally upgraded through equipping, furnishing and minor renovation that includes provision of skill-mixed manpower in phases, and the remainder will be upgraded in phases. To increase the institutional delivery at the community level and early detection of complications and referral to higher centers, services such as safe delivery, obstetric first aid (administering parental Oxytocic drugs, antibiotics, sedative/anticonvulsants and referral), as well as basic EOC services are ensured through these UH\&FWCs. Midwifery trained FWVs have been posted to those upgraded centers. They will work around the clock to provide safe delivery, along with Active Management of Third-Stage of Labour (AMTSL) and newborn care with referrals in addition to normal ongoing MCH-RH-FP services [87].

\section{Services through the Community Clinics}

Primary care for about 6,000 people has begun through the community clinics. The government has already started providing reproductive health related services in more than 10,000 community clinics. The services provided from DGFP include ANC, PNC and under-five childcare, along with contraceptive supply for eligible couples by the FWA within the respective community. Family welfare visitors from the UH\&FWC conduct the satellite clinic in the community clinic and ANC, PNC and other reproductive health-related services are also provided. For these activities, provision of DDS kits and other RTI/STI drugs are to be provided [87].

\section{Satellite Clinic}

Family welfare visitors conduct the satellite clinics (eight satellite clinics organized in each union per month and also at urban slums and hard-to-reach areas) and provide ANC, PNC and other reproductive health-related services [87].

\section{Services to Community Pregnant Mother through CSBA, FWA}

Registration of all pregnant mothers in the community, along with their emergency cell phone number, will be conducted and reported regularly. Misoprostol tablets are to be distributed to all pregnant women (phase by phase) during 32 weeks of pregnancy to be used immediately after delivery of the baby, except in a twin pregnancy, to prevent the postpartum hemorrhage (PPH) in case of home delivery [87].

\section{Emergency Contraceptive Pill (ECP)}

Considering ECP as a back-up support to the family planning method, this is distributed by a Family Welfare Assistant (FWA) free-of-charge to the eligible couples who need it [87].

\section{Nutrition Services through Directorate General of Family Planning}

In accordance with the strategic decision of mainstreaming nutrition through the DGFP, priority nutrition services will be delivered to young children and mothers, both at the facility and community level. The services will include infant and young child feeding (IYCF) counseling; prevention and control of anemia in children, pregnant and lactating women; growth monitoring and promotion; behavioral change communication on nutrition; micronutrient supplementation and service-related trainings and others [87]. 
A recent National Health Facility Assessment mapping of 7,680 public, private and NGO facilities on availability of services showed an inequality in the distribution of MCH-FP facilities [73]. Overall, facility density was found to be very low. Private facilities had the greatest number of basic equipment items compared to the public sector or NGOs. Around $44 \%$ of the facilities had at least four basic amenities of the six that were assessed. Overall, $85 \%$ had power, $91 \%$ had water supply, $84 \%$ had adequate sanitation, $47 \%$ had communication equipment, $7 \%$ had internet connection and $2 \%$ had emergency transportation. Basic equipment of at least four of the six items assessed was found in $75 \%$ of the facilities: $53 \%$ had a light source, $90 \%$ had blood pressure equipment, $90 \%$ had a stethoscope, $78 \%$ had a thermometer, $54 \%$ had a child/infant scale and $75 \%$ had an adult scale. Overall $61 \%$ had the standard precaution for infection control. At least six of the nine items for diagnostic capacity were found in $22 \%$ of the facilities. At least six of the 10 essential medicines assessed were found in $15 \%$ of facilities. Family planning equipment was assessed in terms of availability of six tracer items. It was found that $15 \%$ of facilities had all six tracer items, $37 \%$ had condoms, $32 \%$ had injectable contraceptives, $37 \%$ had combined oral contraceptives and $53 \%$ had staff trained in family planning [73].

\section{E. Health Workforce Availability}

\section{District Level}

In an $\mathrm{MCH}$-FP unit at a 50-bed district hospital, FWVs are the first point of contact for clients. FWVs will refer cases to the medical officer (clinical contraceptive) when necessary. At this level, available services include: antenatal care (ANC), normal delivery (limited facilities for 'at-risk' cases), postnatal care (PNC), expanded program on immunization (EPI), childcare, all contraceptives including sterilization and follow-up care [87].

\section{Sub-district/Upazila Level}

For a MCH-FP unit at the 31-bed upazila /thana health complex (UHC/THC), the following staff are available: family welfare visitors (FWVs) and medical officer (MO) (MCH-FP). Available services include: ANC, normal delivery, PNC, EPI, health education, childcare and all contraceptives including sterilization [87].

\section{Union Level}

At Union Health and Family Welfare Centres (UH\&FWC), staff includes: medical officer (Family Welfare) but not in all facilities, sub-assistant community medical officer (SACMO), pharmacist but not in all facilities and a family welfare visitor (FWV). Available services are: ANC (emphasis on screening for "at-risk" pregnancies and referral), safe delivery through domiciliary care, PNC, childcare, health education and all contraceptives [87].

\section{Unit Level}

Staff delivers basic MNCHFP services through home visits. Staff includes: family welfare assistant (FWA) and family planning inspector (FPI) who supervises all FWAs in a union level. In addition, this unit ensures safe motherhood including EmOC services with the provision of skilled birth attendants (SBA); voluntary traditional birth attendants (TBAs) are trained through government facilities and provided with essential safe delivery kits. Available services are: antenatal screenings, referral for safe delivery, contraceptive supply (pill and condom), vitamin A, ORS packets and EPI. Services are being expanded through satellite clinics at the community level [87].

From the national health facilities assessment, it was observed that public facilities had the largest number of professionals, NGOs had the largest number of community health volunteers and private facilities had the largest number of associates. More doctors and nurses/midwives are needed to achieve universal coverage, and the ratio of 2.28 doctors, nurses/midwives per 1000 population is not a realistic target for Bangladesh. Existing workforce needs 
to be maximized, perhaps by public-private partnership. Inequity in geographical distribution of health workers needs urgent attention [73].

\section{Notable Current Activities}

i) There are currently 21,219 FWAs working for MCH-FP services at the field level throughout the country. According to the new operational plan (OP), every FWA will visit 20-25 households/couples each working day and cover an entire unit every two-to-three months for follow-up; supply oral pill, condom, Vitamin A capsule and ORS; and offer counseling/motivation/ health education on ANC, PNC, newborn care, EPI, LAPM, nutrition, etc.

ii) To improve the maternal and child health at the grass roots level, each union organizes eight satellite services per month, a total of approximately 30,000 satellite sessions per month.

iii) The government has planned to set up a Community Clinic (CC) per 6,000 people at the village level in which 10,723 CCs have already been established.

iv) The government has already ensured preservation of FP methods or supplies up until 2013.

v) At present, there are $184 \mathrm{NGOs}$ working with government for MCH-FP services. NGO sector facilities distribute FP methods among $5 \%$ of users.

vi) To improve maternal and child health, the government is providing six months of CSBA training to FWAs $(4,160$ FWAs have already received the training). In addition, the government is providing six months of midwifery training for FWVs.

vii) To educate eligible couples on FP, the government has initiated 'special service week' since 2007, which encourages the use of male contraceptive methods.

viii) To ensure adequate service in remote areas, the government is providing a permanent FP method facility through the use of four mobile van vehicles.

ix) The government has approved the 'National Communication Strategy for FP-RH' aimed at improving contraceptive prevalence, reducing TFR, meeting demand as well as reducing maternal and child mortality.

$x)$ The IEM unit under DGFP continues its health education campaign for contraceptives, early marriage, birth spacing, delivery by SBA, three delays (delay in decision to seek care, delay in reaching care, and delay in receiving adequate health care) and five pregnancy-related danger signs through the print and electronic media. This unit also focuses on the need for male participation in family planning.

xi) The government has involved religious leaders and has organized workshops to provide education on contraceptives and on preventing early marriage through public-private partnerships.

xii) To ensure adolescent healthcare for males and females, the government has prepared an 'Adolescent Reproductive Health Strategy' in an attempt to make service delivery more adolescent-friendly [88].

Activities under the National Adolescent Reproductive Health strategy include upgrading health facilities (all UHCs, UH \&FWCs and RDs) in phases and providing adolescent-friendly sexual and reproductive health services. Training on adolescent-friendly SRH services including counseling and communication; counseling and developing awareness for adolescents, especially senior female students on personal hygienic practices; management for minor gynecological problems of female adolescents, i.e. dysmenorrhea, puberty, menorrhagia, supplementation of iron \& folic acid; and supply of sanitary pads for emergency purposes in girls' schools. Other activities include establishing of referral linkages between school health clinics and other health facilities; implementing de-worming activities at the field level; forming a coordination committee among the adolescent sexual and reproductive health (ASRH) implementing partners (government, NGO, private sector); incorporation of ASRH component into the existing MIS of the MoHFW; mobilizing the community around ASRH issues through courtyard meetings; offering inter-personal 
communication and workshops; developing and printing training manuals, guidelines, booklets regarding adolescent health; introducing IEC activities like short films, poster, calendar, folder, wall-painting, billboard, mass media campaign on ASRH issues; developing and disseminating key messages and materials; and creating a campaign and message dissemination plan using mass media [16].

Bangladesh will increase access and use for poor people in urban and rural areas, improving choice and availability of LAPMs, including for men and postpartum and post abortion services. The government will work with the private sector and NGOs to address the needs of young people, especially young couples; reduce regional disparities; work with leaders and communities to delay early marriage and child birth; and increase male involvement. One third of MNCH centers will provide adolescent sexual and reproductive health and rights (SRHR) services. Monitoring to ensure quality of care will be strengthened and will include informed consent and choice and support for women to continue using family planning [6].

\section{Private Providers, Including Pharmacies}

The pharmacies continue to be a major source of modern contraceptive methods, serving $33 \%$ of all users and are the predominant source of contraceptive pills and condoms [4]. Pharmacies in Bangladesh have long been used to access care for stigmatising health issues such as FP, STI treatment and abortion or MR. A recent unpublished study on the availability of misoprostol for self-induced MR in urban Bangladesh reveals an alarming number of providers who are ill-equipped to provide clients with the appropriate information regarding the medicine. Only $7 \%$ of the pharmacy workers provided or referred for post-MR family planning methods [personal communication, icddr,b project staff].

Another icddr,b study on the MR program in different districts also found that the highest number of care-seeking episodes occurred at the pharmacies [34]. This was consistent for both women who had undergone MR, or who wanted to have MR but could not. The pharmacy workers were often seen to provide misoprostol during the fourth and fifth month of gestation and told women that they would experience the bleeding within 24 hours. Alarmingly, approximately one-third of women who consulted pharmacy workers had side effects and many self-medicated with a repeat of the dosage initially given to them [personal communication, icddr,b project staff].

\section{F. Social Marketing and Social Franchises}

Over the past two decades, social marketing programs have become an important element of the national family planning strategy in several developing countries [89]. Social marketing in Bangladesh was initiated to challenge the rapid population growth through the marketing of contraceptive products at a price affordable to the general population in order to bring about behavioral change through extensive mass promotion.

\section{Social Marketing Company (SMC)}

Social Marketing Company (SMC), a not-for-profit social marketing organization, uses commercial marketing techniques to motivate people to practice socially beneficial behaviors and purchase socially beneficial products and services at an affordable price [90]. SMC is regarded as a major contributor of contraceptive products in Bangladesh, as it accounts for $35 \%$ of the country's total modern-method CPR. SMC is the source for $58 \%$ of condoms, $45 \%$ of oral pills and $20 \%$ of injectables sold nationwide by complementing the public-sector distribution with a private-sector social marketing model [90]. Under its FP program, SMC markets a variety of oral pill brands (Combination 3, Noret28, Femicon, Minicon and Femipil); and condoms (RAJA, HERO, Panther, Sensation and U\&ME); and clinical (Injectable "" Somaject) contraceptives. To make contraceptive products available and affordable to the lessprivileged people of the country, SMC positions its brands of contraceptive products at different price segments so that revenue generated from the moderately priced brands can cross-subsidize the lower-end brands [90]. 
Supported by USAID since 1974, SMC has recovered $100 \%$ of its operating costs from sales revenue since 2002 and it recovers $79 \%$ of its total costs, including commodity costs. As part of a sustainability plan, USAID's contribution of commodities has gradually reduced from $\$ 13.8$ million in 1991 to $\$ 6$ million in 2011 [90]. By the end of the agreement in 2011 , SMC is expected to recover more than $83 \%$ of its total cost. In 2011, SMC provided 3.49 million couple years of protection (CYP) (The estimated protection provided by family planning (FP) services during a one-year period, based upon the volume of all contraceptives sold or distributed free of charge to clients during that period) through offering three modern methods - oral pills, condoms and injection. SMC distributes reproductive health products, oral rehydration salts (ORS), a micronutrients product to address the iron deficiency/anemia in children, dispersible zinc tablets and safe delivery kits through 210,000 commercial outlets, including 65,000 pharmacies and 3,650 Blue Star outlets (a social franchise network) throughout the country. USAID supports SMC through donated commodities, technical assistance and cash grants [90].

SMC's Blue Star Programme, began in June 1998 as a pilot to address the unmet need of the target population by improving quality, awareness, accessibility and affordability of priority public health services through private health providers. The program initially started with graduate doctors (GDs). Since 2000 , it has been expanded to include non-graduate medical practitioners (NGMPs). SMC distributes the injectable brand Somaject through the Blue Star network of providers (BSPs) [4]. Although the data on injectables used was not collected in BDHS 2011, estimates of use of social marketing brands can be inferred, as the Blue Star is the only formal source of injectables in the private sector of the country. From data on sources of injectables in the BDHS, it was shown that about one fifth of married women of reproductive age who currently use injectables avail them from nonqualified doctors' chambers or pharmacies, which are distributors of Somjaject injectables [4]. The BSPs also provide services, such as family planning counseling, IUD service (selected BSPs), maternal and neonatal health information, services and referral (selected BSPs), referral for LAPM, TB suspects' identification and referral. SMC provides comprehensive training, commodity supply, promotional support, supervision and monitoring of the Blue Star providers. The Blue Star franchise program currently supports around 4,000 providers [90].

The Smiling Sun Franchise Program (SSFP) is USAID/Bangladesh's largest health initiative and is the latest in a series of programs that have sought to improve the ability of local NGOs to provide basic health services to the poor [91]. Social franchise outlets are operator owned, payments are based on services that may be client out-of-pocket (OOP) or insurance, services are standardized and clinical services are offered. Their main goals are access, cost effectiveness, quality and equity. Implemented under a contract between USAID and Chemonics International, SSFP works with 28 NGOs that operate 323 static clinics (286 'vital' clinics offering a basic service package and 34 'ultra' clinics that add emergency obstetric care) and approximately 8,600 satellite clinics held one or more days/week by rotating staff. The NGOs deploy approximately 7,000 paid staff, plus about 6,327 volunteer community service providers (CSPs), or community mobilizers/health educators, and providers of family planning and a few other basic commodities and work across all 64 districts of the country [92].

The Smiling Sun franchise serves over 27.25 million customers contacts every year and is the largest private healthcare network in the country. It targets the low-income population, migrants/refugees and women and youth in providing a variety of primary care, RH/FP and maternal and child care services, including contraceptives, STI treatment, cervical cancer screening, post-abortion care, ANC, labor and delivery, emergency obstetric care, PNC, vaccinations, pediatric consultations, malaria treatment, tuberculosis (TB) case management, diarrheal disease treatment and pneumonia testing and treatment [93]. Additionally, many clinics operate pharmacies, offering quality packaged consumer goods within easy reach of the customers. The 'Vital' clinics have, on average, 12 staff members and the 'Ultra' clinics have, on average, 30 staff members. Currently, $55 \%$ of the payment source is OOP payment, $13 \%$ is third-party payers, $1 \%$ is vouchers and $31 \%$ of the services are provided for free. Smiling Sun is currently partnering with the Government of Bangladesh on a voucher scheme pilot designed to provide safe delivery services to poor women in Chittagong division [93]. 
The revenue generated from the paying customers are used to (i) ensure the sustainability of individual clinics and the franchise as a whole, with higher-income facilities subsidizing lower-income operations, (ii) finance the operation of the Franchise Manager Organization (FMO) and (iii) subsidize the provision of services to the poor, who are the key target group for SSFP [92]. The prices for services include 200 BDT for PAC in rural clinics and 300 BDT for urban, 2 $\mathrm{BDT}$ for rural FP and RH counseling and $5 \mathrm{BDT}$ for urban, $20 \mathrm{BDT}$ for rural injectables and 30 for urban, $20 \mathrm{BDT}$ for IUD insertion or removal in rural and $25 \mathrm{BDT}$ for urban, $10 \mathrm{BDT}$ for Norplant insertion or removal for rural patients and 20 BDT for urban, while pills and condoms are free. MR services are not provided at Smiling Sun clinics, which religious leaders see as a reason for using for their wives' reproductive health needs. MR clients are referred to government clinics. The government provides family planning commodities to SSFP free-of-charge. Emergency obstetric care (EmOC) has been added to SSFP services, and many strategic revenue-generating partnerships with local commercial businesses were also founded by SSFP. Also, twice as many non-service delivery services, such as diagnostics, are provided. Due to these and other activities, cost recovery was $43 \%$ in May 2010 , up from $23.5 \%$ at inception [92].

Smiling Sun's competition includes Marie Stopes International (MSI), the Family Planning Association of Bangladesh and BRAC. Despite being competitors, SSFP has a collaborative relationship with these groups and meets with them monthly at NGO meetings. The Social Marketing Company (SMC) also runs a fractional clinical social franchise in Bangladesh, known as Blue Star, but SSFP does not consider SMC a competitor [92]. Unlike SSFP, Blue Star receives significant $\mathrm{GoB}$ funding to oversee its network of over 3,600 community-based private healthcare providers. Blue Star outlets include trained graduate and non-graduate medical practitioners, nurses, midwives and pharmacists, who provide family planning counseling and dispense SMC-branded products, such as contraceptives priced to be affordable to the poor. SSFP and SMC each fill a different, needed niche in the health sector. SSFP is in negotiation with SMC to provide more regular non-donated contraceptives to the SSFP program [92].

SSFP's target population includes women, men, children and adolescents in all 64 districts of Bangladesh. It is estimated, however, that around $80 \%$ of people served by the program are women, while $90 \%$ or more of clientsthose who actually pay for services, whether for themselves, their children or otherwise - are women [92].

\section{G. Faith-based Organizations (FBO) and Non-governmental Organizations (NGO)}

\section{The Family Planning Association of Bangladesh (FPAB)}

The Family Planning Association of Bangladesh (FPAB) is a member association of the International Planned Parenthood Federation (IPPF) and was established in 1953 with the aim to improve the quality of life for underprivileged groups through advocating family planning as a basic human right and moving people toward the concept of small families [94].

FPAB is utilizing its service network across 32 districts in Bangladesh to provide sexual and reproductive health services through 21 comprehensive clinics and 14 other clinics in the units. These clinics are also operating 55 outreach satellite sessions to reach the poor, underserved and marginalized people of rural areas of the FPAB's project location. There are 1,420 Reproductive Health Promoters (RHPs) providing community-based door-to-door services and actively engaged in client referral to clinics for FP and SRH services, re-supply for FP methods and follow-up clients [94]. 
Table 8: FP, MR and Abortion-related SRH Services

\begin{tabular}{|l|r|}
\hline Service & \multicolumn{2}{|l|}{ Number provided } \\
\hline Mobile sessions held by clinics & 4,590 \\
\hline Separate outreach mobile sessions held for men & 220 \\
\hline Voluntary surgical contraception (VSC) service provided & 3,671 \\
\hline Long-acting contraceptive method & $1,69,319$ \\
\hline Oral pill (OP) and condoms from clinics & 35,711 \\
\hline ECP services & 12,581 \\
\hline OP and condoms from CBD locations & $19,52,206$ \\
\hline Services related to abortion and post abortion & 41,515 \\
\hline
\end{tabular}

Source: FPAB

FPAB clinics provide ANC, PNC, clinical methods of family planning, MR services, PAC services, ECP, prevention and management of RTI/STIs, screening, care and support services for gender-based violence survivors, pediatrics and immunization services for children. These clinics provide a wide range of SRH services to all, including contraceptives, pregnancy tests, counseling and information services. MR and contraceptive service provision has been made at all clinics to prevent unsafe abortion [94].

Around 2.5 million new acceptors of contraceptive methods were recruited during the 1990s by FPAB. Currently, FPAB provides contraceptive and $\mathrm{MCH}$ services to about one million clients. The association contributes to $7 \%$ of the national achievement in family planning with the help of 800 field personnel, 6,000 grassroots volunteers and 43 clinics [50].

\section{Marie Stopes Society (MSS)}

Marie Stopes was founded in 1988 in Bangladesh and is registered under the NGO Affairs Bureau. It is affiliated with Marie Stopes International and is a UK senior member of Marie Stopes International Global Partnership. Marie Stopes aims to be the foremost organization in the SRH sector, providing high-quality services and developing and implementing effective programs, especially for the poor and vulnerable [95].

It covers 62 districts, maintains 143 service delivery facilities and serves 1.6 millions clients annually. More than 900,000 poor and vulnerable people are reached through its innovative approaches. More than 60percent of FP acceptors are long-term and permanent method users. About 80,000 safe MR services are provided every year [95]. MS Bangladesh maintains six emergency obstetric centers (EOC) and conducts 5,500 safe deliveries annually. It is the first-ever health service organization to receive ISO certification. It is recognized by Marie Stopes International (MSI) and the GoB. It provides a wide range of $\mathrm{RH}$ and FP services, including temporary, long-acting and permanent methods, ANC, PNC, general healthcare, RTI/STI management, MR, immunization, child healthcare, supportive pathological tests, essential obstetric care (delivery) in selected clinics. Other services include TB (DOTS), eye care in selected clinics and ultra sonogram services in selected clinics [95].

\section{EngenderHealth}

EngenderHealth has been expanding the availability, quality and use of reproductive healthcare services in Bangladesh since 1974. EngenderHealth implements the 'Mayer Hashi' project in the country. The project, which means 'Smiling Mother' in English, aims to address the need for family planning through expanding contraceptive choices and services [96]. Supported by USAID, the Mayer Hashi project works to improve women's health by increasing awareness of and access to LAPMs, such as implants, IUDs and male and female sterilization. The Mayer Hashi project also works to prevent postpartum hemorrhage (PPH), the major cause of maternal mortality in Bangladesh. Mayer Hashi trains healthcare workers to prevent PPH during facility deliveries and provides training to 
field workers on how to distribute the lifesaving drug misoprostol, to reach $85 \%$ of women who give birth at home without skilled attendants. EngenderHealth promotes efforts to prevent and treat obstetric fistula in Bangladesh through the Fistula Care Project [96].

\section{Pathfinder}

Pathfinder has worked in Bangladesh since the early 1950s and was a pioneer in implementing community-based distribution programs in the country. In 1997, Pathfinder was awarded responsibility for the Rural Service Delivery Partnership and in 2002 was awarded leadership of the follow-on project, the NGO Service Delivery Project (NSDP) [97].

NSDP collaborates with USAID's Leaders Outreach Initiative to introduce imams to services provided in NSDP's Smiling Sun clinics and how they can help improve the health of Bangladeshis. Because mostly women visit the Smiling Sun clinics, it is important to gain the imams' acceptance of the clinics' services so that they can, in turn, engender support from the men in the community. Two-thousand imams were trained in 2005, and NSDP plans to train an additional 3,000 imams throughout Bangladesh in 2006 [97].

The imams' response to the collaboration has been overwhelmingly positive. They have allowed NSDP to use the mosques' loudspeakers to publicize the dates and services available at the Smiling Sun satellite clinic sessions and promote special events like National Immunization Day (NID), Safe Motherhood Day and World Breastfeeding Day. These announcements have been effective because Bangladeshis readily accept information coming from the mosque. Many imams participated in NSDP's World AIDS Day events and distributed information on HIVIAIDS and sexually transmitted diseases [97].

The imams have offered many suggestions for improving the Smiling Sun clinics, such as ensuring the availability of female doctors for women and male doctors for men, integrating HIVIAIDS information into religious messages, expanding clinic operating hours and offering more services. The imams also have expressed interest in helping to promote basic healthcare, both at the community level and within the Smiling Sun clinics. Most recently, a group of imams worked with NSDP staff to develop a series of culturally sensitive leaflets on child health, pregnancy, sexually transmitted infections, HIVIAIDS and family planning. The leaflets have been distributed to all the imams participating in the Leader's Outreach Initiative [97].

\section{H. ICT, E-health/M-health and Media for IEC and SBCC on FP and Abortion/PAC}

Recent advances in information and communication technologies (ICTs) help society to quickly access services for economic and social development. Telehealth/Telemedicine/E-health are the most prominent e-business solutions that impacts MNCH-FP. Telemedicine activities first emerged in Bangladesh in mid-1999 [88]. The government has given immense importance to ICT for development, economic growth and poverty reduction. Mobile phone coverage has grown widely in Bangladesh and cell phone network coverage is widespread.

The importance of information, education and communication (IEC) to FP and unintended pregnancy is often acknowledged. IEC is a cross-cutting issue that plays an important role in promoting short- and longer-acting contraceptive services. This program involves intensive public information, motivation and counseling campaigns to bring about overall changes in attitude, as well as creating a greater awareness of FP issues [88]. Both government and NGOs are using different mass media components for providing FP and related information among populations in Bangladesh through messages promoting short- and longer-acting methods of contraception, delayed marriage, popularizing a maximum two-child family norm, minimizing dropout and unwanted fertility and male involvement in availability of FP services. Mass media has been used to promote these messages, ranging from posters and 
billboards to television campaigns. The promotion activities have specifically targeted newly married couples, religious leaders, professional groups and youth groups [88].

\section{Commodity Procurement and Supply Logistics by Sector}

The Procurement, Storage and Supply Management program (PSSM-FP) of the DGFP is an essential factor contributing to the successful implementation of the family planning program in Bangladesh [16]. The unit is in charge of procuring and supplying all the contraceptives and reproductive health commodities to the service delivery points (SDPs) throughout the country in sufficient quantity in a cost-effective manner and within the due time [16].

Contraceptive items such as low-dose oral pills, condoms, IUDs, implants and MC-RCH commodities---such as drugs and dietary kits, medical and surgical requisites, instruments and equipment, etc.---were procured by the PSSM-FP unit during the last five-year HNPSP program by utilizing an international and national competitive bidding process according to the operational plan requirements of the responsible line directors under the DGFP [16]. These activities of PSSM-FP help achieve the objectives of the concerned line directors and the goals of the DGFP. In order to achieve reproductive health commodity security in Bangladesh (which means that every individual can obtain and use affordable, quality reproductive health supplies of their choice whenever they need them), so as to attain the goals of MDGs and Vision 2021, the PSSM- FP will act as a support service provider to other line directors of DGFP to aid in implementation of their OPs. The PSSM-FP will also introduce e-procurement and automation of the Procurement and Supply Management System (PSMS). Two softwares for inventory management, called Warehouse Inventory Management System (WIMS) and Upazila Inventory Management System (UIMS), in all warehouses and 124 selected upazila FP stores have been successfully installed by the PSSM-FP [16]. During February 2011, a webbased tool called 'procurement tracker' was launched to monitor the status of DGFP procurement packages, and another web-based tool, called Logistics Management Information System (LMIS), was launched to monitor DGFP national and regional logistics data [16].

Their program components include: program organization for procurement and supply management; procurement planning, monitoring \& evaluation; product quality assurance and material standardization; commodity shipment, clearing and delivery; supply chain management; record keeping and feedback mechanism; capacity-building and technical assistance; e-procurement and web-based information system [16]. 


\section{Part 5: Outcomes of Unintended Pregnancies}

\section{Maternal Mortality and Morbidities Attributed to Unintended Pregnancies}

Limited information is available on the proportion of mortality and morbidities directly attributable to unintended and mistimed pregnancies. Unintended pregnancies increase the risk of abortion-related morbidities and mortalities, especially in countries where abortion is illegal [1]. While the current maternal mortality ratio is estimated to be 194 deaths per 100,000 live births, and the percentage of the MMR attributable to abortion is just 1\% [44]; there is a gap in the data that links these figures to unintended pregnancy.

\section{Morbidities Related to MR and Unsafe Abortion as a Consequence of Unintended Pregnancies}

Anecdotal evidence suggests that the huge caseload of MR and unsafe abortion complications in hospitals are mostly the consequence of unintended pregnancies. In a Guttmacher Institute study, facilities reported that slightly less than $22 \%$ of their complication caseload was due to MR [70]. National estimates reveal 78,000 women or 2.2 per 1,000 women of reproductive age are treated annually for MR complications. An estimated 120 women are treated for MR complications for every $1,000 \mathrm{MRs}$. These figures may suggest fewer complications resulting from MR than for induced abortion are treated in the facilities, but these cases have a potential of being even lower for manual vacuum aspiration (MVA) if they are done in hygienic, equipped and safe settings by sufficiently trained health providers [70].

The same study estimated that 231,400 patients received treatment for complications due to induced abortion across the country, a rate of 6.5 per 1,000 women of reproductive age in 2010. The rate was below average [4] in Barisal, while in Khulna it was about twice the average rate [14]. In other divisions, the rate was close to the national average [70].

\section{Impact of MR Use on the Decline of Abortion-related Mortality}

Expanded provision of safer and more accessible MR services is supported by anecdotal evidence in contributing to the dramatic decline in deaths from incomplete and septic abortion as stated in the 2001 Bangladesh Maternal Mortality and Health Care Survey (BMMS). Also, trends in abortion-related mortality can be studied from the longitudinal data available from Matlab, Bangladesh [98]. The annual numbers of MRs and clandestine abortions have been recorded since 1989 in the Demographic Surveillance System (except in 2001) in Matlab in an area with improved family planning services and a comparison area without one. As the comparison area is lacking quality FP services, it is possibly more representative of the nation as a whole. In 1989, data from this comparison area showed a ratio of two to one of clandestine abortions to MRs. This ratio dramatically changed to 1:5 by 2008 [98]. This substantive increase in MRs compared to clandestine abortions may be the cause behind the continued decline in abortion-related maternal mortality in the comparison area. As a matter of fact, between the periods of 1986-1990 and 2001-2005, maternal deaths due to induced abortion in this area reduced from $16 \%$ to $9 \%$. Although the data on abortion-related mortality are from time periods that are far apart, and it cannot be ascertained that the rise in the ratio of MRs to clandestine abortions indeed contribute to the decrease in abortion related mortality, the trends are strong enough to show that use of MR services can be attributed to the lowering of abortion-related mortality [98].

Further data need to be gathered in order to develop a clearer picture of the impact of unintended pregnancy on mortality and morbidity. 


\section{Part 6: Policy and programmatic implications}

There are several areas where Bangladesh has shown great progress and promise related to family planning and contraceptive use. It has reduced its TFR to almost replacement level, and in some areas of the country it is already at or below replacement level. Its' MR program is a unique aspect of the family planning program in Bangladesh and has likely had an important influence in reductions of maternal mortality due to abortion. The recent approval of mifepristone-misoprostol in February of 2013 provides an opportunity for increasing access to MR with medication to women throughout the country.

There remain, however, some stubborn challenges to contend with, such as the heavy reliance on short-term methods, the high rates of discontinuation and switching and the limited use of permanent and long-term methods. The continued early age at marriage and early age at first birth creates a situation where couples may experience unmet need for limiting during a number of their reproductive years. The recent study results suggesting high rates of MR and abortion suggest there is a demand for high-quality, appropriate and accessible family planning methods.

There are, however, several encouraging policy and programmatic initiatives that are ongoing or planned for the future. Many of these specifically address the challenges presented in the earlier sections of this country profile. One such policy entry point is the Health Population and Nutrition Sector Development Program ((HPNSDP)which states as a target the increase of CPR from $61 \%$ to $74 \%$ by 2016 . It raises the question of whether or not this goal is too ambitious and whether it is achievable. One approach may be to focus on the areas of Bangladesh that have not yet achieved TFR and have a lower CPR overall. Such a tailored approach may increase the likelihood that such a goal can be met.

Another important future opportunity for addressing unintended pregnancy is through addressing (and achieving) the country commitments that Bangladesh made in the London Summit on Family Planning. These include:

- Increase access and use for poor people in urban and rural areas;

- Improve choice and availability of long-acting and permanent methods, including for men and post-partum and post-abortion services;

- Government to work with the private sector and NGOs to:

a) address the needs of young people, especially young couples;

b) reduce regional disparities, working with leaders and communities to delay early marriage and childbirth;

c) increase male involvement.

- One-third of MNCH centres to provide adolescent SRHR services;

- Monitoring to ensure strengthened quality of care, including informed consent and choice and to support women to continue use of family planning.

The HPNSDP and the London Summit on Family Planning country commitments provide a timely and robust policy and programmatic framework for addressing unintended pregnancy in Bangladesh.

\section{Recommendations from stakeholder consultation for future policy and programming related to unintended pregnancy in Bangladesh}

A stakeholder workshop was held on 22-23 June 2013 that brought together policymakers, researchers and STEP UP partners and members to discuss the measures that can be taken to reduce the burden of unintended pregnancy in Bangladesh. The following recommendations for future policy and programming were developed from the workshop:

1. Increase investment in reproductive health and family planning services to reduce the subsequent costs related to maternal neonatal and child health (MNCH) and to make further advancement toward the achievement of London Summit on Family Planning goals: Evidence indicates that a dollar invested in family planning services saves roughly two dollars in maternal and newborn healthcare-related costs. Investments in family planning are extremely cost-effective, and support from both the Bangladesh government 
and development partners needs to be strengthened. By working toward achievement of the family planning commitments that Bangladesh has already made, such a reduction in costs can be attained.

2. Improve awareness of family planning (FP) and menstrual regulation (MR) services among particular groups to reduce discontinuation and switching, misconceptions and fears about contraceptive side effects and promote use of long-acting and permanent methods (LAPM) through:

i. Better utilization of media and information and communication technology/mobile (ICT/m) Health: Directorate General of Family Planning (DGFP), ICT/m and NGOs, such as Marie Stopes, should work together to educate the media about reproductive health $(\mathrm{RH})$ and FP issues and develop well-articulated mobile messages to address discontinuation, side effects and to promote LAPM to eligible couples.

ii. Introduction of sexual and reproductive health education into the school curriculum: Evidence shows that sex education does not lead to increased interest in or experimentation with sex, hence specific health education programs need to be integrated into the school curriculum from grade eight and above. Such curriculum may also have a positive effect on decreasing adolescent marriage, pregnancy and childbirth.

iii. Engagement of community leaders, especially faith-based leaders to increase understanding on controversial issues among entire communities: imams (religious leaders) have responded positively to USAID's Leaders Outreach Initiative in publicizing Smiling Sun Clinic services and special MNCH events. Thus, religious and other community leaders should also be trained to dispel myths about side effects of contraceptives, promote LAPM, including male sterilization in Friday prayers and other communal gatherings.

\section{Increase coverage of FP and MR services by:}

\section{A) Targeting FP interventions at specific populations}

i. Increase male involvement in FP programs: As males are the primary decision makers in the family, including decisions about contraceptive use, they must be targeted by:

- Existing policy and programmatic interventions (such as the stipend system or social safety net program) and also by new and innovative provisions (such as tax rebate or conditional cash transfer programs) that can be used as incentives to attract new male FP method users.

- The number of male service providers must be increased to dispel the view that FP is a women's issue. Also, female family welfare visitors (FWVs) can include men in counseling sessions along with their wives to improve husbands' support for their wives in the use of their chosen method. These counseling sessions can also target rural men to increase their use of condoms, which is currently lower than their urban counterparts. Also, older males who prefer larger family size may be counselled about benefits of having a small family.

ii. Publicize LAPMs among couples who have at least two children and have reached the government's two-chid strategy: This may be maximized through mobile healthmHealth initiatives (the practice of medicine and public health, supported by mobile devices) and mass media campaigns.

iii. Satisfied FP method users may be used as ambassadors to motivate new users: Satisfied users of FP methods, such as users of LAPM, non-scalpel vasectomy (NSV), may promote such methods to new users while dispelling any myths about their side effects.

iv. Adolescent couples should be targeted by service providers and be counselled to use short-acting contraceptive methods to delay their first childbirths.

v. Increasing coverage among poor people in slums and rural areas:

- A standard demand-side financing (DSF) card including access to FP services should be made available for the ultra poor: The maternal health voucher scheme run by the Ministry of Health and Family Welfare (MoHFW) targets women from poor communities through the use of demand-side 
subsidies. Including FP services in this DSF scheme may help increase coverage of women in urban slums and rural areas. Also women should be able to access FP services through this card anywhere in the country rather than specific to the area of residence so that migratory groups, such as those who move from one slum to another slum, benefit. This will ensure that their access to free FP services is not disrupted when they migrate. Indicators must be formulated to identify the ultra poor in this regard.

- Urban Primary Health Care (UPHC) program services need to be expanded in urban slums: DGFP and the Directorate General of Health Services (DGHS) should support the local government in health service delivery in expansion of these services in urban slums as they are not currently sufficient in these areas. The national and local governments must update existing guidelines to ensure local governments implement policy into practice.

\section{B) Increasing number of FP and MR providers}

i. More doctors, nurses, midwives and paramedics need to be trained and sent out into the field: There is still a shortage of providers trained in FP practices; hence more health staffs need to be recruited and trained in the latest techniques of family planning counseling and provision.

ii. Task sharing of nurses will help expand their existing skill set: While some staff nurses are able to perform MR and provide post-abortion care (PAC), more nurses should be trained in these critical skills. This will increase the coverage of these services, particularly in rural areas where relatively fewer doctors are available.

iii. Increase home visits by fieldworkers: Fieldworkers may motivate couples to use FP methods and explain the difference between spacing and limiting births. The number of field worker visits should be increased and used as a positive movement of FP method use. Improved supervision of fieldworkers will help to ensure both the number and quality of the fieldworker visits.

iv. Increase MR service provider base: Nurses and fresh medical graduates can also be trained to provide MR in addition to FWVs.

\section{C) Increasing number of facilities providing FP and MR services}

i. The number of satellite clinics in urban and rural areas in both government and NGO sectors needs to be increased to improve service provision of LAPMs.

ii. Number of facilities providing MR should be increased: Numerous facilities in the public and private sector have the potential to provide MR, but not all of them are currently doing so. Shortages of trained providers, lack of equipment, religious and cultural reasons act as barriers in providing MR services and must be addressed in order to increase MR service provision.

4. Improve monitoring and evaluation (M \& E) to increase accountability of providers to help achieve universal access to FP, MR and PAC services:

i. Unofficial payments for MR services at government facilities must be prohibited. The existing Monitoring \& Evaluation (M\&E) unit for MR service should be revitalized to ensure that MR services are provided free-of-charge. Providers may be given incentives to discourage taking under-the-table payments.

ii. Absenteeism of providers must be discouraged: FP officials at the field level must be held accountable through improved monitoring. Disciplinary action must be taken against providers who are frequently absent.

iii. The MR working group and MR committee should work closely together: Revitalization of the MR working group is needed. Ensuring close communication between the MR working group and the MR committee will highlight problems and help to identify solutions. 
iv. The local administration should be empowered to allocate responsibility for performance of health providers: Monitoring and evaluation should be implemented at all stages and levels of FP service delivery to ensure quality of care for FP and MR services. Provider accountability may be increased through empowering local administration, such as union parishad chairman and members, and allocating responsibility for performance. Existing guidelines on how the local administration will monitor and evaluate performance of field visit needs to be updated and improved.

\section{Improve the quality of care and access to FP and MR services}

i. Encourage clearly defined public-private partnership (PPP) to ensure quality FP and MR service provision for young people, young married couples and people in hard-to-reach and disadvantaged areas where there is inadequate service availability.

ii. The quality of counseling services of providers may be improved by:

- Organizing a Training of Trainers (TOT) to improve communication skills of providers: The DGFP and National Institute of Population Research and Training (NIPORT) may take the lead in this. They also should ensure a proper counseling approach in community skilled birth attendant (CSBA)/family welfare visitors (FWV) training courses. Moreover, the medical graduates program (MBBS) curriculum needs to be reviewed to ensure that the value of counseling has been strongly emphasized. Additionally, a specific module may be taught on the duty of care of a health provider and the ethics of withholding services from clients due to the personal views of the provider.

- Developing a counseling manual on MR especially for 30-39-year-old women. As women in their 30s are more likely to use MR, their particular needs should be focused on during MR counseling. A manual may be developed by the DGFP and NIPORT in this regard.

- Ensuring that women admitted to the gynecology unit of the health complexes for the treatment of abortion complications are visited by workers from the FP unit nearby and are counseled on contraceptive methods.

\section{Quality of FP services:}

i. The supply of LAPM should be uninterrupted: Contraceptives forecasting and procurement need to be time-bound to ensure continuous logistic supply of LAPMs. The Health Population Nutrition Sector Development Programme (HPNSDP) has already stated this as part of its operational plan under the DGFP, and efforts should be made to implement this activity accordingly.

ii. Financial incentives for reaching performance targets: The pay for performance (P4P) scheme has been shown to increase quality and quantity of $\mathrm{MNCH}$ services at upazila health complexes (UHCs). As such, similar P4P schemes should be employed for facilities providing FP services in urban slums and rural areas to improve the overall quality of care.

\section{Quality of MR Services}

i. Manual Vacuum Aspiration (MVA) training may be given to PAC service providers to reduce reliance on inpatient D\&C: MVA is less likely to result in post-abortion complications for women and is also a cheaper procedure to perform. Additionally, it can be provided in locations without consistent electricity.

ii. The official time limit of MR may be extended to 10 weeks if performed by FWV and 12 weeks if performed by doctors. This will ensure that women who could not access MR services earlier do not resort to unsafe abortion and save on costs of providing services for post-abortion complications.

iii. MR with medication (MRM) may be included in existing MR guidelines in order to avert unsafe abortion and save on scarce health resources. Introduce monitoring and evaluation to ensure proper 
training and use of MRM. Pictorial and written leaflets on possible side effects of MRM must be supplied to pharmacy workers providing MRM to reduce their provision of incorrect information to users. The Drug Administration (DA) authority needs to enforce policy against selling drugs without a professional qualification or a valid professional license, particularly, against selling non-over-thecounter (OTC) drugs without a prescription. Drug sellers need to be monitored to prevent malpractice.

iv. Separate rooms should be available to provide MR: A separate room for MR procedures will ensure privacy and confidentiality of the woman.

v. Women of age and emancipated minors should be able to consent for themselves. A girl who is underage and unmarried must be accompanied by an adult, although this should be someone she chooses, such as an elder sister or an aunt and not necessarily her legal guardian.

vi. Documentation of MR provision in public, private and NGO facilities to improve recordkeeping: A national database needs to be created across all sectors to reduce poor documentation and underreporting of MR.

vii. Disposable canula should be used during MR procedures: Repeat use of canula must be discouraged, and disposable canula must be introduced to create a more hygienic environment during MR provision.

viii. Early detection of pregnancy to reach MR service on time is needed.

ix. MR services should be a comprehensive one-stop service: It should include support services for women, such as counseling service and legal aid, particularly for those who are victims of domestic violence and abuse.

These recommendations cover a broad range of policy and programmatic areas, and some require immediate attention and investment while others may require a longer time horizon. These recommendations reflect the policy and programmatic need that emerges from the rigorous review of evidence presented in the country profile, as well as the insights and priorities of key stakeholders in the government and NGO sectors in Bangladesh. In order to ensure that these recommendations are put into practice the continued engagement of STEP UP partners with government and NGO counterparts as well as continued policy dialogue are required. 


\section{Appendix 1 - List of FP service fees}

(A) Sterilization Services (Per Client)

\begin{tabular}{|c|c|}
\hline Purpose of Expenses & $\begin{array}{l}\text { Revised fees } \\
\text { according to OP (BDT) }\end{array}$ \\
\hline \multicolumn{2}{|l|}{ Permanent method for women and men in whole country } \\
\hline \multicolumn{2}{|l|}{ For service recipient/client } \\
\hline a. Compensation fees for wage labor & 1400.00 \\
\hline b. Food cost & 300.00 \\
\hline c. Transportation cost & 300.00 \\
\hline Sub-total & 2000.00 \\
\hline For service provider - to bring patient in the sterilization centre & 300.00 \\
\hline Infection prevention and to ensure the quality of services & 80.00 \\
\hline Surgeon's fee per client & 300.00 \\
\hline \multicolumn{2}{|l|}{ Helping assistant fee per client } \\
\hline Surgical assistant (client screening laboratory test) & 60.00 \\
\hline Operation theater in charge (including monitoring during operation) & 60.00 \\
\hline Caring stretcher, autoclaving under the supervision of FWVs, night stay & 40.00 \\
\hline Shaving, AYA for cleaning OT and post-operative room (as per single client cost) & 15.00 \\
\hline Sweeper for cleaning & 20.00 \\
\hline $\begin{array}{l}\text { Record keeping and produce report (FP office assistant who would be involved in this } \\
\text { work) }\end{array}$ & 20.00 \\
\hline Sub-total & 895.00 \\
\hline \multicolumn{2}{|l|}{ For management, motivation and counseling works of managers } \\
\hline \multicolumn{2}{|l|}{ (A) Government level } \\
\hline i. Medical officer (MCH-FP) & 95.00 \\
\hline ii. Upazilla FP officer & 95.00 \\
\hline $\begin{array}{l}\text { iii. Other government organization - } 2 \text { first-class officers or equivalent who have been } \\
\text { involved/working with relevant issues in that organization (MCHTI, MFSTC and } \\
\text { Model FP clinic, medical college hospitals ) }\end{array}$ & 95.00 \\
\hline Purpose of Expenses & $\begin{array}{l}\text { Revised fees } \\
\text { according to OP (BDT) }\end{array}$ \\
\hline $\begin{array}{l}\text { iv. FP visitors/equivalent officers who have been involved/working with relevant issues } \\
\text { in that organization (related non-government organization will select/decide) }\end{array}$ & 55.00 \\
\hline $\begin{array}{l}\text { (B) Non-government - } 2 \text { first-class officers or equivalent who have been } \\
\text { involved/working with relevant issues in that organization (related non-government } \\
\text { organization will select/decide) (Like - A) }\end{array}$ & 300.00 \\
\hline $\begin{array}{l}\text { (C) Upazilla assistant FP officer/non-government equivalent officers who have been } \\
\text { involved/working with relevant issues in that organization (related non-government } \\
\text { organization will select/decide) }\end{array}$ & 55.00 \\
\hline $\begin{array}{l}\text { (D) Assistant FP officer (MCH-FP)/equivalent officers who have been involved/working } \\
\text { with relevant issues in that organization (related non-government organization will } \\
\text { select/decide) }\end{array}$ & 55.00 \\
\hline Sub-total (managerial support) & 355.00 \\
\hline Total cost involvement of permanent method (1-11) & 3250.00 \\
\hline
\end{tabular}


(B) IUD Services (Per Client)

\begin{tabular}{|c|c|c|}
\hline \multicolumn{2}{|l|}{ Purpose of Expenses } & $\begin{array}{l}\text { Revised fees } \\
\text { according to OP }\end{array}$ \\
\hline \multicolumn{2}{|c|}{ Transportation cost for IUD Client } & 150.00 \\
\hline \multicolumn{2}{|c|}{ Insertion fee per client (service provider's) } & 60.00 \\
\hline \multicolumn{2}{|c|}{ To bring the patient into the sterilization center } & 50.00 \\
\hline \multicolumn{2}{|c|}{$\begin{array}{l}\text { Additional costs for infection prevention and ensuring quality of care of services (for } \\
\text { example, purchase of kerosene and soap, towels, washing linen, instruments and } \\
\text { operation theater cleaning.) }\end{array}$} & 50.00 \\
\hline \multicolumn{2}{|c|}{ After IUD insertion, transportation cost to bring the client in for follow-up services } & $\begin{array}{r}80 \times 3=240 \text { (for } \\
\text { visiting three times) }\end{array}$ \\
\hline Steps & Schedule & \\
\hline $1^{\text {st }}$ time & 1 month $(+) 7$ days & \\
\hline $2^{\text {nd }}$ time & 6 months $(+) 1$ month & \\
\hline $3^{\text {rd }}$ time & 12 months $(+) 1$ month & \\
\hline
\end{tabular}

(C) Implant Services (per client)

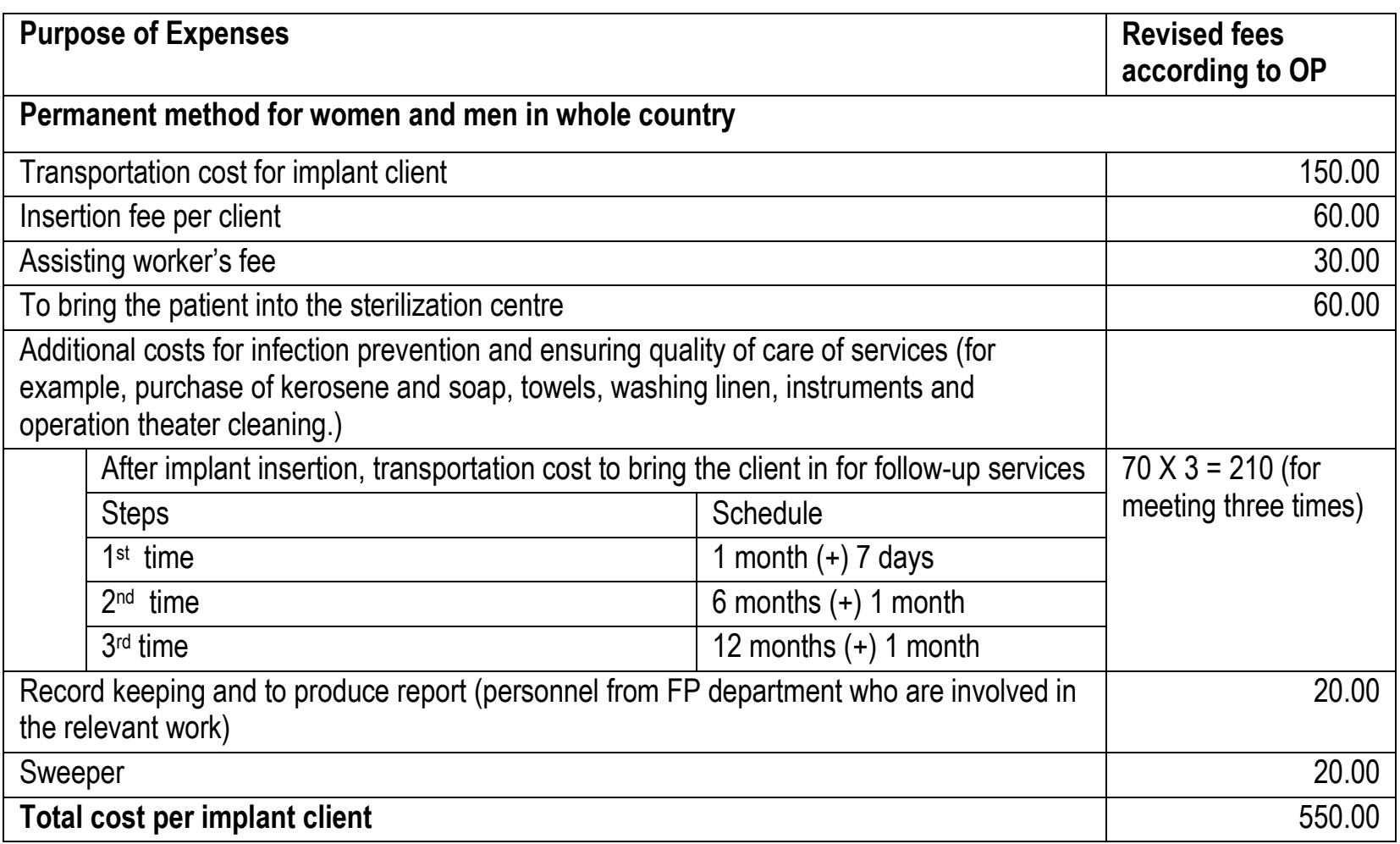

(D) Special Sterilization Service/Activities (each activity)

\begin{tabular}{|l|r|}
\hline Purpose of Expenses & $\begin{array}{l}\text { Revised fees } \\
\text { according to OP }\end{array}$ \\
\hline $\begin{array}{l}\text { Excluding the permanent sterilization centre, each month two or more special } \\
\text { sterilization services/workshops would be arranged in a suitable family welfare certer } \\
\text { where operation may be possible. }\end{array}$ & \\
\hline
\end{tabular}


(E) Re-canalization Services (per client)

\begin{tabular}{|l|r|}
\hline Purpose of Expenses & \multicolumn{1}{|l|}{$\begin{array}{l}\text { Revised fees } \\
\text { according to OP }\end{array}$} \\
\hline $\begin{array}{l}\text { Food, wage-labor, compensation, transportation, etc.- related cost for client who has taken } \\
\text { the re-canalization services }\end{array}$ & 3000.00 \\
\hline Seat charge (highest charge for private hospital/clinic ) & 3000.00 \\
\hline Surgeon fee for re-canalization & 6000.00 \\
\hline Anesthesiologist fees & 2000.00 \\
\hline Assistant fee for re-canalization (2 people, 2000X 2) & 4000.00 \\
\hline OT charge (for private hospitals) & 4000.00 \\
\hline Drugs and MSR & 4000.00 \\
\hline Total cost & 26000.00 \\
\hline
\end{tabular}

(F) Others

\section{Purpose of Expenses}

Post FP method side effects/complication related treatment and management and other related expenses

If death occurs due to post family planning method side effects/complications to any male/female FP method acceptors in any government FP service centre and in any NGOs (those are permitted by the DGFP to provide FP services), payment of his/her burial costs (once/immediately) to their legal successors. 


\section{Appendix 2 - GIS Maps of HealthCare Facilities Offering MNCH- FP Services in Bangladesh}

(Source of all maps: Mridha MK et al. Assessment of Maternal, Neonatal and Child Health and Family Planning Facilities in Bangladesh. Dhaka: icddr,b 2012)

Distribution of Health Care Facilities in Bangladesh

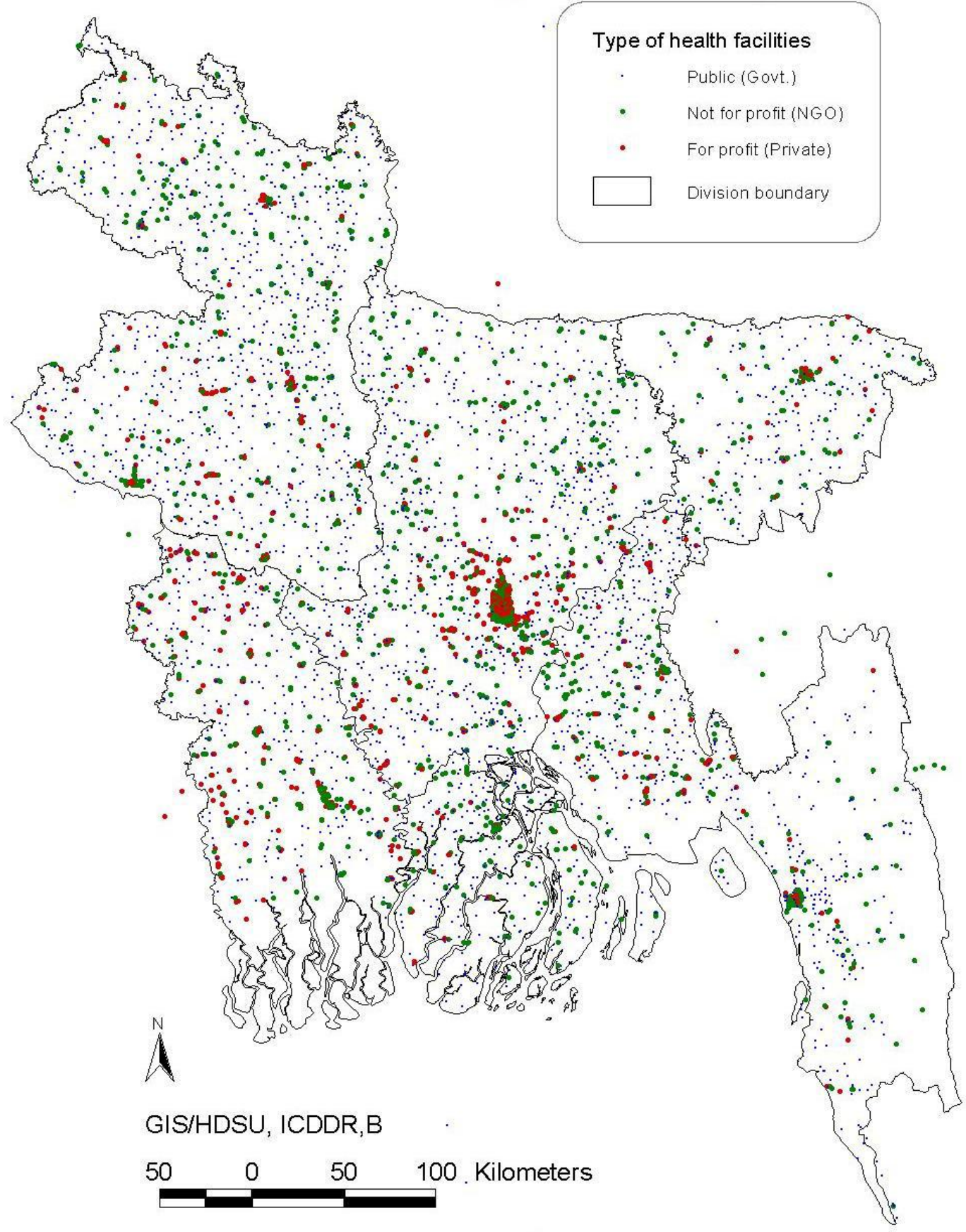




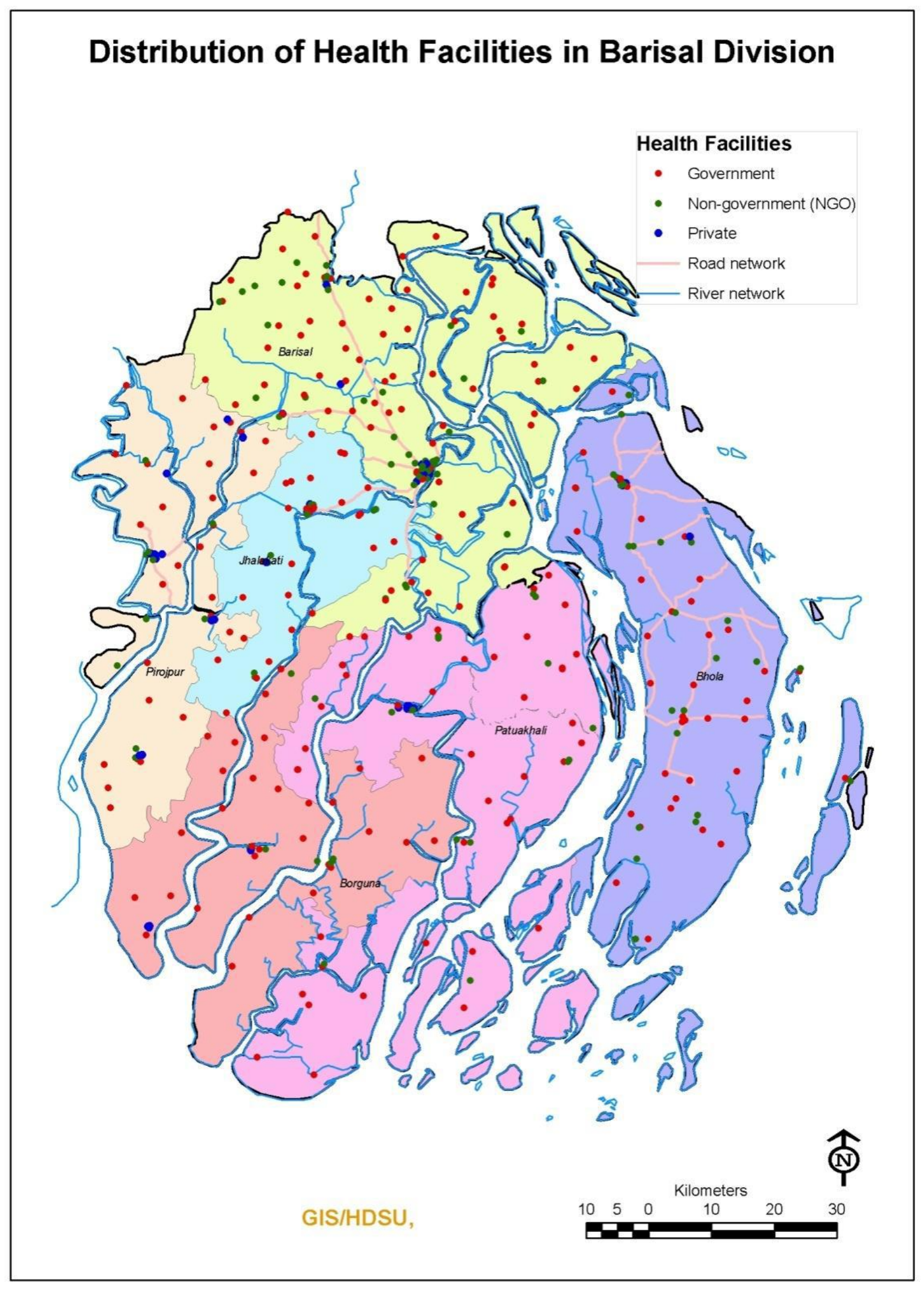




\section{Distribution of Health Facilities in Chittagong Division}

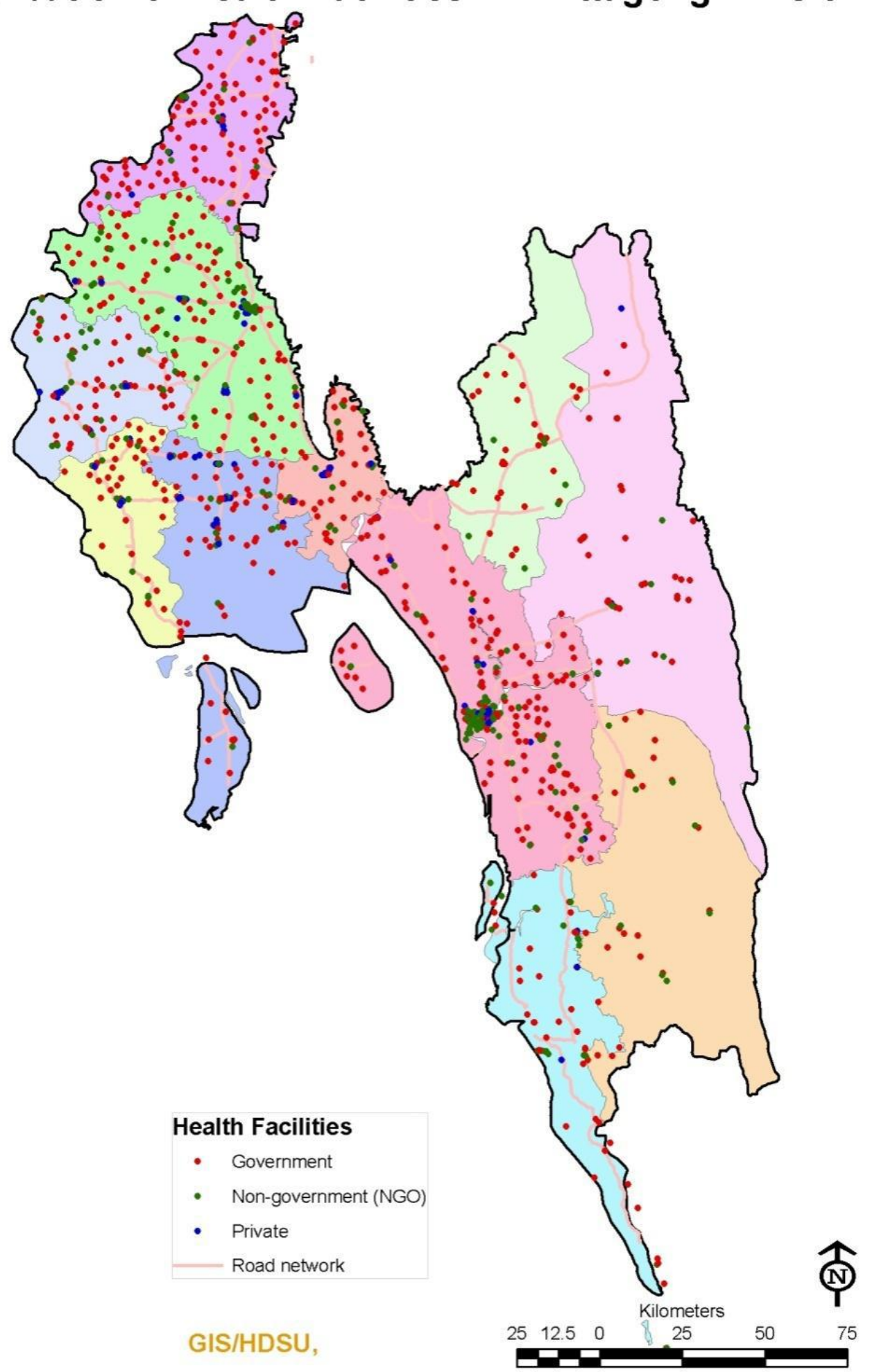




\section{Distribution of Health Facilities in Dhaka Division}

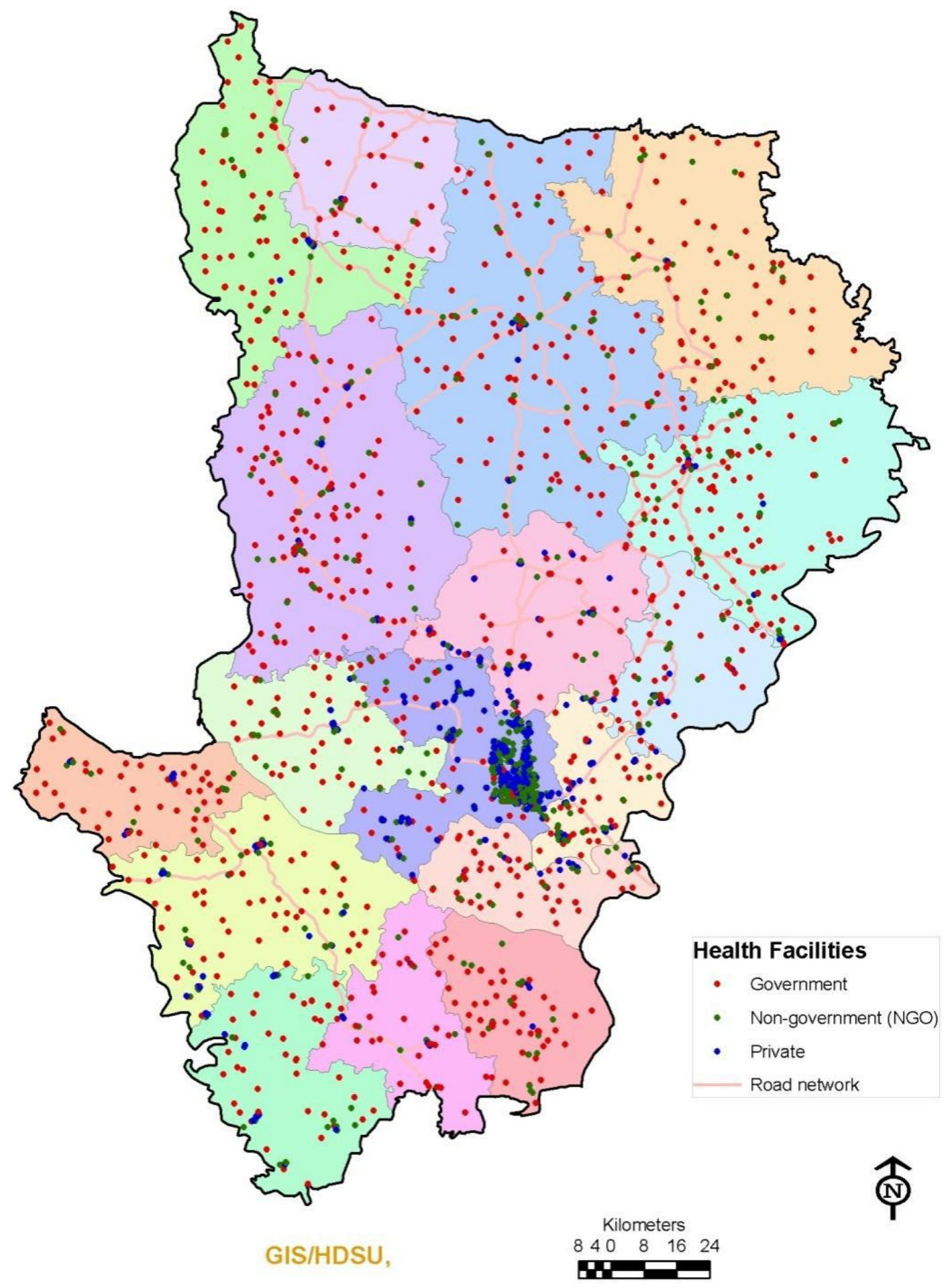




\section{Distribution of Health Facilities in Khulna Division}

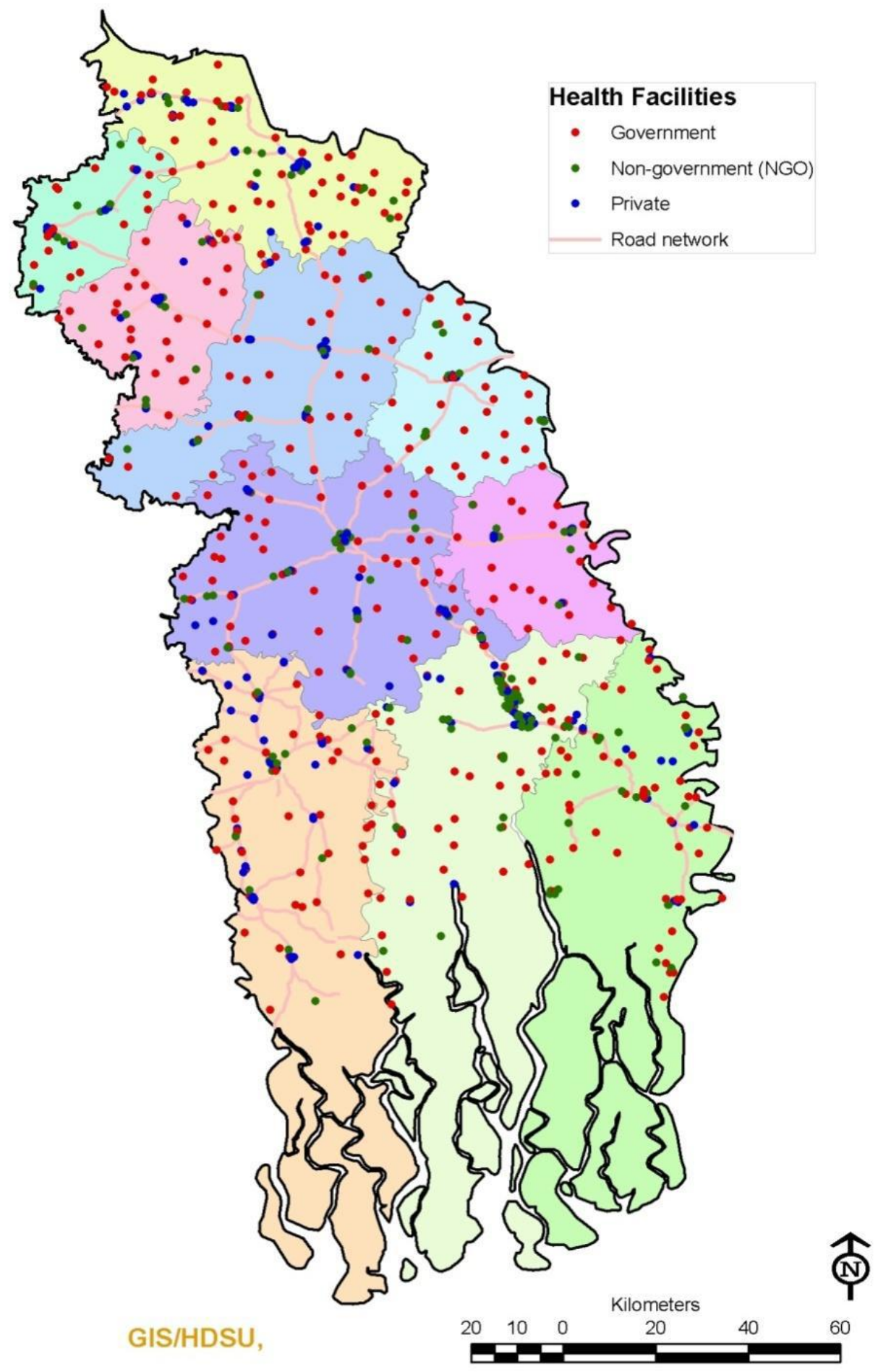




\section{Distribution of Health Facilities in Rajshahi Division}

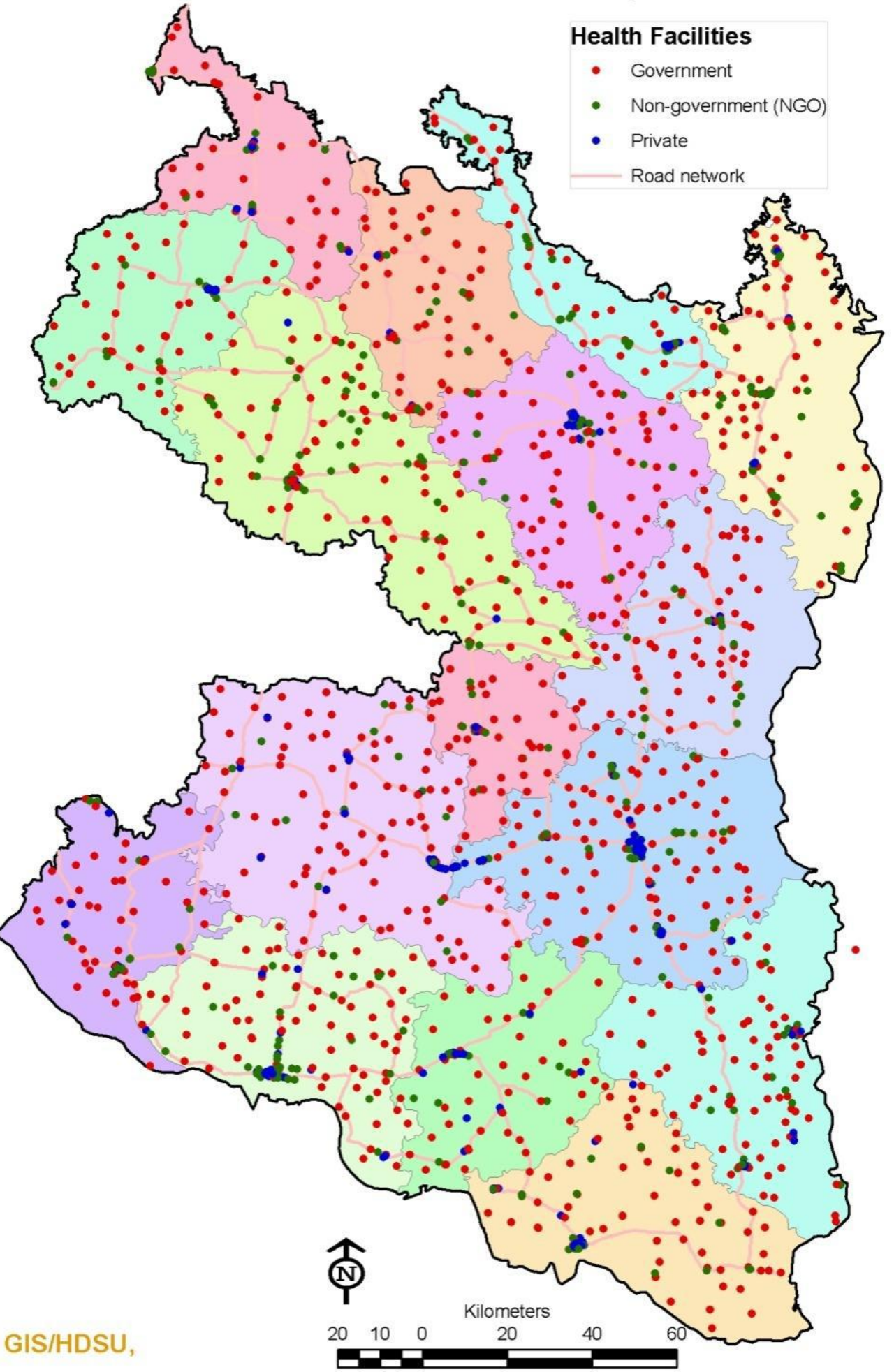




\section{Distribution of Health Facilities in Sylhet Division}

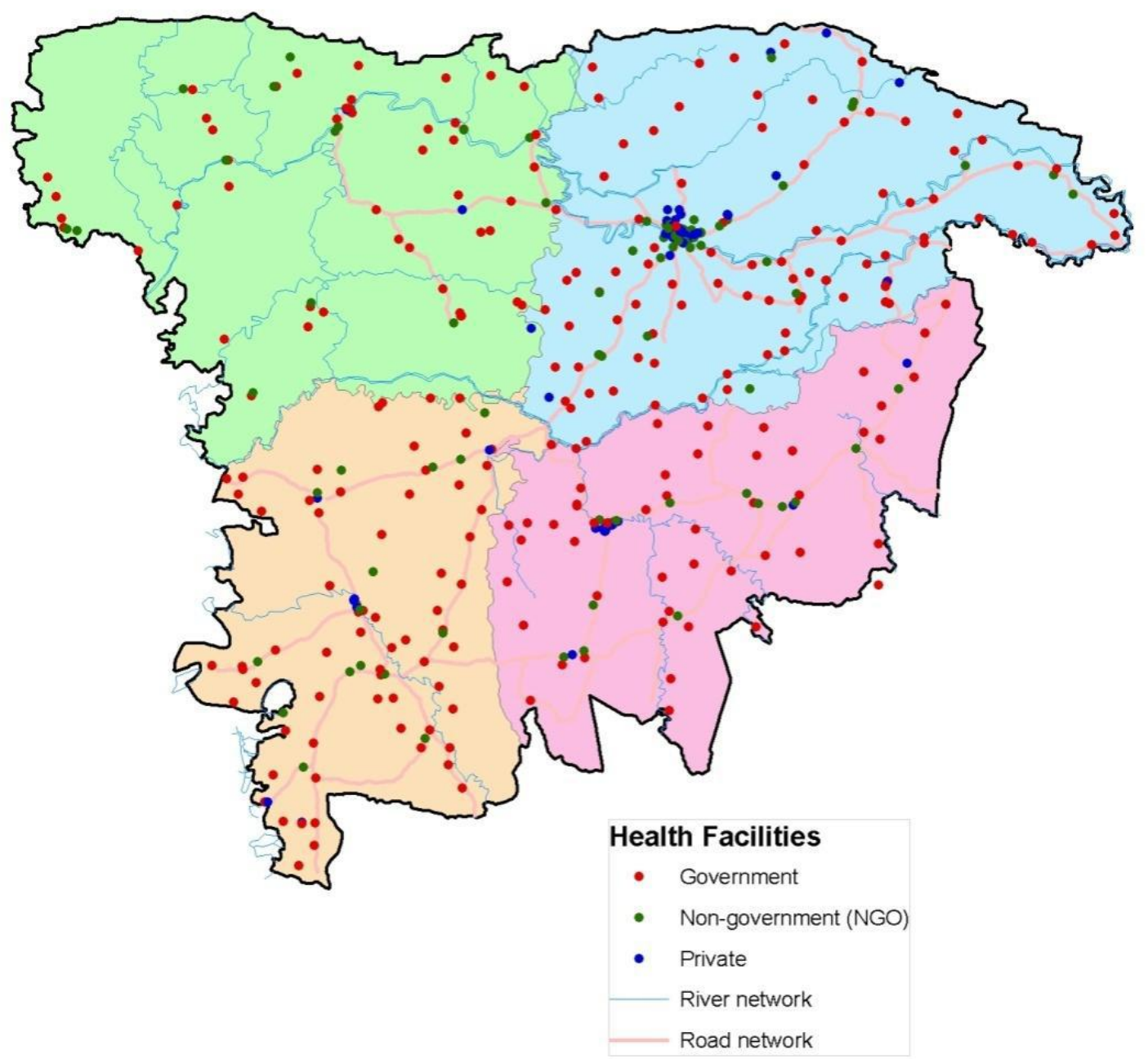




\section{References}

1. Kamal M, Islam A. Prevalence and socioeconomic correlates of unintented pregnancy among women in rural Bangladesh. Salud publica de Mexico. 2011;53(2):108-15.

2. Rahman M. Women's Autonomy and Unintended Pregnancy Among Currently Pregnant Women in Bangladesh. Maternal and Child Health Journal. 2011;16(6):1206-14.

3. Islam MM, Rashid M. Determinants of Unintended Pregnancy among Ever-married Women in Bangladesh Journal of Family Welfare. 2004;50(2):40-7.

4. Bangladesh Demographic and Health Survey 2011. National Instuitute of Population Research and training, Dhaka, Bangladesh. January 2013.

5. Study on unmet need for family planning in Bangladesh. Dhaka: Family Planning Association of Bangladesh 2010.

6. London Summit on Family Planning: Summary of Commitments. Accessed on 25.02.2013. http://www.londonfamilyplanningsummit.co.uk/COMMITMENTS_090712.pdf

7. Bangladesh Population Policy 2004, Ministry of Health and Family Welfare. Government of the People's Republic of Bangladesh.

8. Benson J, Andersen K, Samandari G. Reductions in abortion-related mortality following policy reform: evidence from Romania, South Africa and Bangladesh. Reprod Health. 2011;8:39.

9. Rob U, Mutahara MU, Sprafkin N. Development of population policy in Bangladesh. International Quarterly of Community Health Education. 2004;23(1):25-38.

10. Chowdhury SN, Moni D. A situation analysis of the menstrual regulation program in Bangladesh. Reprod Health Matters. 2004 Nov;12(24 Suppl): 95-104.

11. Singh S, Cabigon JV, Hossain A, Kamal H, Perez AE. Estimating the level of abortion in the Philippines and Bangladesh. International Family Planning Perspectives. 1997;23(3):100-44.

12. Larson A, Mitra SN. Family Planning in Bangladesh: An Unlikely Success Story. International Family Planning Perspectives. 1992;18(4):123-44.

13. Schuler SR, Hashemi SM, Jenkins AH. Bangladesh's Family Planning Success Story: A Gender Perspective. International Family Planning Perspectives. 1995;21:132-7.

14. Bangladesh Demographic and Health Survey 2007. National Instuitute of Population Research and training, Dhaka, Bangladesh. March 2009.

15. Randall E. Family Planning Programmes Review 2012 January. Accessed on 12.02.2013. http://www.populationmatters.org/documents/programmes_review.pdf

16. Health, Population, and Nutrition Sector Development Program (2011 -2016), Program Implementation Plan, Ministry of Health and Family Welfare, Government of Bangladesh 2011.

17. Gill Z, Ahmed JU. Experience from Bangladesh: implementing emergency obstetric care as part of the reproductive health agenda International Journal of Gynecology and Obstetrics 85 (2004) 213-220

18. Combined sixth and seventh periodic report of States parties: Bangladesh. Geneva: Committee on the Elimination of Discrimination against Women2010.

19. Third and fourth periodic reports of States parties due in 2007: Bangladesh. Geneva: Committee on the Rights of the Child2008.

20. Concluding observations of the Committee on the Rights of the Child: Bangladesh. Fifty-first session of the Committee on the Rights of the Child; 2009.

21. Concluding observations of the Committee on the Elimination of Discrimination against Women. Committee on the Elimination of Discrimination against Women: Forty-eighth session; 2011: CEDAW.

22. The Constitution of the People's Republic of Bangladesh. Dhaka: Ministry of Law, Justice and Parliamentary Affairs; 2010 [cited 2012 17.10.2012]; Available from: $\underline{\text { http://bdlaws.minlaw.gov.bd/pdf part.php?id=367. }}$ 
23. Randall E. Family Planning Programmes Review. London: Population Matters2012.

24. Hasan R, Reich M, Fink G. Agenda-setting of population in Bangladesh and West Bengal and impact on fertility. 2012.

25. Forman S, Ghosh R. Promoting Reproductive Health: Investing in Health for Development: Lynne Rienner Publishers Inc. ; 2000.

26. Rannan-Eliya RP. Bangladesh National Health Accounts 1997-2007: Health Economics Unit, MoHFW2010.

27. Reich M. The political economy of health transitions in the third world. Health and Social Change in International Perspective. Boston: Harvard School of Public Health; 1994. p. 413-51.

28. Rashid SF. Human rights and reproductive health: political realities and pragmatic choices for married adolescent women living in urban slums, Bangladesh. BMC Int Health Hum Rights. 2011 Dec 16;11 Suppl 3:S3.

29. Field E, Ambrus A. Early Marriage, Age of Menarche, and Female Schooling Attainment in Bangladesh. Journal of Political Economy. 2008;116(5):881-930.

30. Jensen R, Thornton R. Early Female Marriage in the Developing World. Gender and Development. 2003;11(2):9-19.

31. Gipson JD, Hindin MJ. "Marriage means having children and forming your family, so what is the need of discussion?" Communication and negotiation of childbearing preferences among Bangladeshi couples. Cult Health Sex. 2007 Mar-Apr;9(2):185-98.

32. Schuler SR, Bates LM, Islam F, Islam MK. The timing of marriage and childbearing among rural families in Bangladesh: Choosing between competing risks. Social Science \&amp; Medicine. 2006;62(11):2826-37.

33. Kishor S and Johnson K. Profiling Domestic Violence - A Multi-Country Study. Calverton, Maryland: ORC Macro. 2004

34. Ali NA, Khan R, Akter R, Roza AK, Sultana M, Shelly SB. Strengthening National Menstrual Regulation Programme. 2012.

35. Islam MR, Thorvaldsen G. Family planning knowledge and current use of contraception among the Mru indigenous women in Bangladesh: a multivariate analysis. Open Access Journal of Contraception. 2012;3:916.

36. Matsaert $\mathrm{H}$, Ahmed $\mathrm{Z}$, Hussain $\mathrm{F}$, Islam $\mathrm{N}$. Using actor-oriented tools to analyze innovation systems in Bangladesh. Participatory Learning and Action. 2005(51):100-10.

37. Rahman T. Nodi O Jibon Policy Paper 1: Health poverty in island chars of northwest Bangladesh. Dhaka: Unnayan Shamannay2008.

38. Bangladesh haor infrastructure and livelihood improvement project: enabling poor people to adapt to climate change: IFAD2011.

39. Fitzwarryne $C$. Review of the primary health care and family planning project of the chars livelihoods program (CLP): DFID2010.

40. BRAC Health Programme, Annual Report 2006. Dhaka: BRAC2007.

41. Johnston H. Relationships of exclusion and cohesion with health: the case of Bangladesh. Journal of Health, Population and Nutrition. 2009;27(4):426.

42. Hussain A, Ali SMK, Kvåle G. Determinants of mortality among children in the urban slums of Dhaka city, Bangladesh. Tropical Medicine \& International Health. 1999;4(11):758-64.

43. Rashid SF. Strategies to Reduce Exclusion among Populations Living in Urban Slum Settlements in Bangladesh. J Health Popul Nutr. 2009 Aug;27(4):574-86.

44. Bangladesh Maternal Health Services and Maternal Mortality Survey 2001. Dhaka: NIPORT, ORC, Johns Hopkins University, ICDDRB2003.

45. 2006 Bangladesh Urban Health Survey. Dhaka2008. 
46. Shahjahan $M$, Kabir M. Why males in Bangladesh do not participate in reproductive health: lessons learned from focus group discussions. International Quarterly of Community Health Education. 2006;26(1):45-59.

47. Hossain KJ. Male Involvement in Family Planning in Bangladesh: Factors Constraining Low Use and the Potential for Augmenting the CPR. Dhaka: CPD, UNFPA2003 Contract No.: Paper 27.

48. Khan ME, Townsend JW, D'Costa S. Behind Closed Doors: A Qualitative Study of Sexual Behaviour of Married Women in Bangladesh. Culture, Health \& Sexuality. 2002;4(2):237-56.

49. The National Communication Strategy for Family Planning and Reproductive Health. Ministry of Health and Family Welfare. Directorate General of Family Planning, Dhaka, Bangladesh. November 2008.

50. Family planning Association of Bangladesh website. http://www.fpab.org

51. Ferdousi SK, Jabbar MA, Hoque SR, Karim SR, Mahmood AR, Ara R, Khan NR Unmet Need of Family Planning Among Rural Women In Bangladesh Journal of Dhaka Medical College. 2010; 19(1): 11-15.

52. Gipson JD, Hindin MJ. "Having Another Child Would Be a Life or Death Situation for Her": Understanding Pregnancy Termination Among Couples in Rural Bangladesh. Am J Public Health. 2008 Oct;98(10):1827-32.

53. Chalasani S, Casterline J, Koenig M. Unwanted childbearing and child survival in Bangladesh. Annual Meeting of the Population Association of America; 29-31 March 2007; New York2008.

54. Cleland J, Bernstein S, Ezeh A, Faundes A, Glasier A, Innis J. Family planning: The Unfinished Agenda Lancet 2006; 368: 1810-27

55. Prata, N. The Need for Family Planning. Population Environment 2007 28:212-222

56. Streatfield PK, Kamal N, Taisir R, Hasan MS. Contraceptive Discontinuation and Switching Patterns in Matlab, Bangladesh. TRAction Activity Report: Secondary Data Analysis on Contraceptive Use. September 2012.

57. Saha UR, Bairagi R. Inconsistencies in the Relationship Between Contraceptive Use and Fertlity in Bangladesh. International Family Planning Perspectives, 2007, 33(1):31-37.

58. Reza R. Factors influencing fertility preferences of men in Bangladesh. Phutthamonthon: Mahidol University; 2001.

59. Gipson JD, Hindin MJ. The effect of husbands and wives' fertility preferences on the likelihood of a subsequent pregnancy, Bangladesh 1998-2003. Population Studies. 2009;63(2):135-46.

60. Islam S, Islam MA, Padmadas SS. High fertility regions in Bangladesh: a marriage cohort analysis. Journal of Biosocial Science. 2010;42(06):705-19.

61. DaVanzo J, Hale L, Razzaque A, Rahman M. Effects of interpregnancy interval and outcome of the preceding pregnancy on pregnancy outcomes in Matlab, Bangladesh. BJOG. 2007 Sep 01;114(9):1079-87.

62. DaVanzo J, Razzaque A, Rahman M, Hale L, Ahmed K, Khan MA, et al. The Effects of Birth Spacing on Infant and Child Mortality, Pregnancy Outcomes, and Maternal Morbidity and Mortality in Matlab, Bangladesh. [Working Paper]. In press 2004.

63. Strengthening the National Menstrual Regulation Programme for Reduction of Maternal Mortality and Morbidity in Bangladesh. Dhaka: World Health Organization2010.

64. Oliveras E, Johnston H, Nahar L, Chowdhury ME, Sabir AA, Islam MS. Situation Analysis of Unsafe Abortion and Menstrual Regulation in Bangladesh. Dhaka: International Centre for Diarrhoeal Disease Research, Bangladesh (ICDDR,B)2008.

65. Singh S, Hossain A, Maddow-Zimet I, Bhuiyan HU, Vlassof M, Hussain R. The incidence of menstrual regulation procedures and abortion practices in Bangladesh, 2010. International Perspectives on Sexual and Reproductive Health. 2012;38(3):122-32.

66. Abortion ratios worldwide in 2008. New York: Guttmacher Institute2012.

67. Islam M, Rob U, Chakroborty N. Menstrual Regulation Practices in Bangladesh: An Unrecognized Form of Contraception. Asia-Pacific Population Journal. 2004;20(4):75-99. 
68. Ahmed MK, Ginneken JV and Razzaque A. Factors associated with adolescent abortion in a rural area of Bangladesh. Tropical Medicine and International Health 2005 February; 10 (2):198-205

69. Bhuiya A, Aziz A, Chowdhury M. Ordeal of women for induced abortion in a rural area of Bangladesh. J Health Popul Nutr. 2001 Dec;19(4):281-90.

70. Vlassoff M et al., Menstrual Regulation and Postabortion Care in Bangladesh: Factors Associated with Access to and Quality of Services, New York: Guttmacher Institute, 2012

71. Kapil Ahmed M, Van Ginneken J, Razzaque A. Factors associated with adolescent abortion in a rural area of Bangladesh. Tropical Medicine \& International Health. 2005;10(2):198-205.

72. Khan M, Kabir M, Mori M. Unintended pregnancy in bangladesh. World Health Popul. 2006;8(1):47-57.

73. Mridha MK, Koblinsky MA, Moran AC, Ashraf A, Campbell O, Anwar I. Assessment of Maternal, Neonatal and Child Health and Family Planning Facilities in Bangladesh. Dhaka: icddr,b 2012.

74. Sarkar ZAT, Sabina N. Swedish Support to the Menstrual Regulation Program of Bangladesh - sida evaluation, Asia Department. 07/39, 2007.

75. Understanding the determinants of safe abortion services in Bangladesh: the perspective of users and gatekeepers: IPPF2011.

76. Ahmed S, Islam A, Khanum PA, Barkat e K. Induced abortion: What's happening in rural Bangladesh. Reproductive Health Matters. 1999;7(14):19-29.

77. Johnston HB, Oliveras E, Akhter S, Walker DG. Health System Costs of Menstrual Regulation and Care For Abortion Complications in Bangladesh. International Perspectives on Sexual and Reproductive Health. 2010;36(4):197-204.

78. Routh S, Thwin AA, Kane TT, Baqui AH. User-fees for family-planning methods: an analysis of payment behaviour among urban contraceptors in Bangladesh. Journal of Health, Population and Nutrition. 2000;18(2):69-78.

79. World Data Bank: World Development Indicators and Global Development Finance. Washington DC: WorldBank; 2011.

80. Routh S, Thwin AA, Barb N, Begum A. Cost efficiency in maternal and child health and family planning service delivery in Bangladesh: implications for NGOs. Health Policy and Planning. 2004 January 1, 2004;19(1):11-21.

81. Schuler SR, Bates LM, Islam MK. Paying for reproductive health services in Bangladesh: intersections between cost, quality and culture. Health Policy and Planning. 2002 September 1, 2002;17(3):273-80.

82. Ensor T, Dave-Sen P, Ali L, Hossain A, Begum SA, Moral H. Do essential service packages benefit the poor? Preliminary evidence from Bangladesh. Health Policy and Planning. 2002 September 1, 2002;17(3):247-56.

83. Bongaarts J, Sinding SW. Family planning as an economic investment. Washington D.C.: SAIS Review2011.

84. Ensor T, Ali L, Hossain A, Ferdousi S. Projecting the cost of essential services in Bangladesh. Int J Health Plann Manage. 2003 Apr-Jun;18(2):137-49.

85. Talukder MN, Rob U, Rahman L, Hena IA, Khan AZU. A P4P model for increased utilization of maternal, newborn and child health services in Bangladesh. Dhaka: Population Council 2011.

86. Strategic Plan for Health, Population \& Nutrition Sector Development Program (HPNSDP), 2011-2016. Planning Wing, Ministry of Health and Family Welfare, Government of the People's Republic of Bangladesh. April 2011.

87. Directorate General of Family Planning website (accessed on 25.02.2013). http://www.dgfp.gov.bd

88. Family Planning and Maternal and Child Health Factsheet. Dhaka: MoHFW 2011. http://www.dgfp.gov.bd

89. Meekers $D$, Rahaim S. The importance of socio-economic context for social marketing models for improving reproductive health: Evidence from 555 years of program experience. BMC Public Health. 2005;5(10). 
90. Social Marketing Company website (Accessed on 26.02.2013) . http://www.smc-bd.org/about.html

91. McBride J, Ahmed R. Social Franchising as a Strategy for Expanding Access to Reproductive Health Services: CMS2001.

92. Clinical Social Franchising Case Study Series. Smiling Sun Franchise program Bangladesh/Chemonics International. The Global Health Group, University of California, San Francisco, April 2011.

93. http://healthmarketinnovations.org/program/smiling-sun-franchise-program-ssfp Retrieved 20th February 2013.

94. FPAB Annual Report, 2010

95. Marie Stopes Society website, retrieved on 22.02.2013. http://www.mariestopes-bd.org

96. EngenderHealth website, retrieved on 22.02.2013. (http://www.engenderhealth.org/our-countries/asia-neareast/bangladesh.php)

97. Burket MK. Advancing Reproductive Health and Family Planning through Religious Leaders and Faith-Based Organizations, August, 2006.

98. Hossain A et al.,Menstrual regulation, unsafe abortion and maternal health in Bangladesh, In Brief, New York: Guttmacher Institute, 2012, No. 3. 



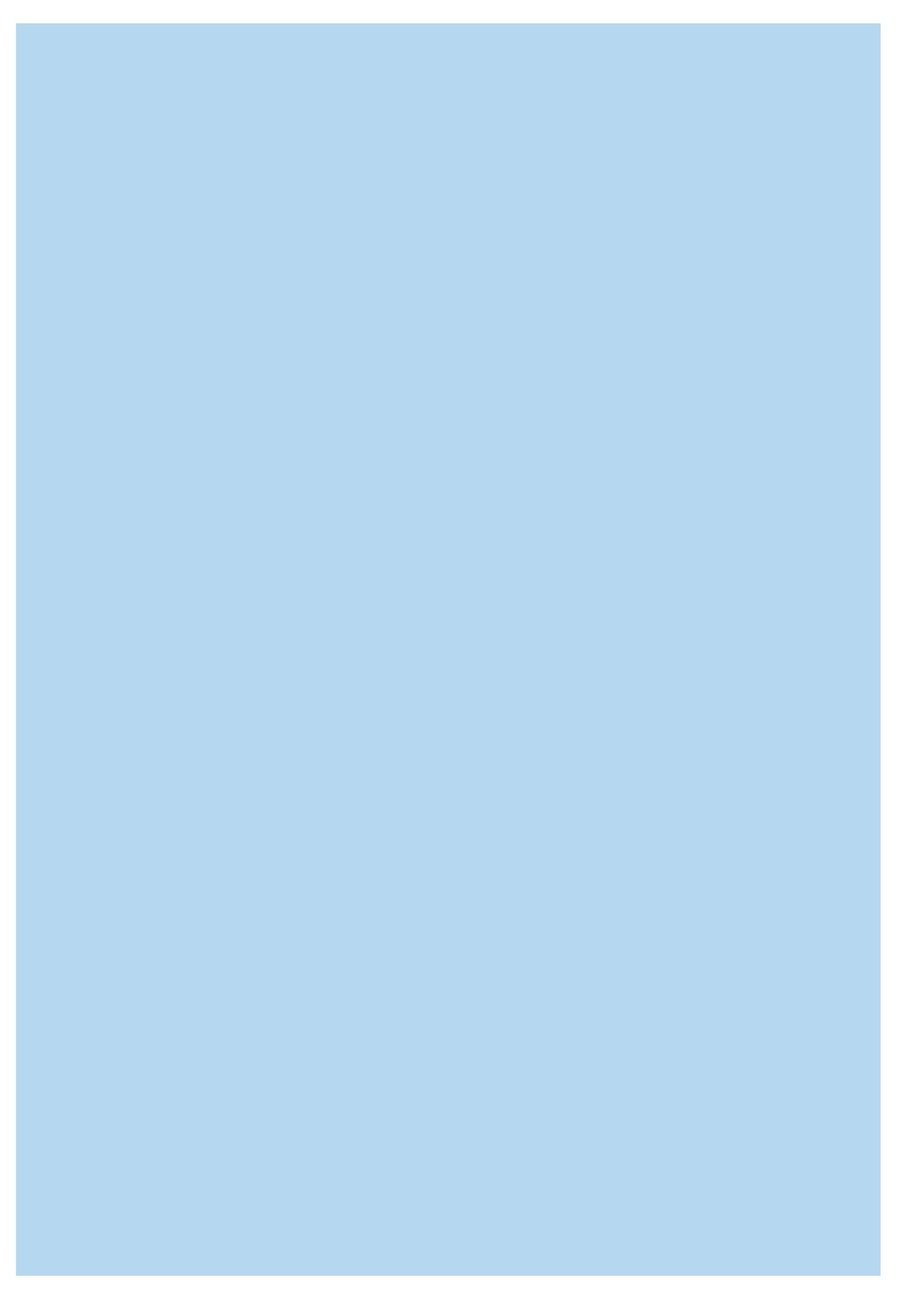

